\title{
Borehole Geophysical Monitoring of Amendment Emplacement and Geochemical Changes During Vegetable Oil Biostimulation, Anoka County Riverfront Park, Fridley, Minnesota
}

By John W. Lane, Jr., Frederick D. Day-Lewis, Carole D. Johnson, Peter K. Joesten, and Christopher S. Kochiss

Prepared in cooperation with the U.S. Navy

Scientific Investigations Report 2006-5199 


\title{
U.S. Department of the Interior DIRK KEMPTHORNE, Secretary
}

\author{
U.S. Geological Survey \\ Mark D. Myers, Director
}

\section{U.S. Geological Survey, Reston, Virginia: 2007}

For more information on the USGS - the Federal source for science about the Earth, its natural and living resources, natural hazards, and the environment:

World Wide Web: http://www.usgs.gov

Telephone: 1-888-ASK-USGS

Any use of trade, product, or firm names is for descriptive purposes only and does not imply endorsement by the U.S. Government.

Although this report is in the public domain, permission must be secured from the individual copyright owners to reproduce any copyrighted materials contained within this report.

Suggested citation:

Lane, J.W. Jr., Day-Lewis, F.D., Johnson, C.D., Joesten, P.K., and Kochiss, C.S., 2007, Borehole geophysical monitoring of amendment emplacement and geochemical changes during vegetable oil biostimulation, Anoka County Riverfront Park, Fridley, Minnesota: U.S. Geological Survey Scientific Investigations Report 2006-5199, 54 p. ONLINE ONLY 


\section{Contents}

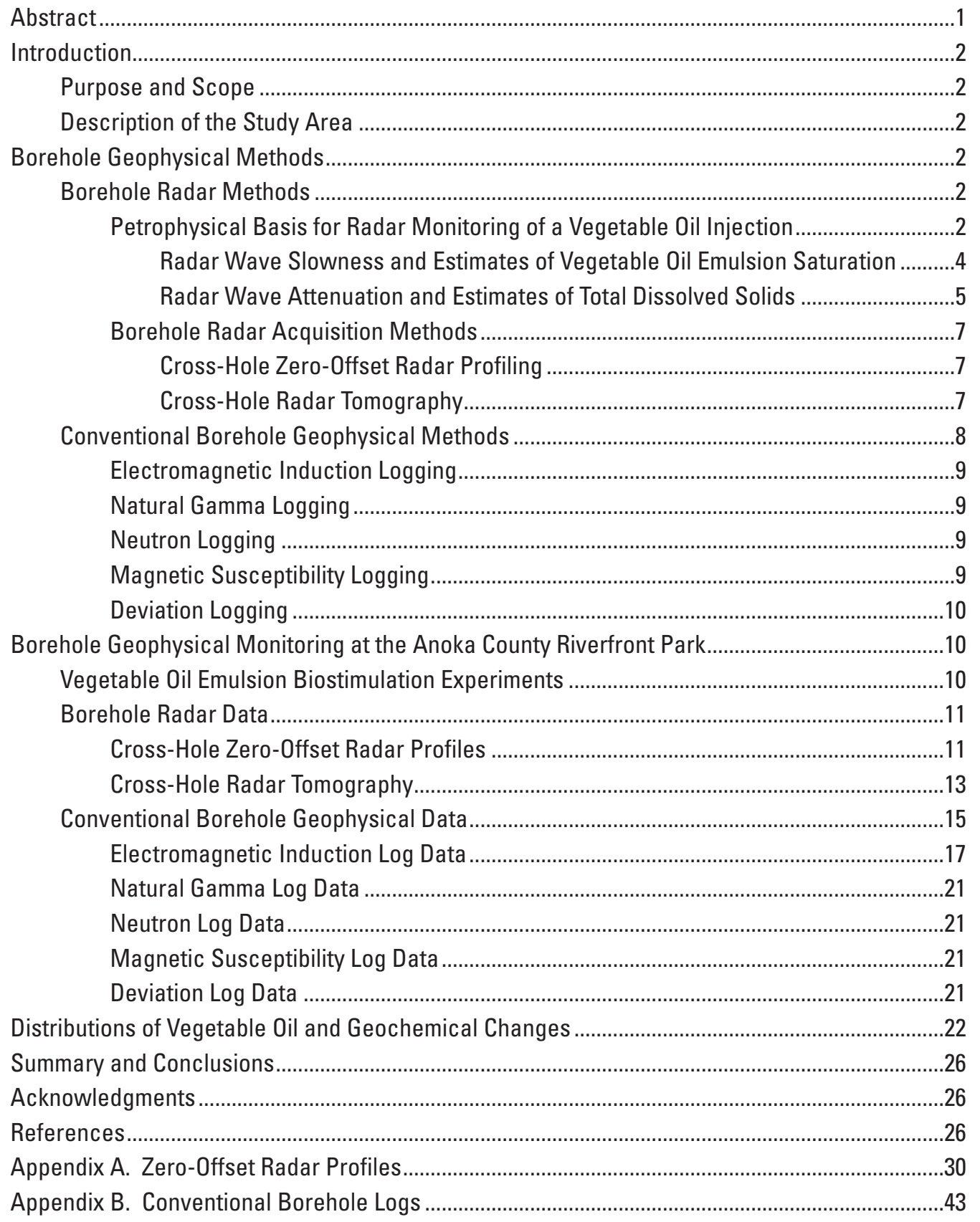




\section{Figures}

1. Map showing (a) location of the study area, Anoka County Riverfront Park, Fridley, Minnesota, and ( $b$ ) location of boreholes at the study area

2. Graphs showing (a) reflective permittivity of vegetable oil emulsions plotted against emulsion water content predicted by the two-phase complex refractive index method (CRIM), (b) electromagnetic (EM) wave radar velocity through quartz sand and saturated by vegetable oil emulsions with different emulsion-towater ratios plotted against porosity predicted by the three-phase CRIM, and (c) expected slowness difference resulting from injecting a vegetable oil emulsion containing 35 percent oil and 65 percent water into a water-saturated quartz sand for different levels of emulsion pore-space saturation plotted against porosity predicted by the CRIM.

3. Diagram showing radar survey geometries for (a) cross-hole zero-offset profiling, and (b) cross-hole tomography

4. Plot showing (a) zero-offset radar slowness, and (b) zero-offset radar amplitude profiles for the MW-1 to INJ-2 plane, Anoka County Riverfront Park, Fridley, Minnesota

5. Diagram showing cross-hole radar tomography raypath geometry for the MW-7 to INJ-3 plane, Anoka County Riverfront Park, Fridley, Minnesota

6-7. Plots showing-

6. December 2001 cross-hole radar tomograms for the (a) MW-1 to INJ-2 planes, and (b) MW-7 to INJ-3 planes, Anoka County Riverfront Park, Fridley, Minnesota

7. (a) Raypaths corresponding to slowness-difference data of greater than the median value of the dataset, and (b) raypaths corresponding to slownessdifference data showing less than the 30th percentile, Anoka County Riverfront Park, Fridley, Minnesota .

8. Diagram showing conceptual diagram of the object-based inversion parameterization of slowness difference $(\Delta s)$ in the tomographic image plane

9-11. Plots showing-

9. Radar slowness-difference tomography inversion results from well-pair MW-7 and INJ-3 using the object-based inversion (OBI) method

10. Borehole geophysical logs for MW-1, Anoka County Riverfront Park, Fridley, Minnesota

11. Borehole geophysical logs for INJ-2, Anoka County Riverfront Park, Fridley, Minnesota

12-13. Diagrams showing-

12. Interpreted conceptual model of the June 2003 areal distribution of ground water with altered chemistry (blue) and the area where pure-phase vegetable oil emulsion is found in the subsurface (green), Anoka County Riverfront Park, Fridley, Minnesota

13. Interpreted conceptual model of the June 2003 cross-sectional distribution of ground water with inferred, highly elevated total dissolved solids (TDS) (dark blue), moderately elevated TDS (light blue), and the region where pure-phase vegetable oil emulsion is found in the subsurface (green), Anoka County Riverfront Park, Fridley, Minnesota . 
A1-A13. Plots showing (a) zero-offset radar slowness, and (b) zero-offset radar amplitude profiles, Anoka County Riverfront Park, Fridley, Minnesota, for the-

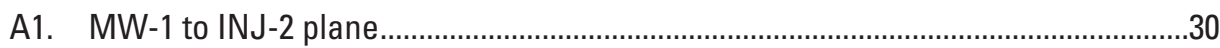

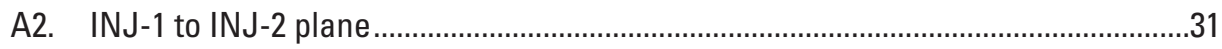

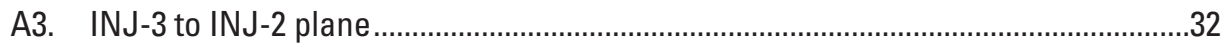

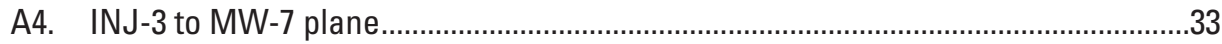

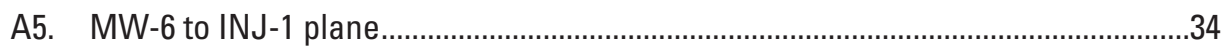

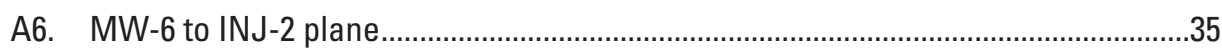

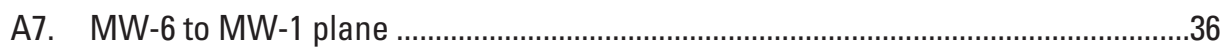

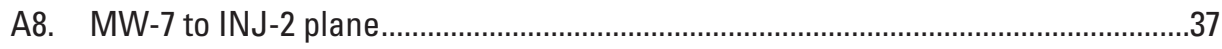

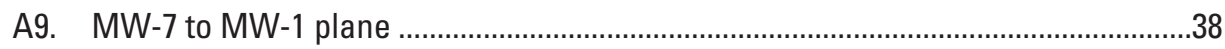

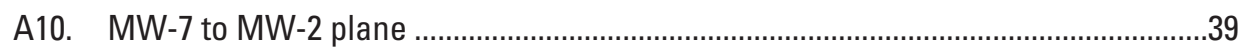

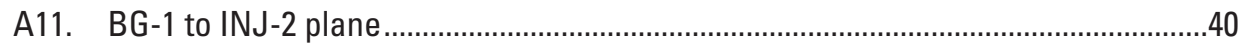

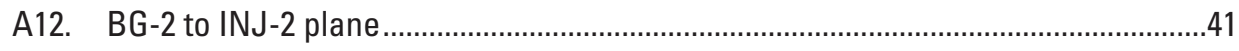

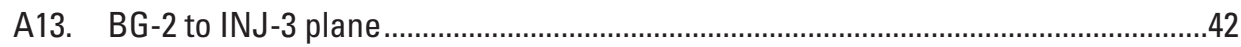

B1-B12. Plots showing borehole geophysical logs, Anoka County Riverfront Park, Fridley, Minnesota, for-

B1. BG-1 ……

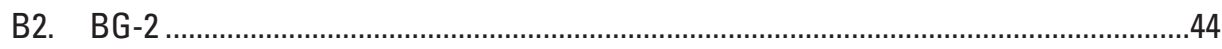

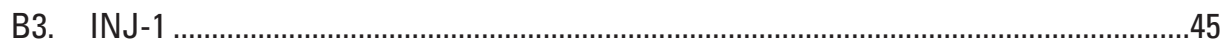

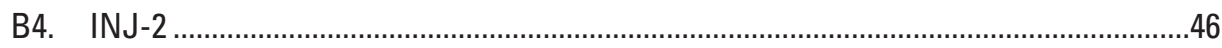

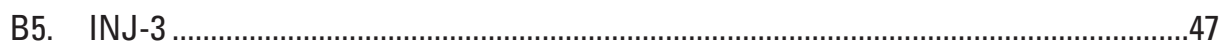

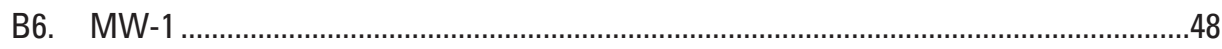

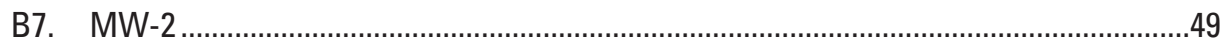

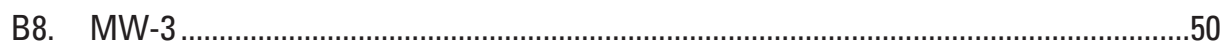

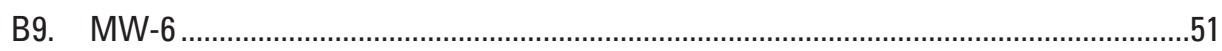

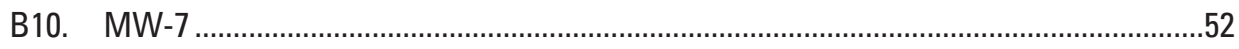

B11. MW-8

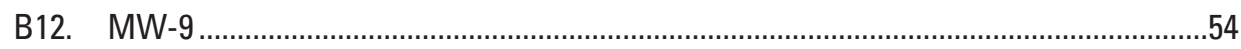




\section{Tables}

1. Borehole constructions for injection and observation wells at the Anoka County Riverfront Park, Fridley, Minnesota ..............................................................................10

2. Zero-offset radar datasets used in this study .............................................................11

3. Estimates of vegetable oil emulsion saturation .............................................................19

4. Conventional borehole geophysical data considered in this report...............................21

5. Estimates of changes in attenuation and total dissolved solids for selected anomalies in zero-offset radar data .................................................................................25

\section{Conversion Factors and Abbreviations}

\begin{tabular}{lcl}
\hline \multicolumn{1}{c}{ Multiply } & By & \multicolumn{1}{c}{ To obtain } \\
\hline & Length & \\
\hline centimeter $(\mathrm{cm})$ & 0.3937 & inch (in.) \\
meter $(\mathrm{m})$ & 3.281 & foot $(\mathrm{ft})$ \\
\hline & Volume & \\
\hline liter $(\mathrm{L})$ & 0.2642 & gallon (gal) \\
\hline & Mass & \\
\hline kilogram $(\mathrm{kg})$ & 2.205 & pound avoirdupois (lb) \\
\hline
\end{tabular}

Vertical coordinate information is referenced to the National Geodetic Vertical Datum of 1929 (NGVD 1929).

Specific conductance is given in microsiemens per centimeter at 25 degrees Celsius $\left(\mu \mathrm{S} / \mathrm{cm}\right.$ at $\left.25^{\circ} \mathrm{C}\right)$.

Electrical conductivity in siemens per meter $(\mathrm{S} / \mathrm{m})$ may be converted to mhos per meter (mho/m) as follows: $1 \mathrm{mho} / \mathrm{m}=1 \mathrm{~S} / \mathrm{m}$.

Electrical conductivity in siemens per meter $(\mathrm{S} / \mathrm{m})$ may be converted to electrical resistivity in ohm-meters $(\Omega \mathrm{m})$ as follows: $\Omega \mathrm{m}=1 /(\mathrm{S} / \mathrm{m})$.

\section{ABBREVIATIONS:}

$\mathrm{dB}$ decibels

$\mathrm{dB} / \mathrm{m} \quad$ decibels per meter

$\mathrm{MHz}$ megahertz

$\mu \mathrm{S} / \mathrm{cm}$ microsiemens per centimeter

$\mathrm{mg} / \mathrm{L} \quad$ milligram per liter

s second

$S \quad$ seimens 


\title{
Borehole Geophysical Monitoring of Amendment Emplacement and Geochemical Changes During Vegetable Oil Biostimulation, Anoka County Riverfront Park, Fridley, Minnesota
}

\author{
By John W. Lane, Jr., Frederick D. Day-Lewis, Carole D. Johnson, Peter K. Joesten, and \\ Christopher S. Kochiss
}

\begin{abstract}
The U.S. Geological Survey (USGS) conducted a series of geophysical investigations to monitor a field-scale biostimulation pilot project at the Anoka County Riverfront Park (ACP), downgradient from the Naval Industrial Reserve Ordnance Plant, in Fridley, Minnesota. The pilot project was undertaken by the U.S. Naval Facilities Engineering Command, Southern Division, for the purpose of evaluating biostimulation using emulsified vegetable oil to treat ground water contaminated with chlorinated hydrocarbons. Vegetable oil was introduced to the subsurface to serve as substrate for naturally occurring microbes, which ultimately break down chlorinated hydrocarbons into chloride, carbon dioxide, and water through oxidation-reduction reactions. In support of this effort, the USGS collected cross-borehole radar data and conventional borehole geophysical data in five site visits over 1.5 years to evaluate the effectiveness of geophysical methods for monitoring emplacement of the vegetable oil emulsion and for tracking changes in water chemistry. Radar zero-offset profile (ZOP) data, radar traveltime tomograms, electromagnetic (EM) induction logs, natural gamma logs, neutron porosity logs, and magnetic susceptibility logs were collected and analyzed.

In order to facilitate data interpretation and to test the effectiveness of radar for monitoring oil-emulsion placement and movement, three injection mixtures with different radar signatures were used: (1) vegetable oil emulsion, (2) vegetable oil emulsion with a colloidal iron tracer, and (3) vegetable oil emulsion with a magnetite tracer. Based on petrophysical modeling, mixture (1) was expected to increase radar velocity and decrease radar attenuation relative to background-a water-saturated porous medium; mixtures (2) and (3) were expected to increase radar velocity and increase radar attenuation because of their greater electrical conductivity compared to background ground water.
\end{abstract}

Radar ZOP data and tomograms show increased EM velocity in the vicinity of injection wells. Comparison of pre- and post-injection datasets shows that velocity anomalies are observed only in planes connected to injection wells, indicating that the emulsified vegetable oil does not migrate far after injection. In contrast to the localization of velocity anomalies, radar attenuation anomalies are observed in all zero-offset profiles, particularly those downgradient from the injection wells. Despite the expected signatures of different tracers, increases in attenuation are observed downgradient from all three injection wells; thus, we infer that the attenuation changes do not result from the iron tracers alone. Over the period of data collection, the slowness (reciprocal velocity) anomalies are relatively stable, whereas the attenuation anomalies generally increase in magnitude and extent. One explanation for the attenuation changes is that products of vegetable oil-enhanced biodegradation (for example, chloride) increase the specific conductance of ground water and thus bulk electrical conductivity and radar attenuation. This interpretation is supported by the results of EM-induction and magnetic susceptibility logs, which indicate increases in electrical conductivity in the absence of magnetic anomalies that might result from the iron and magnetite.

Based on the geophysical data, conceptual models of the distributions of emulsified vegetable oil and ground water with altered chemistry were developed. The field data indicate that, in several cases, the plume of ground water with altered chemistry would not be detected by direct chemical sampling given the construction of monitoring wells; hence the geophysical data provide valuable site-specific insights for the interpretation of water samples and monitoring of biostimulation projects. Application of geophysical methods to data from the ACP demonstrated the utility of radar for monitoring biostimulation injections. 


\section{Introduction}

In biostimulation, an amendment (for example, emulsified vegetable oil) is introduced into the subsurface to enhance bioremediation by serving as a substrate to native microbes, which ultimately transform chlorinated hydrocarbons into carbon dioxide, water, and chloride by oxidation-reduction reactions. The effectiveness of biostimulation is predicated on emplacement of the substrate in contact with the contaminant and at sufficient concentration to support microbial activity. Field procedures capable of monitoring the spatial and temporal distribution and saturation of amendments are needed to aid engineers and hydrologists in designing, implementing, and evaluating biostimulation projects.

The U.S. Naval Facilities Engineering Command, Southern Division, has undertaken a field-scale biostimulation pilot project at the Anoka County Riverfront Park (ACP), located downgradient from the Naval Industrial Reserve Ordnance Plant (NIROP), Fridley, Minnesota (fig. 1). The purpose of the pilot project is to assess biostimulation using emulsified vegetable oil for remediation of chlorinated hydrocarbons including trichloroethene (TCE) and dichloroethene (DCE), which are present in ground water at the site $(\mathrm{CH} 2 \mathrm{M}$ Hill Constructors, Inc., 2002). In support of this effort, the U.S. Geological Survey (USGS) collected geophysical data over the course of 1.5 years to monitor the emplacement and movement of the vegetable oil emulsion and resulting changes in groundwater chemistry.

Lane and others (2003, 2004a, 2004b, 2004c, 2006) evaluated the use of cross-borehole radar methods to monitor the injections of vegetable oil emulsion and the subsurface changes resulting from the bioremediation effort at the ACP. Modeling results and analysis of field experimental data from the ACP indicated that radar methods can provide valuable information about the spatial distribution of emulsified vegetable oil. Comparison of pre- and post-injection datasets provided insights into the spatial and temporal distribution of both emulsified vegetable oil and the extent of ground water with altered chemistry.

\section{Purpose and Scope}

The purpose of this report is to describe the geophysical methods used to monitor the biostimulation experiment at the $\mathrm{ACP}$ and to report the interpretation of the geophysical data. A suite of geophysical measurements were made to monitor the emplaced vegetable oil emulsion and the plume of ground water chemically altered as a result of the injections; these methods include (1) cross-hole zero-offset radar profiles,

(2) cross-hole radar traveltime tomograms, (3) electromagnetic (EM) induction logs, (4) magnetic susceptibility logs, (5) neutron porosity logs, (6) natural gamma logs, and (7) deviation logs. The data are interpreted to provide distributions of emulsified vegetable oil and ground water with altered chemistry.

\section{Description of the Study Area}

The ACP is adjacent to and northeast of the Mississippi River and is downgradient from the NIROP in Fridley, Minnesota (fig. 1). The surficial deposits at the site are of glacial and glacial-fluvial origin and consist of unconsolidated coarse- to fine-grained sediments. Regional ground-water flow is inferred to be toward the Mississippi River to the southwest. Chlorinated-hydrocarbon contamination at the site includes TCE and DCE (CH2M Hill Constructors, Inc., 2002).

\section{Borehole Geophysical Methods}

Borehole radar and conventional borehole geophysical methods were used in this study. The radar methods provide time-lapse information about the subsurface distribution of vegetable oil emulsion and about changes in ground-water chemistry, which may indicate oxidation-reduction reactions occurring in the vicinity of the injected vegetable oil emulsion. The conventional borehole geophysical methods provide information about lithology, aquifer structure, porosity, and ground-water chemistry.

\section{Borehole Radar Methods}

Cross-well radar tomography is an established method for dynamic imaging of mass transport associated with tracer tests, fluid injection tests, and natural physical processes. Cross-well radar and EM tomography methods have been used with tracers to (1) identify permeable fractures and fracture zones in igneous and metamorphic rocks (Ramirez and Lytle, 1986; Niva and others, 1988; Olsson and others, 1992; Lane and others, 1996, 2000; Wright and others, 1996; Day-Lewis and others, 2003); (2) identify flow paths in dual-porosity media (Lane and others, 1998) and unconsolidated sediments (Kong and others, 1994; Hubbard and others, 2001); and (3) monitor unsaturated zone recharge (Eppstein and Dougherty, 1998; Binley and others, 2001).

This section includes discussion of (1) a petrophysical model to interpret radar measurements in terms of changes in subsurface vegetable oil emulsion saturation and estimates of total dissolved solids, and (2) two cross-hole radar methods used to acquire data for this study-ZOPs and radar tomography.

\section{Petrophysical Basis for Radar Monitoring of a Vegetable Oil Injection}

In geophysical radar methods, high-frequency EM waves are generated by a transmitter, and waveform traces are recorded at receivers. Measurements of EM-wave traveltime and (or) amplitude provide information about subsurface lithology, geologic or sedimentary structure, porosity, and pore 
(a)

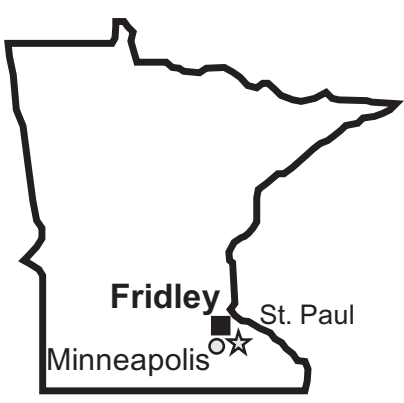

(b)
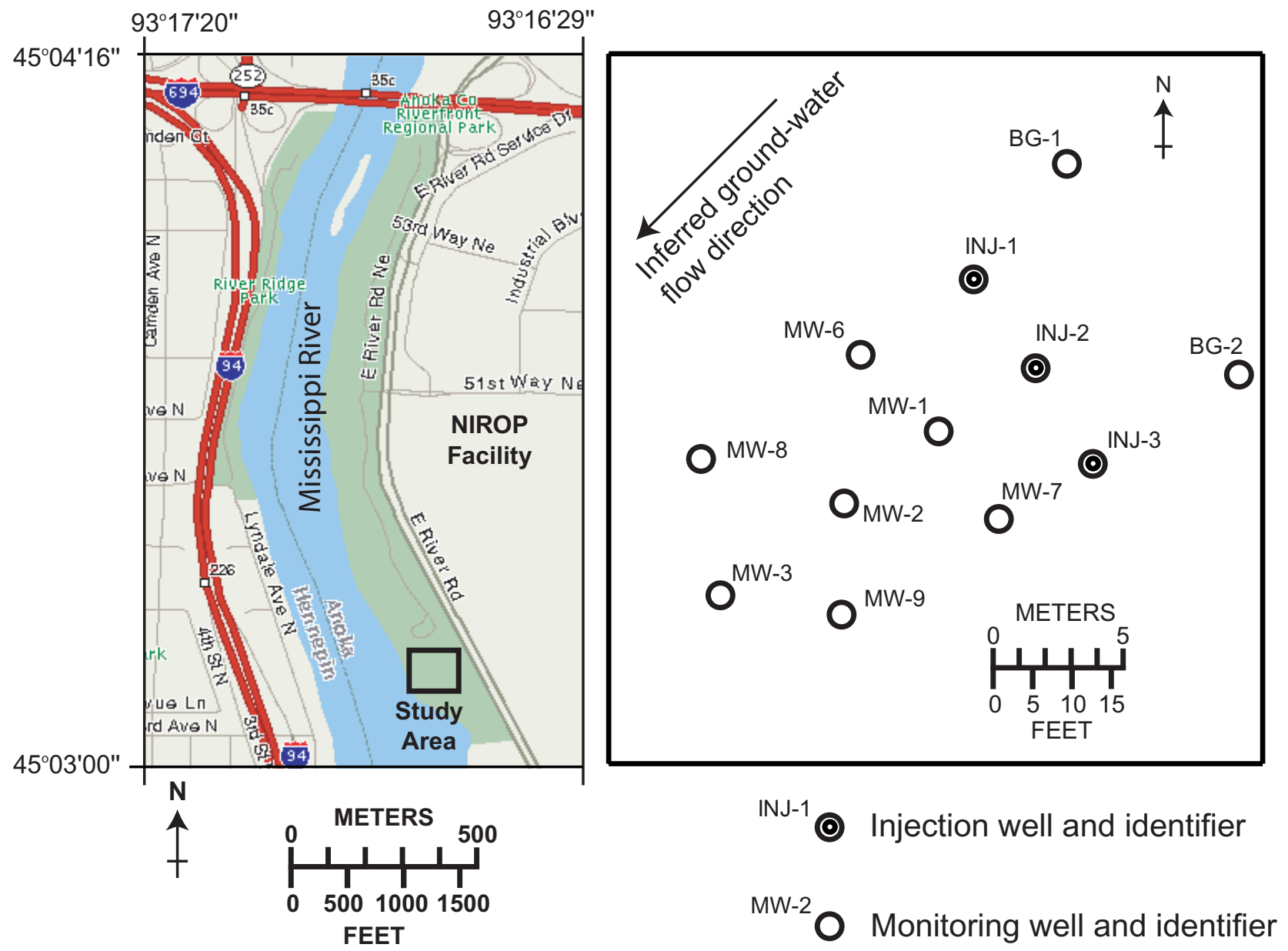

Figure 1. (a) Location of the study area, Anoka County Riverfront Park, Fridley, Minnesota, and (b) location of boreholes at the study area (modified from Lane and others, 2004a, fig. 10). 
fluid. The utility of radar methods for time-lapse monitoring of injection experiments depends on the contrasts between the dielectric permittivity and (or) electrical conductivity of the injectate relative to those of native ground water.

\section{Radar Wave Slowness and Estimates of Vegetable Oil Emulsion Saturation}

The slowness (reciprocal velocity) at which radar-frequency EM waves propagate is a function of dielectric permittivity, which is determined by pore fluid, porosity, saturation, and the soil or rock matrix:

$$
s=\frac{1}{v} \approx \frac{\sqrt{\varepsilon_{r}}}{c}
$$

where

$s \quad$ is radar slowness, in seconds/meter;

$v \quad$ is radar velocity, in meters/second;

$\varepsilon_{r} \quad$ is the dielectric permittivity of the medium, relative to a vacuum, dimensionless;

and

$$
\text { c is the velocity of EM waves in a vacuum, }
$$$$
\text { in meters/second. }
$$

This discussion of radar methods focuses on slowness rather than the more intuitive velocity, because (1) slowness, and not velocity, is the property estimated in the tomographic inversion, and (2) slowness is, in theory, linearly related to the saturation of injected vegetable oil emulsion, as shown subsequently.

The effect of vegetable oil emulsion on bulk slowness can be derived using the complex refractive index method (CRIM) (Birchak and others, 1974; Wharton and others, 1980). The CRIM model predicts the bulk dielectric permittivity of a mixture based on the relative dielectric permittivities of the component materials and their volume fractions:

$$
\sqrt{\varepsilon_{r}^{b u l k}}=\sum_{i=1}^{n} \phi_{i} \sqrt{\varepsilon_{r, i}}
$$

where

$$
\begin{gathered}
\varepsilon_{r}^{b u l k} \quad \text { is the relative bulk dielectric permittivity of } \\
\text { the mixture, dimensionless; } \\
n \quad \text { is the number of materials the mixture } \\
\quad \text { comprises; } \\
\phi_{i} \quad \text { is the fraction of the total volume occupied by } \\
\text { material } i, \text { dimensionless; }
\end{gathered}
$$

and

To relate changes in radar slowness to vegetable oil emulsion saturation, a three-phase CRIM model was developed for vegetable oil emulsion saturation. Implicit in the CRIM modeling are assumptions that electrical conductivity effects are negligible ("low-loss" assumption) and EM-wave propagation velocity is controlled by the real components of the relative dielectric permittivity. If matrix porosity is known or can be estimated from other information (such as cores, neutron logs, or petrophysical analysis of pre-injection EM-wave velocity), the vegetable oil emulsion saturation, $S^{V O E}$, can be estimated from the inverted slowness difference. For pre-injection conditions, the CRIM formula gives the relative dielectric permittivity of the bulk medium as a function of the relative dielectric permittivities of the sediment matrix and water:

$$
\sqrt{\varepsilon_{r}^{\text {bulk,pre }}}=(1-\phi) \sqrt{\varepsilon_{r}^{\text {sed }}}+\phi \sqrt{\varepsilon_{r}^{H_{2} O}},
$$

where

$$
\varepsilon_{r}^{\text {bulk,pre }}
$$

$$
\varepsilon_{r}^{\text {sed }}
$$

and

$$
\begin{gathered}
\varepsilon_{r}^{\mathrm{H}_{2} \mathrm{O}} \quad \text { is the relative dielectric permittivity of water, } \\
\text { dimensionless. }
\end{gathered}
$$

The CRIM formula for post-injection conditions includes an additional term to account for the presence of vegetable oil emulsion, which has a dielectric permittivity of $\varepsilon_{r}^{V O E}$ :

$$
\sqrt{\varepsilon_{r}^{\text {bulk,post }}}=(1-\phi) \sqrt{\varepsilon_{r}^{\text {sed }}}+\phi\left(1-S^{V O E}\right) \sqrt{\varepsilon_{r}^{H_{2} O}}+\phi S^{V O E} \sqrt{\varepsilon_{r}^{V O E}}
$$

where

$$
\begin{gathered}
\varepsilon_{r}^{\text {bulk,post }} \quad \text { is the relative dielectric permittivity } \\
\text { of the bulk medium, post-injection, } \\
\text { dimensionless; }
\end{gathered}
$$

and

$$
S^{V O E} \quad \text { is the saturation of the vegetable oil emulsion. }
$$

Modeling slowness as $\sqrt{\varepsilon_{r}} / c$ (eq. 1), the slowness difference, $\Delta s=s_{2}-s_{1}$, can be calculated by subtracting equation 3 from equation 4 , and dividing by $c$, the velocity of EM waves in a vacuum:

$$
\Delta s=s_{2}-s_{1}=\frac{\sqrt{\varepsilon_{r}^{\text {bulk,post }}}-\sqrt{\varepsilon_{r}^{\text {bulk,pre }}}}{c}=\frac{\phi S^{\text {VOE }}\left(\sqrt{\varepsilon_{r}^{\text {VOE }}}-\sqrt{\varepsilon_{r}^{H_{2} O}}\right)}{c}
$$


Thus, the saturation of the vegetable oil emulsion is related to slowness difference by

$$
S^{V O E}=\frac{\Delta s c}{\phi\left(\sqrt{\varepsilon_{r}^{V O E}}-\sqrt{\varepsilon_{r}^{H_{2} O}}\right)} .
$$

According to equation 6 , the change in radar slowness varies linearly with the saturation of vegetable oil emulsion.

In the design phase of this study, the CRIM model was used to predict (1) the relative permittivity of vegetable oil emulsions for a range of water/oil ratios (fig. 2a); (2) the bulk EM velocity assuming a sediment matrix of low-loss quartz sand ( $\varepsilon_{r}^{\text {quartz }}$ about 4.5 ), for a range of porosities and saturations of vegetable oil emulsion (fig. 2b); and (3) the slownessdifference anomaly that would result from injection of a vegetable oil emulsion containing 35 percent oil and 65 percent water into water-saturated quartz sand for different levels of pore-space fluid displacement by the emulsion (emulsion saturation) (fig. 2c). Because the relative dielectric permittivity of pure vegetable oil is much lower than that of water ( $\varepsilon_{r}^{\text {oil }}$ about $2.9-3.5 ; \varepsilon_{r}{ }_{2} O$ about 80 ), the presence of emulsified vegetable oil in the saturated zone is expected to decrease radar slowness (increase radar velocity).

In the data-analysis stage of this investigation, the CRIM model was used to interpret the degree of pore-fluid displacement resulting from injection of the vegetable oil emulsion. Equation 6 can be applied to tomograms of slowness difference to yield estimates of $S^{V O E}$; however, the reliability of such estimates is difficult to quantify, as tomograms may include inversion artifacts and blurring (for example, Day-Lewis and Lane, 2004; Lane and others, 2004a).

\section{Radar Wave Attenuation and Estimates of Total Dissolved Solids}

The attenuation (absorption) of radar-frequency EM waves propagating through earth materials is a strong function of electrical conductivity, which depends on the chemical composition of the soil or rock matrix and pore fluid. In low-loss, non-magnetic earth materials where EM waves propagate relatively independent of frequency, EM attenuation is approximately:

$$
\alpha=B \sigma / \sqrt{\varepsilon_{r}},
$$

where

$\alpha \quad$ is attenuation, in decibels/meter;

$B \quad$ is $1.685 \times 10^{3} \mathrm{~dB} /$ siemens; $B$ incorporates

free-space impedence and unit conversion to work in decibels rather than nepers;

and
Because the electrical conductivity of oil is less than that of native ground water at ACP, the presence of emulsified oil in the saturated zone is expected to decrease radar attenuation; however, the addition of magnetite and colloidal-iron tracers to emulsified vegetable oil results in mixtures with bulk electrical conductivities higher than that of native ground water.

Also, the presence of the vegetable oil promotes oxidationreduction reactions that can increase the electrical conductivity of ground water. For example, reduction of solid ferric iron in soils to ferrous iron in ground water could result in increased electrical conductivity; furthermore, biodegradation of hydrocarbons is expected to result in increased chloride concentration. Recent research by Atekwana and others (2004) indicates that biodegradation processes can increase bulk electrical conductivity of aquifer materials. Increases in conductivity resulting from the presence of bacteria can be greater than decreases that result from the presence of light non-aqueous phase liquid (LNAPL) contaminants of low electrical conductivity.

To convert measurements of amplitude to estimates of total dissolved solids (TDS), we assume a mixing law for electrical conductivity based on a porosity-weighted arithmetic average of the conductivities of the soil matrix and pore fluid:

$$
\sigma=\phi \sigma_{f}+(1-\phi) \sigma_{s},
$$

where

$$
\sigma_{f} \quad \text { is the fluid specific conductance, in siemens }
$$

and

$$
\begin{gathered}
\sigma_{s} \quad \text { is the electrical conductivity of the sediment } \\
\text { matrix, in siemens per meter. }
\end{gathered}
$$

For pre-injection conditions, superscript "(1)," we can combine equations (7) and (8) to define the attenuation coefficient:

$$
\alpha^{(1)}=1685 \sigma^{(1)} / \sqrt{\varepsilon_{r}^{(1)}}=\frac{1685}{\sqrt{\varepsilon_{r}^{(1)}}}\left[\phi \sigma_{f}^{(1)}+(1-\phi) \sigma_{s}^{(1)}\right] .
$$

For post-injection conditions, superscript “(2),"

$$
\alpha^{(2)}=1685 \sigma^{(2)} / \sqrt{\varepsilon_{r}^{(2)}}=\frac{1685}{\sqrt{\varepsilon_{r}^{(2)}}}\left[\phi \sigma_{f}^{(2)}+(1-\phi) \sigma_{s}^{(2)}\right]
$$

Assuming no change in the electrical conductivity of the rock matrix, difference attenuation, $\Delta \alpha$ is modeled as

$$
\Delta \alpha=\alpha^{(2)}-\alpha^{(1)}=1685 \phi\left[\frac{\sigma_{f}^{(2)}}{\sqrt{\varepsilon_{r}^{(2)}}}-\frac{\sigma_{f}^{(1)}}{\sqrt{\varepsilon_{r}^{(1)}}}\right] .
$$

$\sigma \quad$ is the bulk electrical conductivity, in siemens/meter. 
(a)

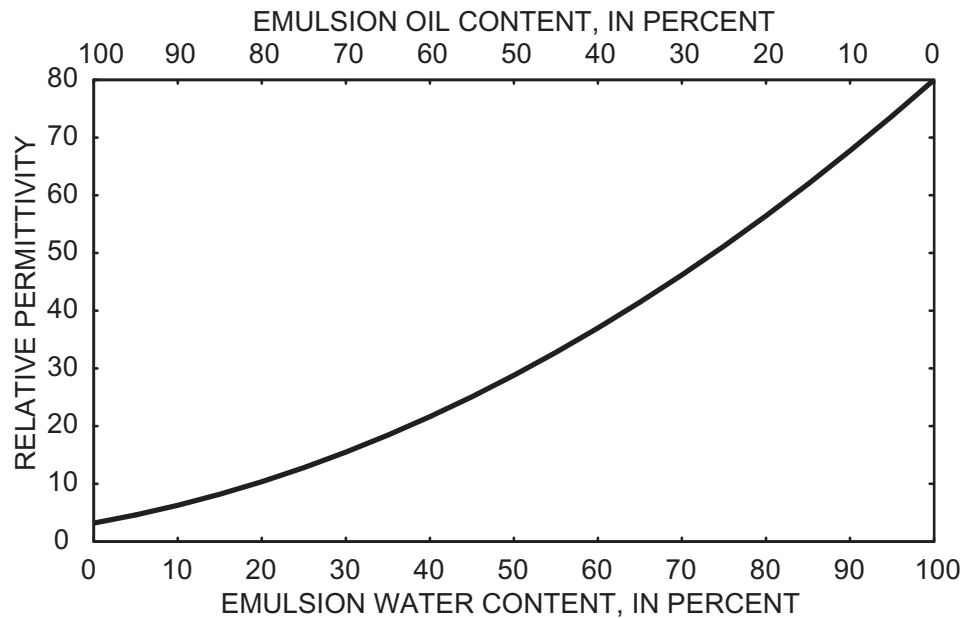

(b)
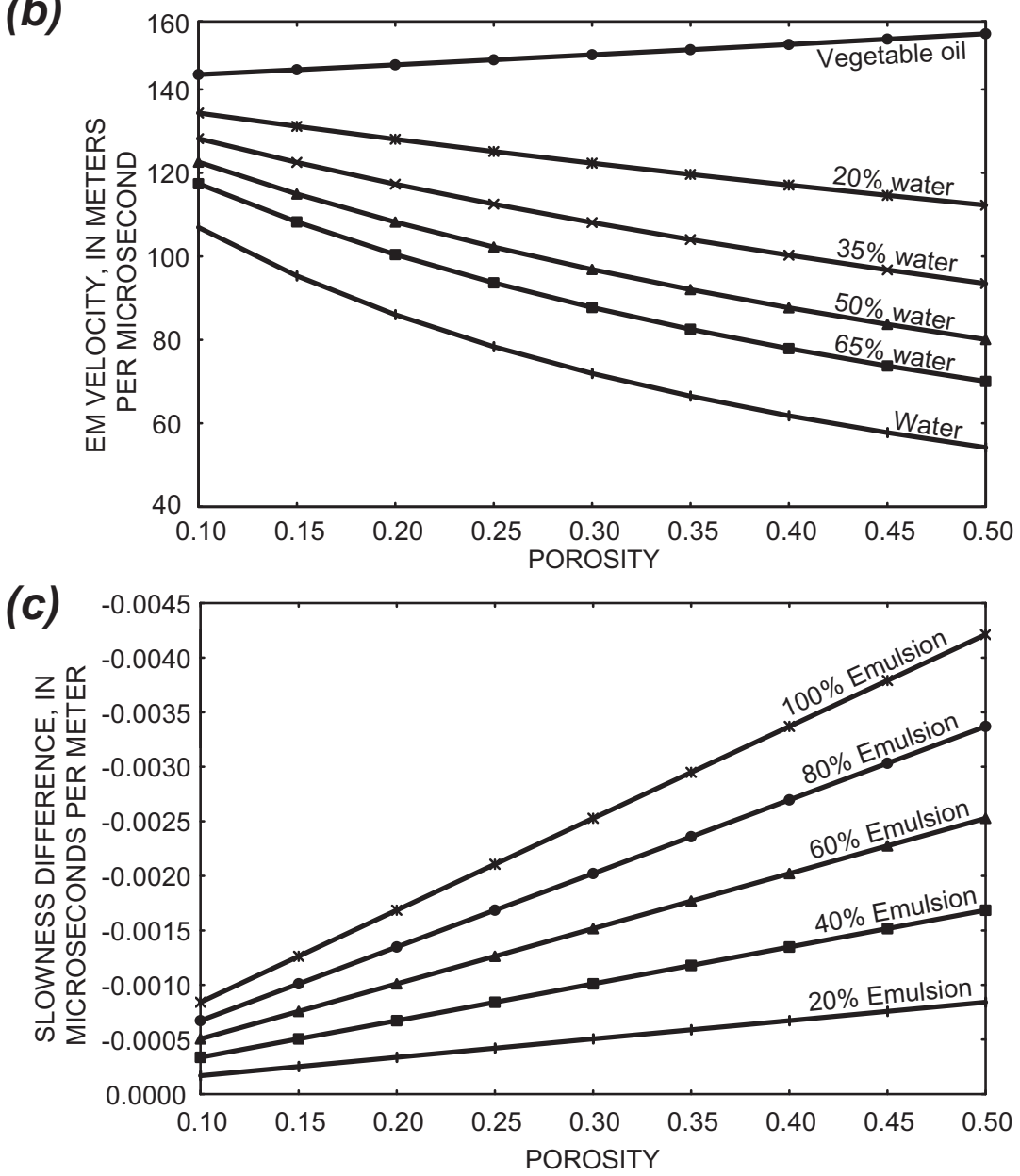

Figure 2. (a) Reflective permittivity of vegetable oil emulsions plotted against emulsion water content predicted by the two-phase complex refractive index method (CRIM), (b) electromagnetic (EM) wave radar velocity through quartz sand and saturated by vegetable oil emulsions with different emulsion-to-water ratios plotted against porosity predicted by the three-phase CRIM, and (c) expected slowness difference resulting from injecting a vegetable oil emulsion containing 35 percent oil and 65 percent water into a water-saturated quartz sand for different levels of emulsion pore-space saturation plotted against porosity predicted by the CRIM (modified from Lane and others, 2004a, fig. 1). 
Dielectric permittivity is not a strong function of TDS or fluid specific conductance, allowing the additional approximation that $\varepsilon_{r}^{(2)} \approx \varepsilon_{r}^{(1)}$, which simplifies the analysis:

$$
\Delta \alpha \approx 1685 \frac{\phi}{\sqrt{\varepsilon_{r}}}\left[\sigma_{f}^{(2)}-\sigma_{f}^{(1)}\right]
$$

Changes in attenuation can be related to changes in TDS through an empirical relation (Todd, 1980, p. 281) with fluid specific conductance:

$$
T D S \approx 1.56 \times 10^{4} \sigma_{f},
$$

where TDS is total dissolved solids, in milligrams per liter, and fluid specific conductance is in siemens per meter. This specific conductance/TDS relation applies over the range from 0.01 to $0.5 \mathrm{~S} / \mathrm{m}$, or an equivalent TDS range of about 150 to $7,800 \mathrm{mg} / \mathrm{L}$. Substituting equation 13 into equation 12 ,

$$
\Delta \alpha \approx \frac{1685 \phi}{1.56 \times 10^{4} \sqrt{\varepsilon_{r}}}\left[T D S^{(2)}-T D S^{(1)}\right]=1.080 \times 10^{-1} \frac{\phi}{\sqrt{\varepsilon_{r}}} \Delta T D S
$$

Equation 14 can be cast in terms of slowness or velocity, using equation 1, and rearranged to yield estimates of $\triangle T D S$ from field-experimental difference attenuation:

$$
\Delta T D S \approx \frac{\Delta \alpha s}{3.6 \times 10^{-10} \phi}=\frac{\Delta \alpha}{3.6 \times 10^{-10} \phi v},
$$

where $s$ is in seconds per meter or $v$ is in meters per second. In a saturated porous medium with a porosity of 30 percent and EM wave velocity of $60 \mathrm{~m} / \mu \mathrm{s}$, equation 15 predicts a linear attenuation increase of $1 \mathrm{~dB} / \mathrm{m}$ per additional $155 \mathrm{mg} / \mathrm{L}$ of TDS, assuming negligible velocity change.

To calculate difference attenuation from measured amplitudes, the ray-theoretic approximation is used and straight raypaths are assumed to be unaffected by the presence of the vegetable oil emulsion:

$$
\Delta \alpha=\frac{1}{R} \ln \frac{A^{(1)}}{A^{(2)}},
$$

where

$\Delta \alpha \quad$ is difference attenuation, in decibels per meter;

$R \quad$ is the length of the raypath between the transmitter and receiver, in meters;

$A^{(1)} \quad$ is the amplitude in the pre-injection, background dataset, in microvolts;

and

$A^{(2)} \quad$ is the amplitude in the post-injection dataset, in microvolts.

\section{Borehole Radar Acquisition Methods}

Borehole radar data were collected with a Malå GeoScience RAMAC borehole radar system using broad-band electric-dipole antennas. Most data were collected with antennas having a center frequency in air of about $100 \mathrm{MHz}$, though several datasets were collected with $250-\mathrm{MHz}$ antennas, which would have higher resolution. Additional vertical-radar profile (VRP) data were collected and reported in Witten and Lane (2003); however, the results of the VRP surveys provide information primarily for the unsaturated zone above the vegetable oil emulsion injections, which is not the focus of this report. The cross-hole ZOP and tomographic data provide information down to the bottom of the boreholes, and were able to provide results for the saturated zone where the injections occurred.

\section{Cross-Hole Zero-Offset Radar Profiling}

The cross-hole ZOP survey consists of measurements taken between transmitter and receiver antennas located at identical depths in different boreholes (fig. 3a). ZOP data provide horizontally averaged measurements of EM properties at different depths. In contrast to tomography data, ZOP data do not require tomographic inversion, which can result in artifacts and blurring (Day-Lewis and Lane, 2004); furthermore, the acquisition of ZOP data is fast, and the processing and interpretation of ZOP data are straightforward. Although the ZOP geometry provides less information about spatial variability than do tomography or VRP surveys, the dense network of ZOP data collected at the ACP provides sufficient spatial coverage to develop a conceptual model of the distribution of vegetable oil emulsion and ground water with altered chemistry. The interpretations developed in this report rely heavily on ZOP data.

\section{Cross-Hole Radar Tomography}

In cross-hole tomography, the transmitter antenna is located at multiple depths in one borehole, and for each transmitter location, measurements are made at multiple receiver locations in a second borehole (fig. 3b). Arrival time or amplitude data are inverted to produce tomograms of radar slowness or attenuation, respectively.

Tomographic inversion consists of solving an optimization problem to identify the two-dimensional (2D) or three-dimensional (3D) slowness or attenuation model that minimizes a weighted combination of (1) weighted errors between predicted and measured data in a least-squares sense, and (2) a measure of solution complexity, for example, roughness or deviations from a mean value. Numerous algorithms have been developed for this purpose, including the simultaneous iterative reconstruction technique (SIRT) (for example, Dines and Lytle, 1979; McMechan and others, 1987), the LSQR algorithm (for example, Bregman and others, 1989), and conjugate-gradients (for example, Olsson and others, 1992). Most approaches involve parameterizations that discretize the interwell region as a grid of 2D pixels or 
(a)

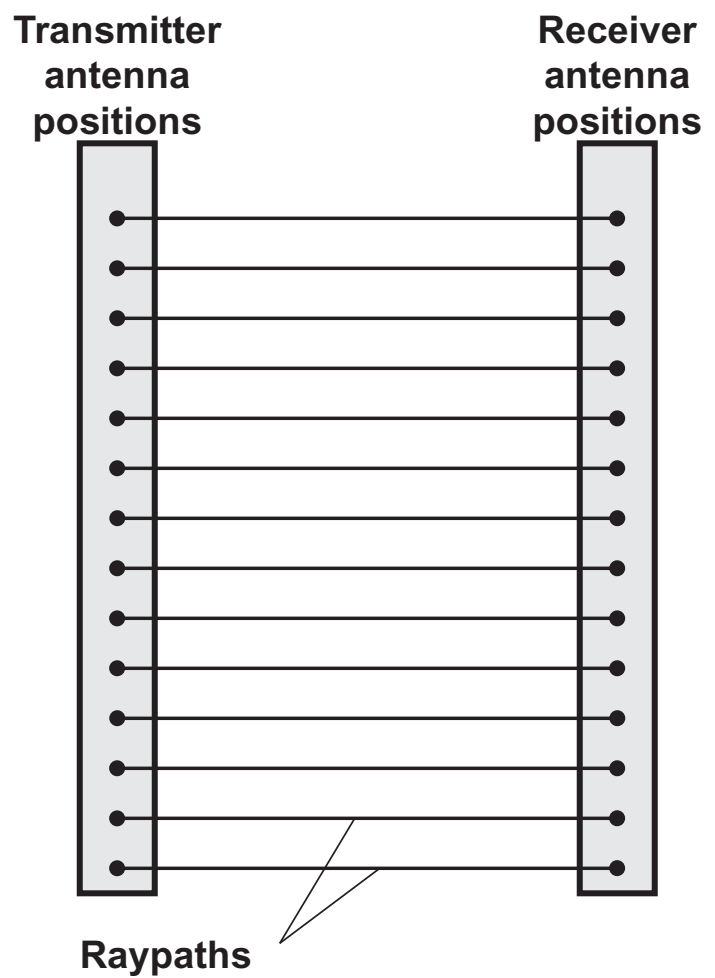

(b)

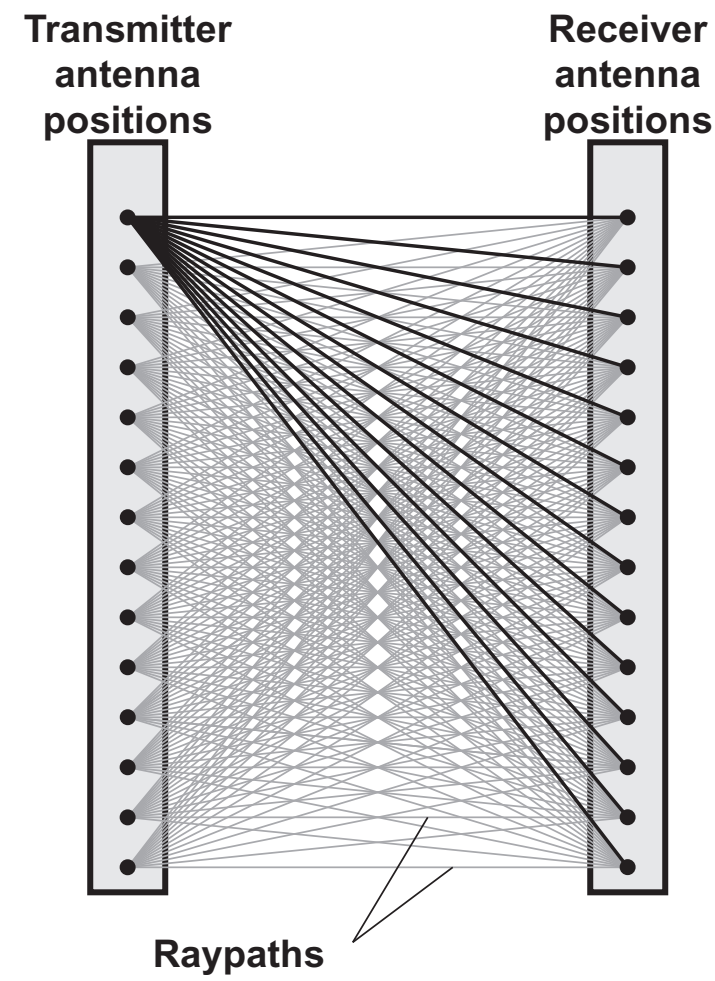

Figure 3. Radar survey geometries for (a) cross-hole zero-offset profiling, and (b) cross-hole tomography.

3D voxels. In this study, a weighted damped least-squares algorithm (Lane and others, 2003) was used to invert each tomography dataset; the resulting image was then refined by running one iteration of a SIRT algorithm considering only ZOP data. The final SIRT step places greater emphasis on the ZOP data, which, in our experience, are more reliable than measurements for the higher-angle raypaths included in the tomography data. Measurements for higher-angle raypaths tend to have low signal-to-noise ratios because of their lengths and antenna radiation patterns. Borehole deviations are accounted for by projecting data to a best-fit image plane between transmitter and receiver boreholes. The tomographic inversion is implemented in MATLAB®.

Tomograms provide qualitative information about vertical and horizontal variations in radar properties between wells; however, resolution depends on data error, the survey geometry, and prior information used for inversion (Day-Lewis and Lane, 2004). Tomograms tend to be smoother than reality and overestimate the size and underestimate the magnitude of target anomalies; moreover, tomograms often include artifacts; thus quantitative estimates of the saturation and extent of vegetable oil emulsion from tomograms are potentially unreliable
(Lane and others, 2004a). For the dataset collected at the ACP, Lane and others (2004a) ran a series of synthetic experiments to identify likely artifacts in the tomograms and to improve interpretation of observed anomaly extent and magnitude; in addition, they demonstrated a novel object-based inversion that, based on synthetic examples, yields more reliable models of the vegetable oil emulsion anomaly magnitude and extent. These results are summarized later in this report.

\section{Conventional Borehole Geophysical Methods}

Borehole geophysical methods measure the physical and chemical properties of the aquifer material, borehole fluid, and pore fluid, and thus provide information about subsurface structure, lithology, and ground-water chemistry. At the ACP, the USGS collected a suite of conventional borehole geophysical logs, including EM induction, magnetic susceptibility, neutron porosity, natural gamma, and borehole deviation. A brief background on the physics, instruments, and analysis of the borehole measurements is provided. Additional details about borehole geophysical methods are given by Keys (1990) and Hearst and others (2000). 


\section{Electromagnetic Induction Logging}

EM induction logs measure the electrical conductivity of the bulk medium, averaged over a volume extending radially from the borehole into the surrounding formation. A Mount Sopris 2PIA-1000 tool was used in this study. A transmitter generates a primary EM field, which induces eddy currents in the formation surrounding the borehole. The primary field induces a secondary magnetic field that is measured by two receiver coils. The strength of the secondary magnetic field is proportional to the electrical conductivity of the volume over which the instrument samples. The instrument's peak response comes from a distance of $28 \mathrm{~cm}$ from the tool, with half of the response contributed from distances more than $58 \mathrm{~cm}$; thus, the instrument response is not dominated by the borehole fluid, particularly in small diameter (less than $15 \mathrm{~cm}$ ) boreholes (McNeill, 1986). The EM tool is capable of measuring through polyvinyl chloride (PVC) casing, but not metal. In this study, the EM induction log is used to monitor emplacement of the oil emulsion, which manifests initially as a low conductivity anomaly, and to monitor changes in ground-water chemistry. An 11-point moving-average filter was applied to the data to suppress noise and reveal larger-scale variations indicative of lithology and (or) water chemistry. McNeill (1986) provides additional background on EM induction logging tools, data analysis, and theory.

\section{Natural Gamma Logging}

Natural gamma log instruments measure the natural gamma radiation emitted by the formation surrounding the borehole. Gamma logs are commonly used for identification of lithology and for correlating stratigraphy between boreholes. The most important natural sources of gamma radiation include potassium- 40 and daughter products of the uranium and thorium decay series. Potassium- 40 is abundant in some feldspar and mica that weather to clay; uranium and thorium also concentrate in clay, through adsorption and ion exchange processes (Keys, 1990, p. 79). Fine-grained, detrital sediments with abundant clay tend to have high gamma emissions.

A Mount Sopris 2PGA-1000 natural gamma probe was used in this study. The vertical resolution of the probe is about 30 to $60 \mathrm{~cm}$. Measurements are possible through both PVC and steel casing. In this study, gamma radiation is measured in counts per second, to provide a relative measurement. An 11point moving-average filter was applied to the data to suppress noise and reveal larger-scale variations indicative of lithology.

\section{Neutron Logging}

The neutron logging tool includes a neutron source, which emits neutrons that bombard the formation surrounding the borehole, and one or two neutron detectors. As the neutrons collide with atomic nuclei in the formation, they lose energy. The rate of energy loss is a function of the hydrogen content of the bulk rock, and thus water content (Keys, 1990, p. 93). In this study, a Mount Sopris LLP-2676 probe was used. This is an epithermal instrument with a single $\mathrm{Am}_{241} / \mathrm{Be}$ (americium-241/beryllium) neutron source and a single $\mathrm{He}^{3}$ (helium-3) detector. In saturated, porous formations, the emitted neutrons lose energy within a short distance of the borehole, and the tool response is dominated by the region within $20 \mathrm{~cm}$ of the borehole; in low porosity media, the response region may extend to about $60 \mathrm{~cm}$ from the borehole (Telford and others, 1990, p. 678).

The neutron-porosity probe provides raw data consisting of detection counts per second, which are converted to estimates of porosity through an empirically derived instrument calibration. Different regression equations are required, depending on the particular instrument and on the borehole diameter. Ideally, a site-specific or formation-specific calibration would be made; however, this is usually impractical. Corrections for lithology, bound water, and casing type may be required in some applications; these corrections were not considered here. For the 7.62-cm diameter PVC wells at the ACP, the following calibration formula was used (Richard Hodges, U.S. Geological Survey, written commun., 2002):

$$
\phi=217-26.22 \ln (C P S)
$$

where

and

$\phi \quad$ is the estimated porosity;

CPS is the counts per second measured by the probe.

The calibration (eq. 17) is based on data from the calibration pits in Grand Junction, Colorado, and Houston, Texas, where the lithologies consist of limestone and dolomite (Roger Morin, U.S. Geological Survey, oral commun., 2004). Because the calibration is not local or specific to the geologic materials at the ACP site, neutron-porosity estimates in this study should be viewed as approximate; use of limestone calibration for sandstone can result in negative porosity estimates for low porosity values (Schlumberger, 1989, p. 5-22).

\section{Magnetic Susceptibility Logging}

Magnetic susceptibility logs provide information about the mineral composition of rocks around the borehole. Two instruments, based on the same principle and design, were used in this investigation: the Mount Sopris 2PMA-1000 and the Geonics EM-39S. Magnetic susceptibility is a function primarily of magnetite content, although the minerals pyrrhotite, ilmenite, chromite, and hematite also have pronounced magnetic susceptibility (Telford and others, 1990, p. 74). The borehole magnetic susceptibility probe consists of two coils, a transmitter and receiver. An audio-frequency alternating current is passed through the transmitter coil. The resulting magnetic field is measured at the receiver coil. The magnetic field is a function of the magnetic permeability and 
electrical conductivity of the earth, the instrument frequency, and the coil spacing (McNeill and others, 1996). Under the low-induction number assumption, which is valid at low frequencies, the effects of electrical conductivity and magnetic susceptibility can be separated; in these cases, the measured magnetic field can be approximated as having an in-phase component that is a function solely of magnetic susceptibility, and a quadrature component that is a function solely of electrical conductivity (McNeill and others, 1996). The instrument measures only the in-phase component of the magnetic field. In areas of moderate-to-high conductivity or low susceptibility, additional conductivity measurements are necessary to correct for the effect of conductivity on the in-phase response; however, this effect is commonly small (McNeill and others, 1996). Magnetic susceptibility may be calculated from the raw data (in counts per second), using an instrument calibration. In this study, only time-lapse changes in susceptibility resulting from the presence of a dissolved magnetite tracer were of concern, not accurate determination of the susceptibility at the site; thus, the data were examined in parts-per-thousand units, rather than applying the instrument calibration. For additional information about magnetic susceptibility logs, the interested reader is referred to Hearst and others (2000).

\section{Deviation Logging}

The borehole deviation log provides a model of 3D borehole geometry (Keys, 1990). The log measures the azimuthal direction and inclination of the borehole at different depths. In general, deviation logs provide direction information within $\pm 2^{\circ}$ and inclination within $\pm 0.5^{\circ}$. The same tool used for magnetic susceptibility, the Mount Sopris 2PMA-1000, was used for borehole deviation.

\section{Borehole Geophysical Monitoring at the Anoka County Riverfront Park}

The field data presented in this report were collected from nine wells in the ACP (fig. 1). The wells are cased with 7.62-cm-diameter PVC and completed to depths ranging from 13.0 to $22.9 \mathrm{~m}$. Table 1 summarizes the borehole constructions. Data were collected during five site visits between December 2001 and June 2003, and include pre- and postinjection surveys.

\section{Vegetable Oil Emulsion Biostimulation Experiments}

Oil emulsion injections were performed in boreholes INJ-1, INJ-2, and INJ-3 on December 11-12, 2001. Three injection mixtures with different radar signatures were evaluated:

Table 1. Borehole constructions for injection and observation wells at the Anoka County Riverfront Park, Fridley, Minnesota.

[All wells are cased with polyvinyl chloride]

\begin{tabular}{|c|c|c|c|c|c|}
\hline Borehole & $\begin{array}{l}\text { Borehole diameter } \\
\text { (centimeters) }\end{array}$ & $\begin{array}{l}\text { Depth of screened interval } \\
\text { (from top of casing) } \\
\text { (meters) }\end{array}$ & $\begin{array}{l}\text { Borehole depth } \\
\text { (meters below } \\
\text { top of casing) }\end{array}$ & $\begin{array}{l}\text { Altitude of top } \\
\text { of casing } \\
\text { (meters) }\end{array}$ & $\begin{array}{l}\text { Height of measuring point } \\
\text { above land surface } \\
\text { (meters) }\end{array}$ \\
\hline BG-1 & 7.6 (3 inch) & 11.24 to 14.29 & 22.72 & 253.81 & 0.87 \\
\hline BG-2 & 7.6 (3 inch) & 11.29 to 14.33 & 22.87 & 253.80 & .92 \\
\hline MW-1 & 7.6 (3 inch) & 11.52 to 14.57 & 22.17 & 253.73 & .85 \\
\hline MW-2 & 7.6 (3 inch) & 11.48 to 14.53 & 18.85 & 253.71 & .82 \\
\hline MW-3 & 7.6 (3 inch) & 9.98 to 13.03 & 13.04 & 253.83 & .84 \\
\hline MW-6 & 7.6 (3 inch) & 11.49 to 14.54 & 18.68 & 253.71 & .83 \\
\hline MW-7 & 7.6 (3 inch) & 13.04 to 16.09 & 21.87 & 253.76 & .85 \\
\hline MW-8 & 7.6 (3 inch) & 10.00 to 13.04 & 13.04 & 253.78 & .85 \\
\hline MW-9 & 7.6 (3 inch) & 9.98 to 13.02 & 13.09 & 253.84 & .83 \\
\hline INJ-1 & 7.6 (3 inch) & 11.53 to 14.58 & 21.97 & 253.71 & .87 \\
\hline INJ-2 & 7.6 (3 inch) & 13.09 to 16.14 & 21.72 & 253.85 & .90 \\
\hline INJ-3 & 7.6 (3 inch) & 13.02 to 16.07 & 21.87 & 253.80 & .83 \\
\hline
\end{tabular}


1. $4,542 \mathrm{~L}$ of 65 percent native water and 35 percent soybean oil and a lecithin emulsifier were injected in INJ-2;

2. 4,542 $\mathrm{L}$ of 65 percent native water and 35 percent soybean oil and a lecithin emulsifier and $3.5 \mathrm{~kg}$ of dissolved magnetite were injected in INJ-3; and

3. $4,542 \mathrm{~L}$ of 65 percent native water and 35 percent soybean oil and a lecithin emulsifier and $50 \mathrm{~kg}$ of colloidal iron were injected in INJ-1.

Based on petrophysical modeling and laboratory experiments (Lane and others, 2003, 2004a, 2004b), mixture (1) was expected to increase radar velocity and decrease radar attenuation relative to background; mixtures (2) and (3) were expected to increase radar velocity and also increase radar attenuation because of their greater electrical conductivity relative to native ground water. The magnetite tracer remained in solution, but the colloidal iron settled out quickly during the injection. Boreholes INJ-1, INJ-2, and INJ-3 were screened over depth intervals of 11.5 to $14.6,13.1$ to 16.1 , and 13.1 to $16.1 \mathrm{~m}$ below ground surface, respectively. At the time of the injections, the water table in the vicinity of the boreholes was about $8 \mathrm{~m}$ below ground surface; thus, the top of the well screens were about $2.5 \mathrm{~m}$ below the water table.

\section{Borehole Radar Data}

Cross-hole borehole radar data were collected in two modes-zero-offset profiling and tomography; these data were used to provide information about the deeper regions around the boreholes and to detect slowness changes that were interpreted to indicate the presence of oil emulsion.

\section{Cross-Hole Zero-Offset Radar Profiles}

Cross-hole ZOP radar data were collected at one or more times between 13 borehole pairs (table 2). Data were collected in 0.2-m depth increments, with the transmitter antenna in one borehole, and the receiver antenna in a second borehole at the same depth.

Based on the petrophysical model (eq. 3), the presence of oil emulsion should produce a decrease in radar slowness (increase in velocity) in the saturated zone, or an increase in

Table 2. Zero-offset radar datasets used in this study.

[X, data collected for this well pair; S, dataset for the given well pair that shows maximum slowness change from background dataset; A, dataset from the given well pair that shows maximum amplitude change from background dataset; --, no data]

\begin{tabular}{|c|c|c|c|c|c|c|}
\hline Well pair & Background & $\begin{array}{l}\text { December } 2001 \\
\text { after INJ-3 } \\
\text { injection }\end{array}$ & $\begin{array}{l}\text { December } 2001 \\
\text { during INJ-1 } \\
\text { injection }\end{array}$ & May 2002 & November 2002 & June 2003 \\
\hline MW-1 to INJ-2 & $\mathrm{X}$ & -- & $S$ & A & $\mathrm{X}$ & $\mathrm{X}$ \\
\hline INJ-1 to INJ-2 & $\mathrm{X}$ & $\mathrm{X}$ & ${ }^{1} \mathrm{X}$ & $\mathrm{S}, \mathrm{A}$ & $\mathrm{X}$ & $\mathrm{X}$ \\
\hline INJ-3 to INJ-2 & $\mathrm{X}$ & $\mathrm{X}$ & -- & S, A & $\mathrm{X}$ & $\mathrm{X}$ \\
\hline INJ-3 to MW-7 & $\mathrm{X}$ & -- & $\mathrm{X}$ & A & $\mathrm{X}$ & S \\
\hline MW-6 to INJ-1 & $\mathrm{X}$ & $\mathrm{X}$ & -- & $\mathrm{S}, \mathrm{A}$ & -- & -- \\
\hline MW-6 to INJ-2 & $\mathrm{X}$ & S, A & -- & -- & -- & -- \\
\hline${ }^{2} \mathrm{MW}-6$ to MW-1 & $\mathrm{X}$ & $\mathrm{X}$ & -- & -- & A & -- \\
\hline MW-7 to INJ-2 & $\mathrm{X}$ & $\mathrm{S}, \mathrm{A}$ & -- & -- & -- & -- \\
\hline${ }^{2} \mathrm{MW}-7$ to MW-1 & $\mathrm{X}$ & $\mathrm{X}$ & -- & -- & A & -- \\
\hline MW-7 to MW-2 & $\mathrm{X}$ & -- & -- & -- & A & -- \\
\hline BG-1 to INJ-2 & $\mathrm{X}$ & $\mathrm{X}$ & S & -- & $\mathrm{X}$ & -- \\
\hline BG-2 to INJ-2 & $\mathrm{x}$ & S & -- & -- & $\mathrm{X}$ & -- \\
\hline BG-2 to INJ-3 & $\mathrm{X}$ & -- & X & S, A & $\mathrm{X}$ & $\mathrm{X}$ \\
\hline
\end{tabular}

${ }^{1}$ Only the upper $14 \mathrm{~m}$ of the borehole was logged, due to obstruction by the injection apparatus.

${ }^{2}$ No substantial changes in slowness were observed in this plane. 
(a)

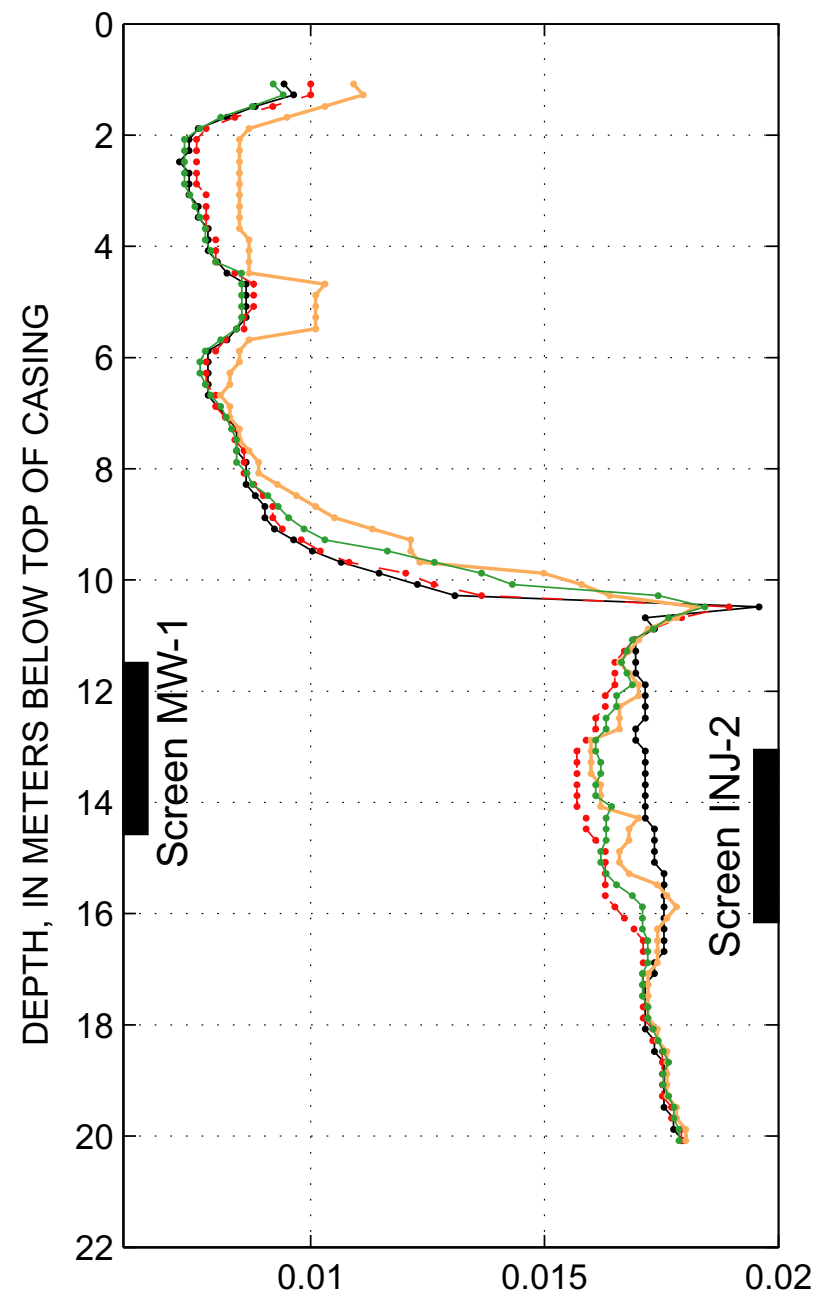

RADAR SLOWNESS, IN MICROSECONDS PER METER (b)

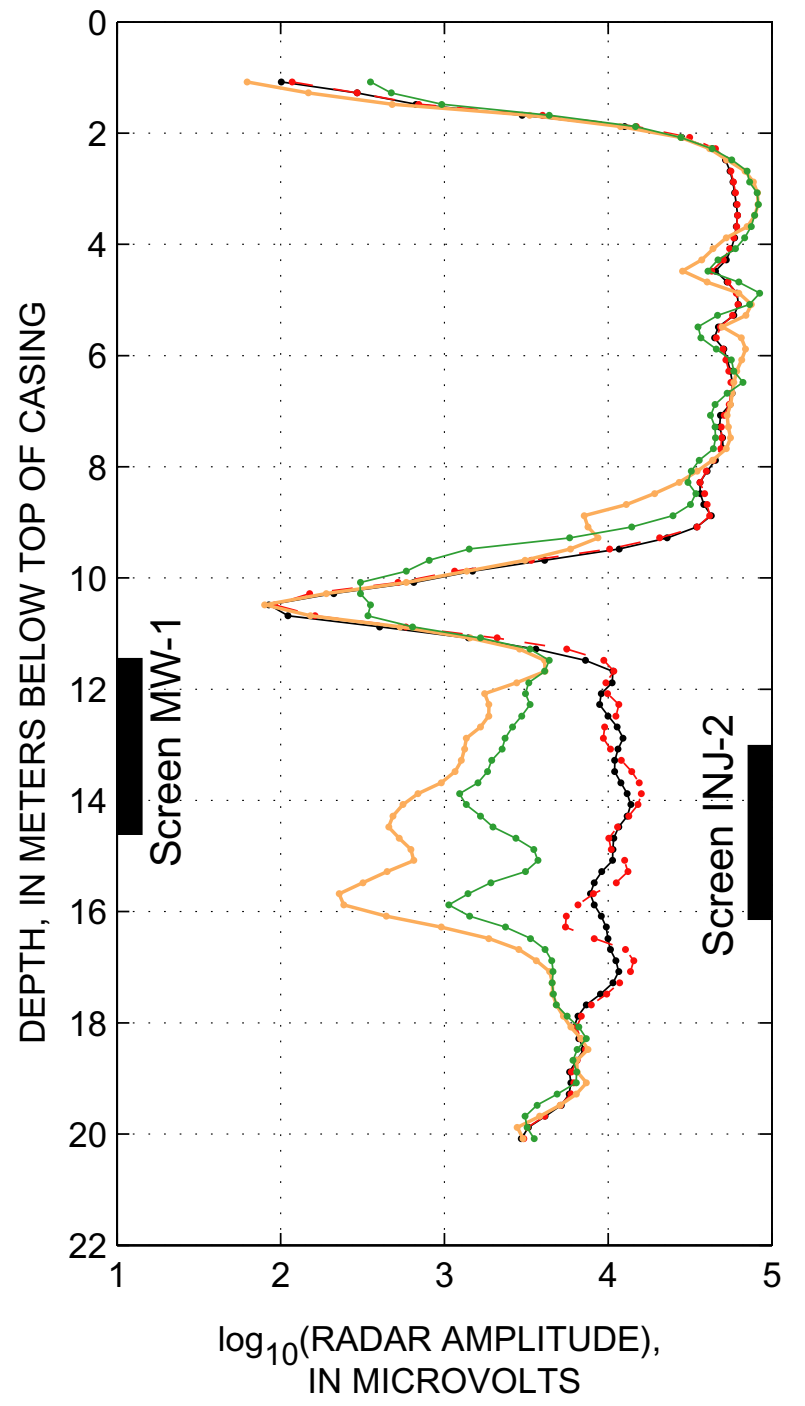

\section{EXPLANATION}

Background radar data

Radar data collected December 2001, during INJ-1 injection

Radar data collected May 2002

Radar data collected November 2002

Figure 4. (a) Zero-offset radar slowness, and (b) zero-offset radar amplitude profiles for the MW-1 to INJ-2 plane, Anoka County Riverfront Park, Fridley, Minnesota. Decrease in radar slowness indicates the presence of vegetable oil emulsion. Decrease in radar amplitude indicates elevated electrical conductivity, and thus altered geochemistry. 
slowness (decrease in velocity) in the unsaturated zone. The ZOP slowness data for well pair MW-1 to INJ-2 are shown in figure $4 \mathrm{a}$, and all processed ZOP data are reported in appendix A. Well-defined slowness anomalies are evident in many of the ZOP radar datasets. Decreases in slowness are observed below the water table in all planes connected to injection wells (fig. 4 and appendix A, figs. A1, A2, A3, A4, A5, A6, A8), but no substantial changes in traveltime are observed for well pairs that do not include an injection well (appendix A, figs. A7, A9, A10); thus, the field data indicate that the emulsified oil has not migrated far from injection wells.

Decreases in amplitude, diagnostic of increased TDS, are observed in ZOP data collected for well pairs downgradient from the injections. Small increases in amplitude, indicative of the presence of iron-free oil, are observed only in planes connecting to INJ-2 (for example, fig. 4b), where the tracerfree emulsified oil mixture was injected; over time, however, the amplitudes in these planes decrease, a possible result of biodegradation and increased TDS.

Although the principal geophysical anomalies observed at the ACP are located in the saturated zone, several radar ZOP datasets indicate changes in the unsaturated zone. In several planes, increases in slowness (decreases in velocity) are observed directly above the water table, for example, the MW-6 to INJ-2 plane (fig. A6), the MW-6 to MW-1 plane (fig. A7), and the MW-7 to INJ-2 plane (fig. A8). These changes are consistent with the presence of vegetable oil emulsion above the water table, which could result from the lighter-than-water vegetable oil emulsion rising up to the water table in the same manner as LNAPL "skims" or "pancakes." In the absence of direct sampling to corroborate this interpretation, however, the ZOP radar results are inconclusive.

\section{Cross-Hole Radar Tomography}

Tomography data collection focused on planes MW-7 to INJ-3 and MW-1 to INJ-2. For tomography surveys, the transmitter antenna was positioned at different locations in one borehole, and the receiver antenna was moved from the top to the bottom of a second borehole, with measurements triggered at $0.2-\mathrm{m}$ depth increments. A representative transmitter-receiver geometry used for tomography surveys is shown in figure 5 for the plane between boreholes INJ-3 and MW-7; this tomography dataset includes measurements for 325 raypaths, each measurement corresponding to a unique transmitterreceiver combination. The tomography data were inverted on a grid of 0.5 -m square pixels.

The results of cross-hole radar tomography at the site corroborate the interpretation of the ZOP data. Slowness-difference tomograms for December 2001 for the MW-1 to INJ-2 and MW-7 to INJ-3 planes are shown in figures $6 \mathrm{a}$ and $6 \mathrm{~b}$, respectively. The presence of emulsified vegetable oil appears as blue (negative) slowness-difference anomalies-velocity increases - in both planes. In both tomograms, the anomalies extend away from the injection well toward the monitoring

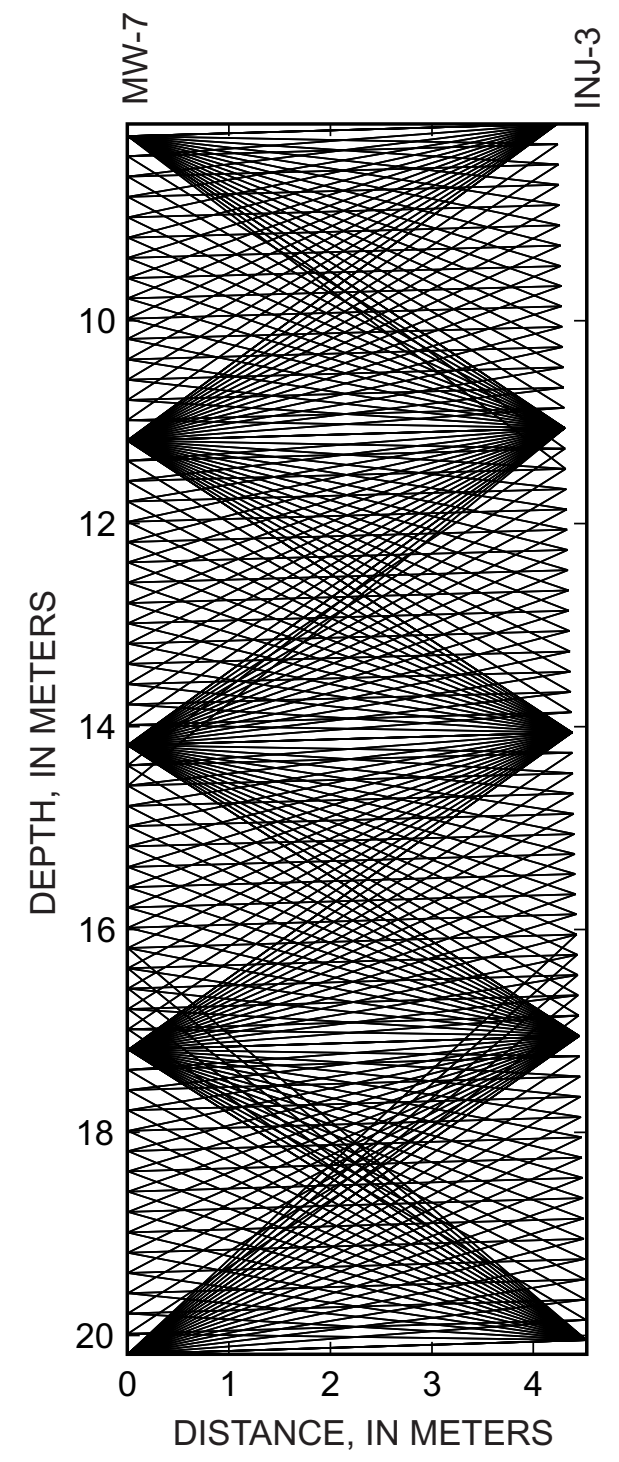

Figure 5. Cross-hole radar tomography raypath geometry for the MW-7 to INJ-3 plane, Anoka County Riverfront Park, Fridley, Minnesota.

wells. In the MW-1 to INJ-2 plane, the anomaly extends away from INJ-2 and appears to pinch out at a depth of about $18 \mathrm{~m}$, near MW-1. Results for the MW-7 to INJ-3 plane are similar, with the anomaly localized between depths of about 13 and $16 \mathrm{~m}$, and pinching out perhaps $2 \mathrm{~m}$ from MW-7. The actual region affected by oil is likely smaller than the estimated anomalies, as blurring and streaking of anomalies are expected due to the underdetermined nature of the tomographic inverse problems. 
(a) $M W-1$ to $I N J-2$

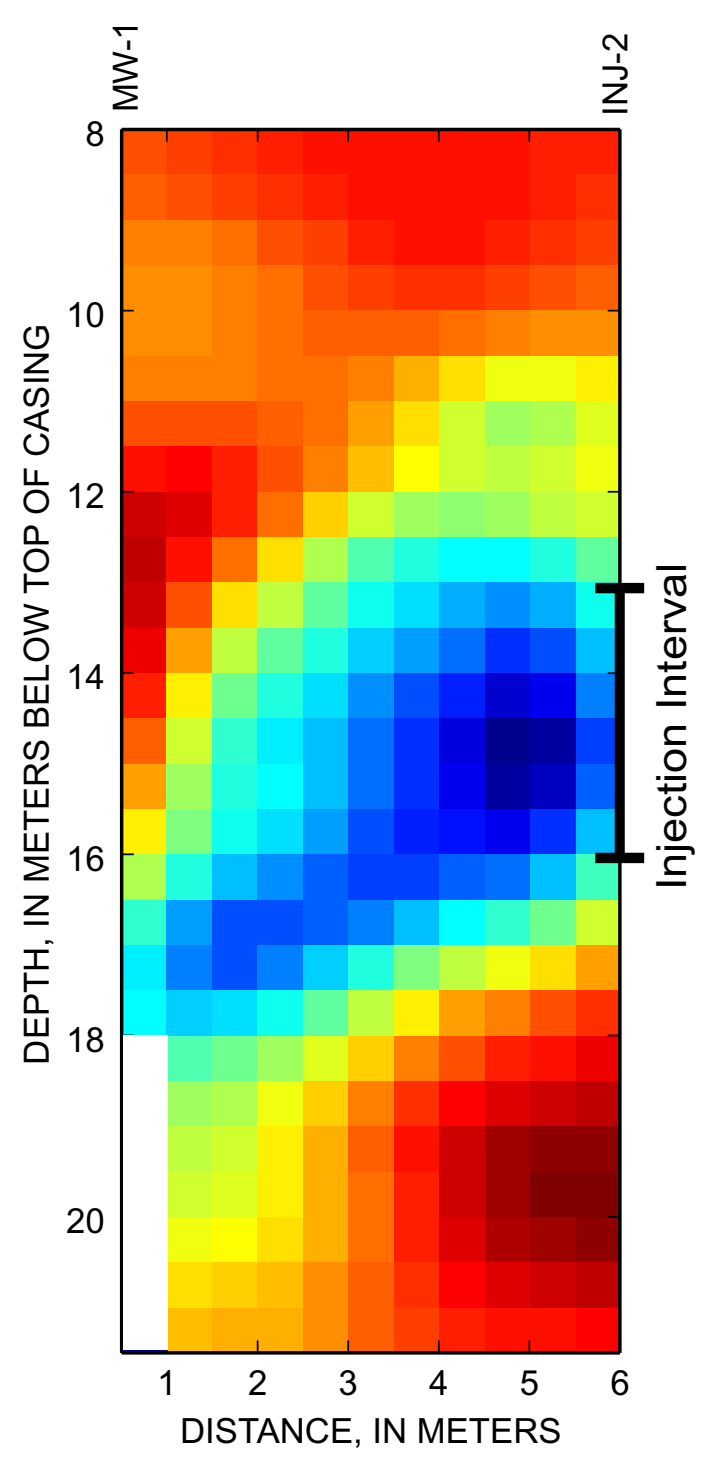

(b) $M W-7$ to INJ-3
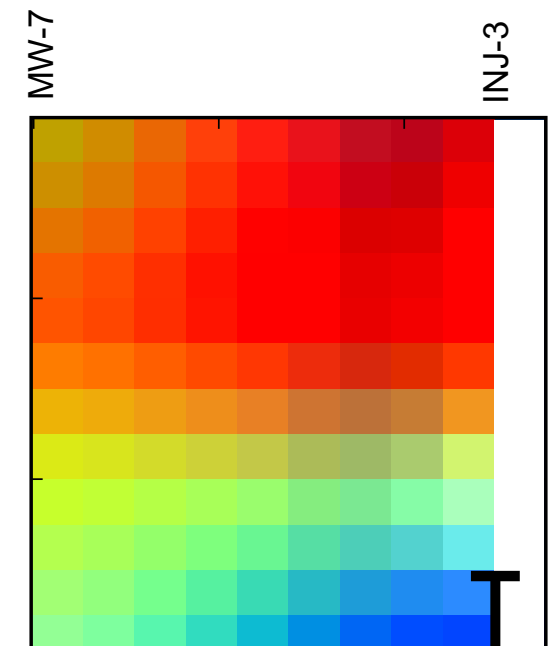

$\stackrel{m}{i}$

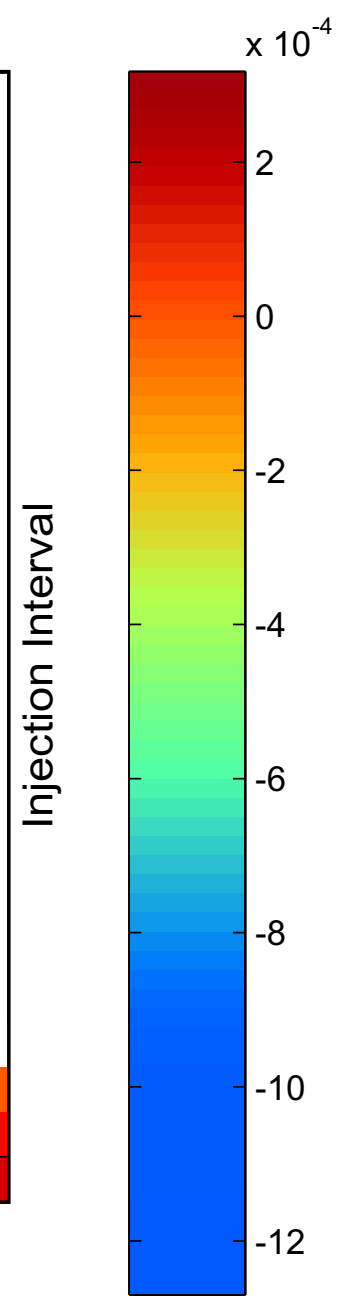

Figure 6. December 2001 cross-hole radar tomograms for the (a) MW-1 to INJ-2 planes, and (b) MW-7 to INJ-3 planes, Anoka County Riverfront Park, Fridley, Minnesota. Decrease in radar slowness (blue) indicates the presence of vegetable oil emulsion. 
A powerful method for exploratory analysis of cross-hole radar tomography data and interpretation of anomaly extent is to compare plots of (1) raypaths for measurements showing large changes in slowness or attenuation and (2) raypaths for measurements showing small or insignificant changes in slowness or attenuation (Day-Lewis and others, 2003). For data collected in December 2001 and differenced against the background dataset, figure 7a shows raypaths in the MW-7 to INJ-3 plane with slowness-difference values above the median value (50th percentile) for the dataset, that is, measurements that do not indicate decreases in radar slowness or the presence of vegetable oil emulsion. Figure $7 \mathrm{~b}$ shows raypaths in the same plane for which slowness-difference values are below the 30th percentile of the dataset, that is, measurements that indicate substantial decreases in slowness, and possibly the presence of vegetable oil emulsion. By visualizing raypaths that are not affected (fig. 7a), and those that are strongly affected (fig. 7b), it is possible to infer where emulsified vegetable oil is likely to be found in the interwell region. The inferred altered region extends from INJ-3 toward MW-7, but appears to pinch out near MW-7. The raypath plots (fig. 7) are qualitatively consistent with the location and extent of the anomaly in the MW-7 to INJ-3 plane, providing a check on the tomographic inversion results (fig. 6b). Although the 50th and 30 th percentiles were used as cutoffs for raypath visualization, other cutoffs might be equally or more appropriate for other datasets, depending on the degree of error and magnitude of slowness difference.

Although the pixel-based tomograms (fig. 6) provide qualitative insight into the extent of injected vegetable oil emulsion, the tomograms include spurious positive-valued slowness-difference anomalies (red) that frame the target negative-valued anomaly (blue). The measurements do not indicate the presence of such positive-valued anomalies; rather, they are inversion artifacts that result from the regularization, which forces the image to be smooth (Lane and others, 2003, 2004a). Because of the presence of such artifacts and blurring, application of petrophysical models to pixel-based tomograms is, in many situations, inappropriate (Day-Lewis and Lane, 2004). As an alternative to conventional pixel-based parameterization of the tomographic inverse problem, Lane and others (2004a) used an object-based inversion (OBI) approach, in which the parameters to be estimated are chosen based on a conceptual model of the geology and physics controlling the process being monitored.

Based on the results of ZOP radar data and pixel-based tomograms, the ACP aquifer materials appear approximately horizontally stratified. The injected vegetable oil emulsion appears to move outward from injections wells, with oil penetrating farther and at higher saturation in certain layers. Using these insights, Lane and others (2004a) chose a parsimonious parameterization that resulted in an overdetermined inverse problem, thus eliminating the need for regularization criteria regarding the smoothness or flatness of the tomogram. In their inversion of data from the ACP, they assume the cross-sectional geometry of the geophysical anomaly can be adequately described by a stack of rectangles having variable extents and radar slownesses (fig. 8). The inversion parameters include (1) the top of the anomaly, (2) the bottom of the anomaly, (3) the horizontal coordinate at the left edge of each component rectangle, (4) the horizontal coordinate at the right edge of each component rectangle, (5) the slowness difference inside each rectangle, and (6) the slowness difference of the region outside the anomaly.

Application of the OBI approach to tomography data from the MW-7 to INJ-3 plane yielded the tomogram shown in figure 9. Based on results of synthetic modeling (Lane and others, 2003, 2004a), the OBI approach was shown to provide better estimates of anomaly magnitude compared to pixel-based approaches; moreover, the OBI tomograms are not subject to the spurious postitive-valued slowness-difference anomalies seen in the pixel-based tomograms (fig. 6). Applying the petrophysical model (eq. 6) to the OBI tomogram, slowness-difference estimates are converted to estimates of vegetable oil emulsion saturation (table 3 ). To model the $3 \mathrm{D}$ shape of the oil-affected region based on the 2D cross section, Lane and others (2004a) assumed that each block in the OBI tomogram is a cross section of a cylinder centered on the borehole. ZOP data considered here (table 2), however, indicate the anomaly is not symmetric about the borehole; rather, the geophysical anomaly extends farther in downgradient cross sections. In this study, the cylinders' common axis is assumed to lie along the transect between the injection well (INJ-3) and monitoring well (MW-7) directly downgradient. The location of the axis is identified such that the 3D stack of cylinders would account for all of the injected vegetable oil emulsion mass, allowing for mass outside the $2 \mathrm{D}$ cross section of the tomogram and upgradient of INJ-3. By trial-and-error, the axis of symmetry was determined to lie $0.8 \mathrm{~m}$ downgradient from INJ-3. Although additional direct sampling would be necessary to confirm this interpretation, the result is qualitatively consistent with the radar ZOP data, which indicate a stronger slowness anomaly downgradient from INJ-3 (fig. A4a) than upgradient (fig. A13a).

\section{Conventional Borehole Geophysical Data}

Representative borehole geophysical data for wells MW-1 and INJ-2 are shown in figures 10 and 11, respectively. Data include well construction and lithology logs, electromagnetic conductivity, natural gamma logs, neutron porosity logs, and magnetic susceptibility logs. Processed borehole geophysical data for other wells are included in appendix B. Table 4 provides a list of the borehole geophysical data considered in this report. 
(a)

(b)

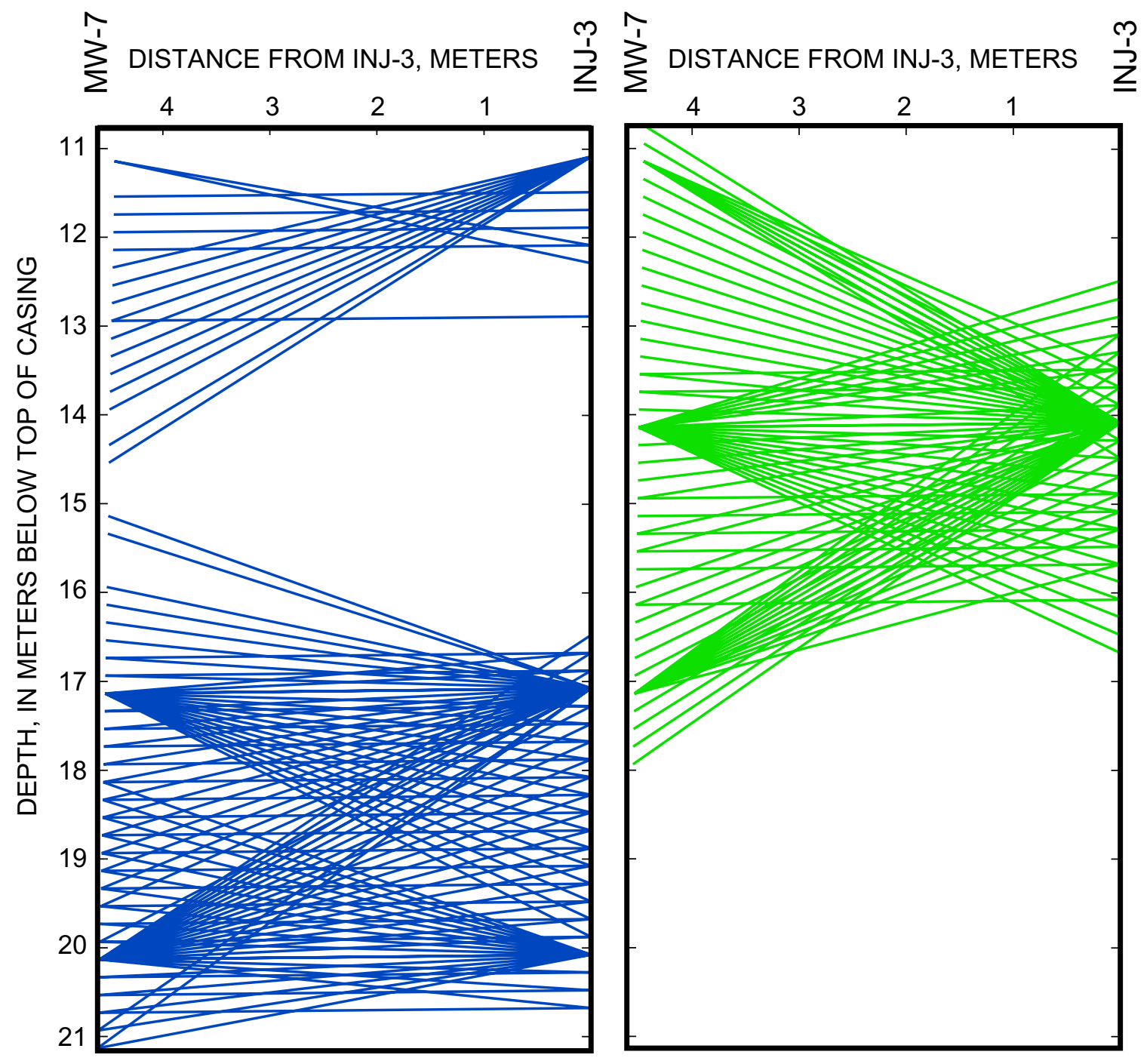

Figure 7. (a) Raypaths corresponding to slowness-difference data of greater than the median value of the dataset, and (b) raypaths corresponding to slowness-difference data showing less than the 30th percentile, Anoka County Riverfront Park, Fridley, Minnesota. Relatively large decreases in radar slowness are observed along raypaths shown in green (b), presumably resulting from replacement of pore water by vegetable oil emulsion. Raypaths shown in blue (a) seem largely unaffected by the oil injection. Differences are calculated against the background dataset. 


\section{Tomographic Image}

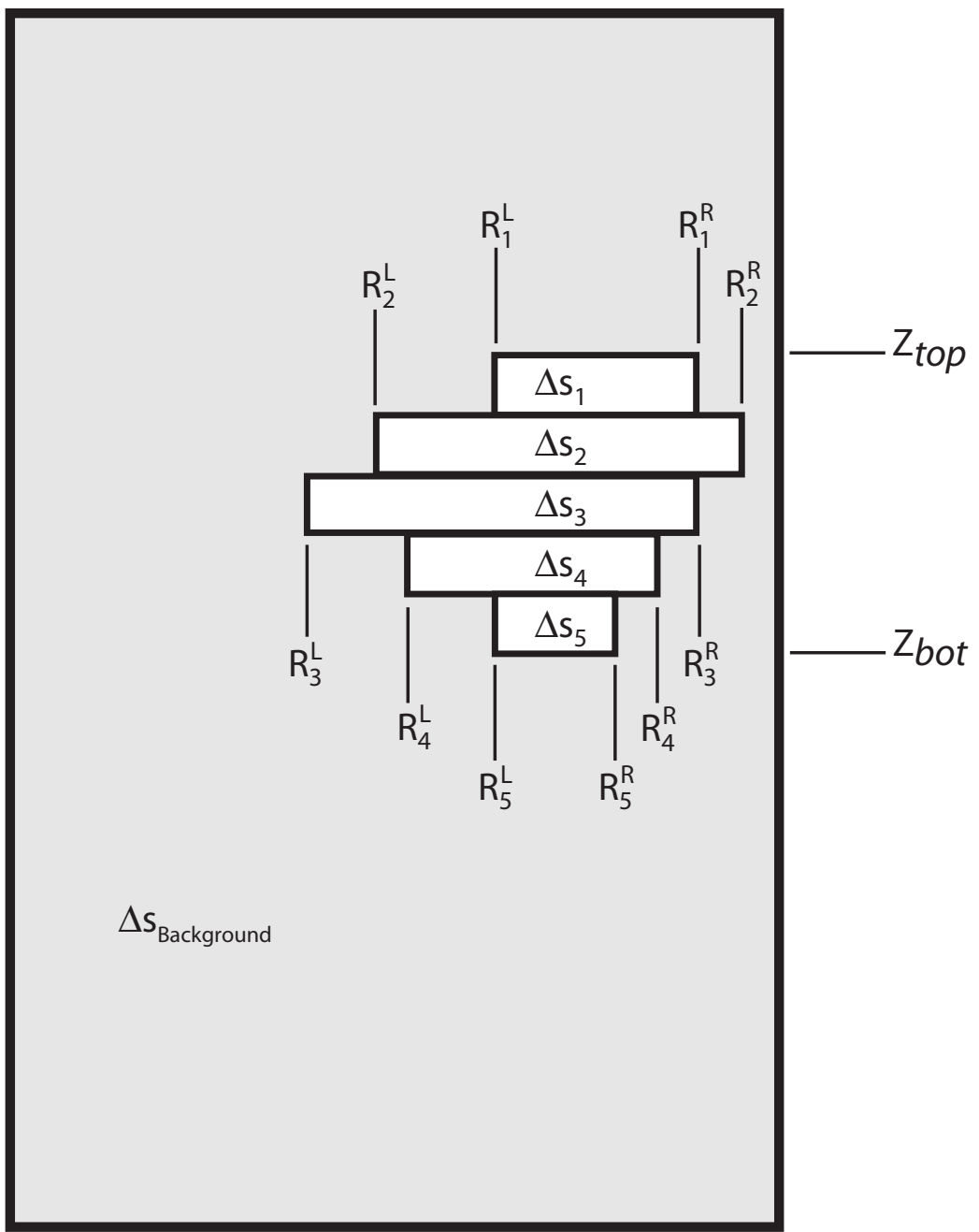

Figure 8. Conceptual diagram of the object-based inversion parameterization of slowness difference $(\Delta s)$ in the tomographic image plane. The region affected by oil-tracer injection is discretized as an object consisting of a small number of rectangles. The shape and extent of the affected region are determined by the inversion (modified from Lane and others, 2004a, fig. 7). See text for definition of symbols.

\section{Electromagnetic Induction Log Data}

EM induction logs collected at the ACP indicate changes in electrical conductivity at the injection wells and wells downgradient from the injections. These logs were calibrated using the background dataset as reference; thus the numerical conductivity values should be considered as qualitative, not quantitative, measures relative to the background. In general, there is good correlation between electromagnetic conductivity and the radar results in the saturated zone. In the upper parts of logs, the effects of time-varying saturation result in differences between datasets that are not indicative of changes in water chemistry or emulsion saturation. Well-defined increases in conductivity were observed in many of the downgradient wells, at depth ranges similar to the locations of radar-attenuation anomalies. For example, in the MW-1 to INJ-2 zero-offset radar amplitude profile, amplitude decreases are observed at depths of 12 to $18 \mathrm{~m}$ after the injection (fig. 4b). In the electro- magnetic conductivity for the two wells, changes are observed from depths of about 12 to $20 \mathrm{~m}$ (figs. 10 and 11). The EM changes in the vicinity of the water table, which can be large, result from changing water saturation and not changing water chemistry or the presence of vegetable oil emulsion.

Comparisons of borehole logs (appendix B) and ZOP radar data (appendix A) are useful to interpret the proximity of target anomalies to wells. Whereas ZOP radar data give horizontal averages between wells, the conventional logs give measurements local to a single well. A zero-offset radar attenuation anomaly observed between two wells at which no electromagnetic anomalies were seen might indicate that high TDS ground water was migrating between, but not directly adjacent to, the two wells; conversely, if an electromagnetic anomaly is relatively strong but the radar anomaly is weak, the feature may be closer to the borehole where the EM induction $\log$ was collected. 


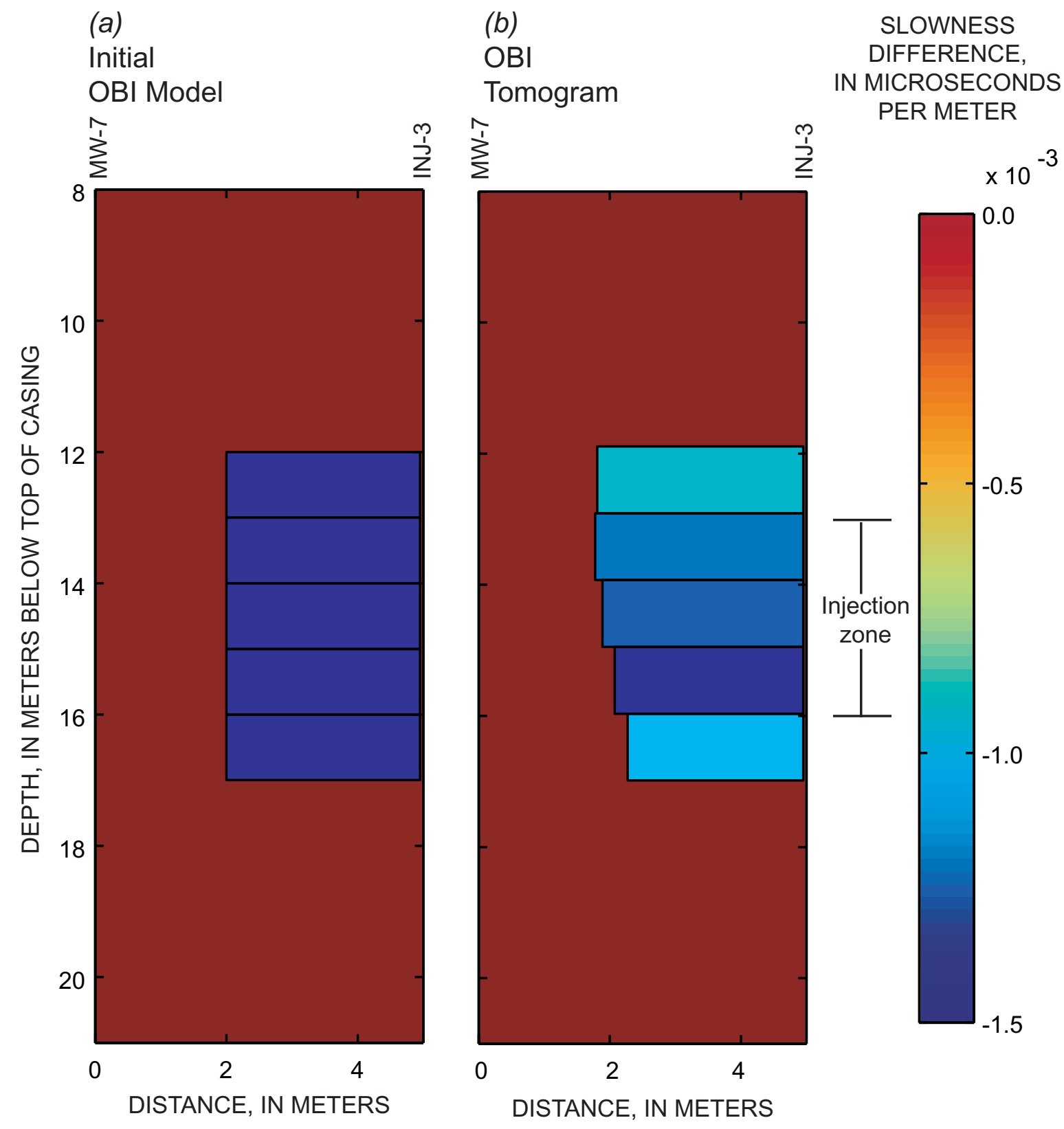

Figure 9. Radar slowness-difference tomography inversion results from well-pair MW-7 and INJ-3 using the object-based inversion (OBI) method. (a) The OBI starting model, and (b) OBI tomogram, Anoka County Riverfront Park, Fridley, Minnesota (modified from Lane and others, 2004a, fig. 13). Decreases in radar slowness indicate the presence of vegetable oil emulsion. 
Table 3. Estimates of vegetable oil emulsion saturation (modified from Lane and others, 2004a, table 2).

[OBI, object-based inversion]

\begin{tabular}{cccccc}
\hline $\begin{array}{c}\text { Layer } \\
\text { number }\end{array}$ & $\begin{array}{c}\text { OBI inverted slowness difference } \\
\text { (microseconds per meter) } \\
(\mathbf{1} \text { x 10-4) }\end{array}$ & $\begin{array}{c}\text { Layer radius } \\
\text { (meters) }\end{array}$ & $\begin{array}{c}\text { Layer thickness } \\
\text { (meters) }\end{array}$ & $\begin{array}{c}\text { Mean neutron } \\
\text { log porosity }\end{array}$ & $\begin{array}{c}\text { Estimated saturation } \\
\text { (percent) }\end{array}$ \\
\hline 1 & -8.8 & 3.1 & 1.3 & 0.31 & 33 \\
2 & -11.9 & 3.2 & 1.3 & .31 & 45 \\
3 & -12.3 & 3.1 & 1.3 & .31 & 46 \\
4 & -15.3 & 2.9 & 1.3 & .31 & 57 \\
5 & -9.8 & 2.7 & 1.3 & .31 & 36 \\
\hline
\end{tabular}

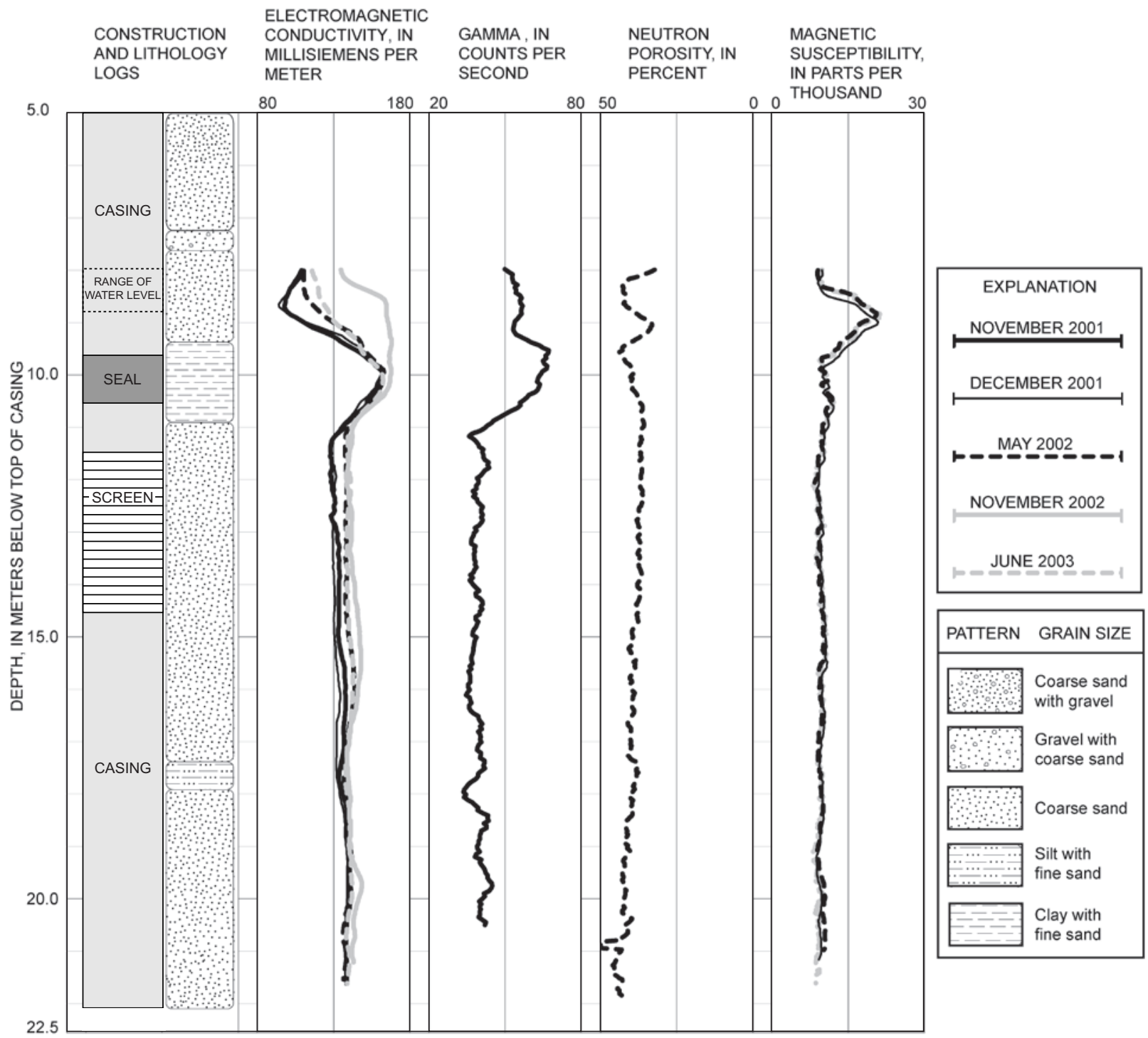

Figure 10. Borehole geophysical logs for MW-1, Anoka County Riverfront Park, Fridley, Minnesota. 


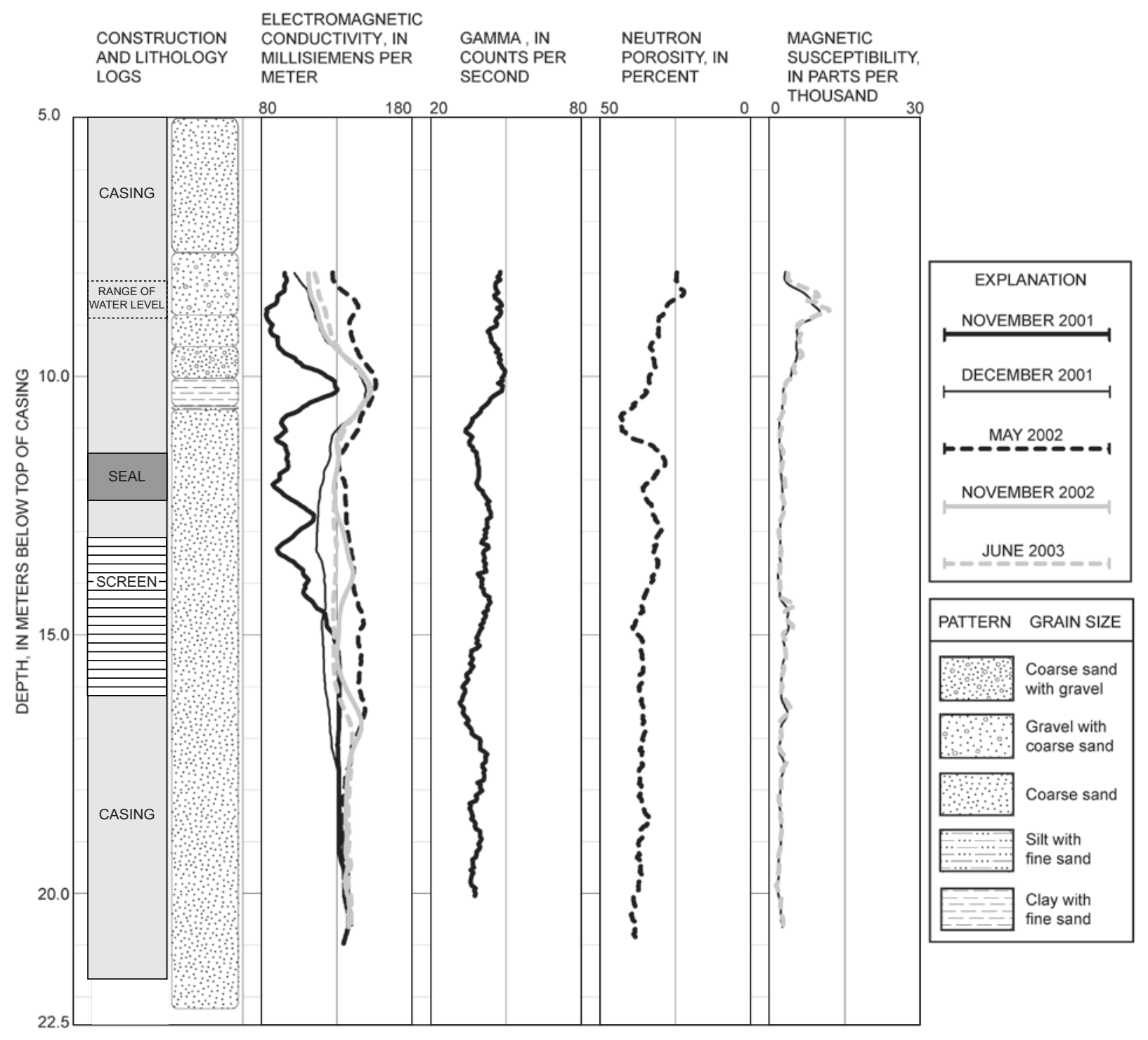

Figure 11. Borehole geophysical logs for INJ-2, Anoka County Riverfront Park, Fridley, Minnesota. 
Table 4. Conventional borehole geophysical data considered in this report.

[Date given as month/year; ' $\mathrm{X}$ ' indicates the dataset was collected and processed; --, no data]

\begin{tabular}{|c|c|c|c|c|c|c|c|c|c|c|c|c|}
\hline \multirow[b]{2}{*}{ Date } & \multicolumn{5}{|c|}{ Electromagnetic conductivity } & \multicolumn{3}{|c|}{ Natural gamma } & \multicolumn{3}{|c|}{ Magnetic susceptibility } & \multirow{2}{*}{$\begin{array}{c}\text { Neutron } \\
5 / 02\end{array}$} \\
\hline & $11 / 01$ & $12 / 01$ & ${ }^{15} / 02$ & $11 / 02$ & $6 / 03$ & $11 / 01$ & $12 / 01$ & $11 / 02$ & $11 / 01$ & $5 / 02$ & $6 / 03$ & \\
\hline BG-1 & $\mathrm{x}$ & $\mathrm{X}$ & $\mathrm{X}$ & $\mathrm{X}$ & $\mathrm{X}$ & $\mathrm{X}$ & $\mathrm{X}$ & $\mathrm{X}$ & $\mathrm{X}$ & $\mathrm{X}$ & $\mathrm{X}$ & $\mathrm{X}$ \\
\hline BG-2 & $\mathrm{x}$ & $\mathrm{X}$ & $\mathrm{X}$ & $\mathrm{X}$ & $\mathrm{X}$ & $\mathrm{X}$ & $\mathrm{X}$ & $\mathrm{X}$ & $\mathrm{X}$ & $\mathrm{X}$ & $\mathrm{X}$ & $\mathrm{X}$ \\
\hline INJ-1 & $\mathrm{x}$ & $\mathrm{X}$ & $\mathrm{x}$ & $\mathrm{X}$ & $\mathrm{X}$ & $\mathrm{x}$ & $\mathrm{X}$ & $\mathrm{x}$ & $\mathrm{x}$ & ${ }^{2} \mathrm{X}$ & $\mathrm{X}$ & $\mathrm{X}$ \\
\hline $\mathrm{INJ}-2$ & $\mathrm{x}$ & $\mathrm{X}$ & $\mathrm{X}$ & $\mathrm{X}$ & $\mathrm{X}$ & $\mathrm{X}$ & $\mathrm{X}$ & $\mathrm{X}$ & $\mathrm{X}$ & $\mathrm{X}$ & $\mathrm{X}$ & $\mathrm{X}$ \\
\hline INJ-3 & $\mathrm{x}$ & $\mathrm{X}$ & $\mathrm{X}$ & $\mathrm{X}$ & $\mathrm{X}$ & $\mathrm{X}$ & $\mathrm{X}$ & $\mathrm{X}$ & $\mathrm{X}$ & ${ }^{2} \mathrm{X}$ & $\mathrm{X}$ & $\mathrm{X}$ \\
\hline MW-1 & $\mathrm{x}$ & $\mathrm{X}$ & $\mathrm{X}$ & $X$ & $\mathrm{X}$ & $\mathrm{X}$ & $\mathrm{X}$ & $\mathrm{X}$ & $\mathrm{X}$ & $\mathrm{X}$ & $\mathrm{X}$ & $\mathrm{X}$ \\
\hline MW-2 & $\mathrm{X}$ & -- & $\mathrm{X}$ & $\mathrm{X}$ & $X$ & $\mathrm{X}$ & -- & $\mathrm{X}$ & $X$ & ${ }^{2} \mathrm{X}$ & $X$ & $X$ \\
\hline MW-3 & $\mathrm{X}$ & -- & $\mathrm{X}$ & $\mathrm{X}$ & $X$ & $\mathrm{X}$ & -- & $\mathrm{X}$ & $\mathrm{X}$ & ${ }^{2} \mathrm{X}$ & $\mathrm{X}$ & $\mathrm{X}$ \\
\hline MW-6 & $\mathrm{X}$ & $\mathrm{X}$ & $\mathrm{X}$ & $\mathrm{X}$ & $X$ & $\mathrm{X}$ & $X$ & $\mathrm{X}$ & $\mathrm{X}$ & $X$ & $\mathrm{X}$ & $X$ \\
\hline MW-7 & $\mathrm{X}$ & $X$ & $\mathrm{X}$ & $X$ & $X$ & $X$ & $X$ & $\mathrm{X}$ & $\mathrm{X}$ & $\mathrm{X}$ & $X$ & $X$ \\
\hline MW-8 & $\mathrm{X}$ & -- & $X$ & $\mathrm{X}$ & -- & -- & -- & $\mathrm{X}$ & $\mathrm{X}$ & ${ }^{2} \mathrm{X}$ & $\mathrm{X}$ & $X$ \\
\hline MW-9 & $X$ & -- & $X$ & $X$ & -- & -- & -- & $X$ & $X$ & ${ }^{2} \mathrm{X}$ & $X$ & $X$ \\
\hline
\end{tabular}

${ }^{1}$ Electromagnetic conductivity data collected in May 2002 were collected using a different tool of the same model.

${ }^{2}$ These magnetic susceptibility datasets were collected with a different tool.

\section{Natural Gamma Log Data}

The natural gamma logs collected at the site (figs. 10 and 11 , and appendix B) show only a weak relation to sedimentary stratigraphy, as identified in drillers' logs at the site $(\mathrm{CH} 2 \mathrm{M}$ Hill Constructors, Inc., 2002; appendix B2). In some cases, silty or clayey layers manifest as positive gamma-log anomalies; however, the magnitude of these anomalies is on the same order as the variability seen within thick layers identified in drillers' logs as poorly sorted sand. The gamma measurements did not change substantially with the presence of vegetable oil emulsion, and thus only gamma logs from November 2001 are shown.

\section{Neutron Log Data}

The neutron logs (figs. 10 and 11, and appendix B) were used to estimate a representative porosity value to use in the calculation of vegetable oil emulsion saturation (table 3). The logs show a wide range in porosity values, particularly in the unsaturated zone. It is important to reiterate the caveat stated earlier in this report-the porosity-neutron calibration used was based on data from a limestone, and does not account for variations in lithology or saturation.

\section{Magnetic Susceptibility Log Data}

Magnetic susceptibility logs collected at the site were used primarily to detect the magnetite mixtures. The only substantial magnetic susceptibility changes over time were observed at INJ-3 (fig. B5); thus, it appears that the magnetite tracer remained in the vicinity of INJ-3 and did not reach downgradient wells. The magnetic susceptibility logs indicate that electromagnetic conductivity and radar attenuation anomalies do not result from the presence of the magnetite tracer; rather, these changes are attributed to changes in TDS.

\section{Deviation Log Data}

In this study, deviation logs were not used to provide information about subsurface materials or architecture, but rather to provide accurate antenna positions for inversion of radar data. Radar antenna offsets must be known accurately for calculation of radar velocity or slowness. Small errors in antenna position result in large errors in estimates of EM properties. 


\section{Distributions of Vegetable Oil and Geochemical Changes}

The borehole geophysical logs and cross-hole radar data were interpreted together to develop a site conceptual model for the spatial and temporal distribution of emulsified vegetable oil and the extent of ground water with altered chemistry. The vegetable oil emulsions appear to remain in the vicinity of the three injection wells-the ZOP radar data show slowness changes, diagnostic of the presence of vegetable oil emulsion, only in planes connected to injection wells. Slowness-difference anomalies develop simultaneously with the injections and are observed in all planes connected to injection wells (figs. A1, A2, A3, A4, A5, A6, A8); no substantial changes in slowness are observed in planes that do not include an injection well (figs. A7, A9, A10). The borehole magnetic susceptibility logs corroborate this interpretation-no magnetic anomalies are seen at downgradient wells.

The timing of maximum changes in slowness varies spatially, with peak changes occurring at different times in different zero-offset planes. For planes connecting injection wells with other injection wells or downgradient monitoring wells (MW-1 to INJ-2, INJ-1 to INJ-2, INJ-3 to INJ-2, INJ-3 to MW-7, and MW-6 to INJ-2), the peak change in slowness is observed months to years after the injections (figs. A1, A2, A3, A4, A5, respectively). Differences in the timing of maximum attenuation change (table 2) may result from spatial variability in microbial activity, contaminant concentrations, vegetable oil emulsion saturation, hydraulic properties, or other unknown factors.

In contrast to the apparent localization of the vegetable oil emulsion inferred from traveltime data, changes in water chemistry are inferred at all downgradient wells based on changes in both zero-offset radar amplitude (appendix A) and EM conductivity (appendix B). In general, changes in the EM conductivity are consistent with changes in radar attenuation; discrepancies can be explained by the different sample volumes for the two measurements. Whereas the radar measurements average over a volume that extends between two wells, the EM induction logs are sensitive only to changes near to the boreholes; about half of the EM induction log measurement response comes from within $58 \mathrm{~cm}$ of the borehole (McNeill, 1986). In cases where the radar measurements show large changes and the electromagnetic conductivity does not, we interpret the differences to result from spatial variations in electrical conductivity between the boreholes. For example, no substantial changes in EM conductivity were observed at MW-6 (fig. B9), yet the zero-offset radar amplitude profile for the INJ-1 to MW-6 plane (fig. A5) indicates substantial changes; these findings are consistent with a scenario where the plume of increased TDS migrates through the INJ-1 to MW-6 plane but does not come within about a meter of MW-6.

Based on the integrated interpretation of borehole geophysical and radar data, a conceptual model was developed for the spatial distribution of vegetable oil emulsion and ground water with altered chemistry as of June 2003; the model is shown in plan view in figure 12 and cross section in figure 13. The vegetable oil remains close to the injection wells throughout the period of monitoring. The water-chemistry changes propagate downgradient from the injection wells, with the largest changes in radar amplitude and electromagnetic conductivity occurring at different times across the site (table 2).

The ZOP and borehole geophysical log data (appendixes $\mathrm{A}$ and $\mathrm{B}$, respectively) indicate that direct fluid sampling does not target all regions where large changes in TDS are inferred. For example, in the interpreted cross section (fig. 13), large changes are inferred at two intervals of MW-1 (at depths of about $14 \mathrm{~m}$ and $16 \mathrm{~m}$ ) based on zero-offset amplitude data (fig. A1b) and a third, deeper interval is inferred (at a depth of about 20-21 m) from borehole geophysical logs (fig. B6); however, the screened interval of MW-1 intersects only one of the three geophysical anomalies identified. Similarly at MW-2, large changes are observed in the ZOP data at two depth intervals (at depths of about $14.5 \mathrm{~m}$ and $16 \mathrm{~m}$ ), yet the screened interval intersects only the upper zone. Thus, the geophysical measurements provide additional information that supplements direct fluid sampling of monitoring wells.

Equations 15 and 16 can be used to estimate TDS changes ( $\triangle$ TDS) from measured zero-offset radar amplitude data. Estimates of $\triangle T$ TDS are made for selected geophysical anomalies in zero-offset planes where substantial changes in radar amplitude are observed; table 5 summarizes these results. In many cases, changes in TDS are indicated at depth intervals where wells are unscreened and direct fluid sampling is not possible. Given the simplifying assumptions and approximations underlying the $\triangle$ TDS calculations, estimates should be viewed as approximate; moreover, zero-offset measurements average over the interwell region, and thus $\triangle T D S$ estimates also should be considered horizontal averages. Based on the geophysical data alone, it is not possible to conclusively attribute the changes in electrical conductivity to biodegradation of contaminants or biologic processes. Abiotic breakdown of the amendment or soil-water reactions might also affect water chemistry and, therefore, electrical conductivity. 


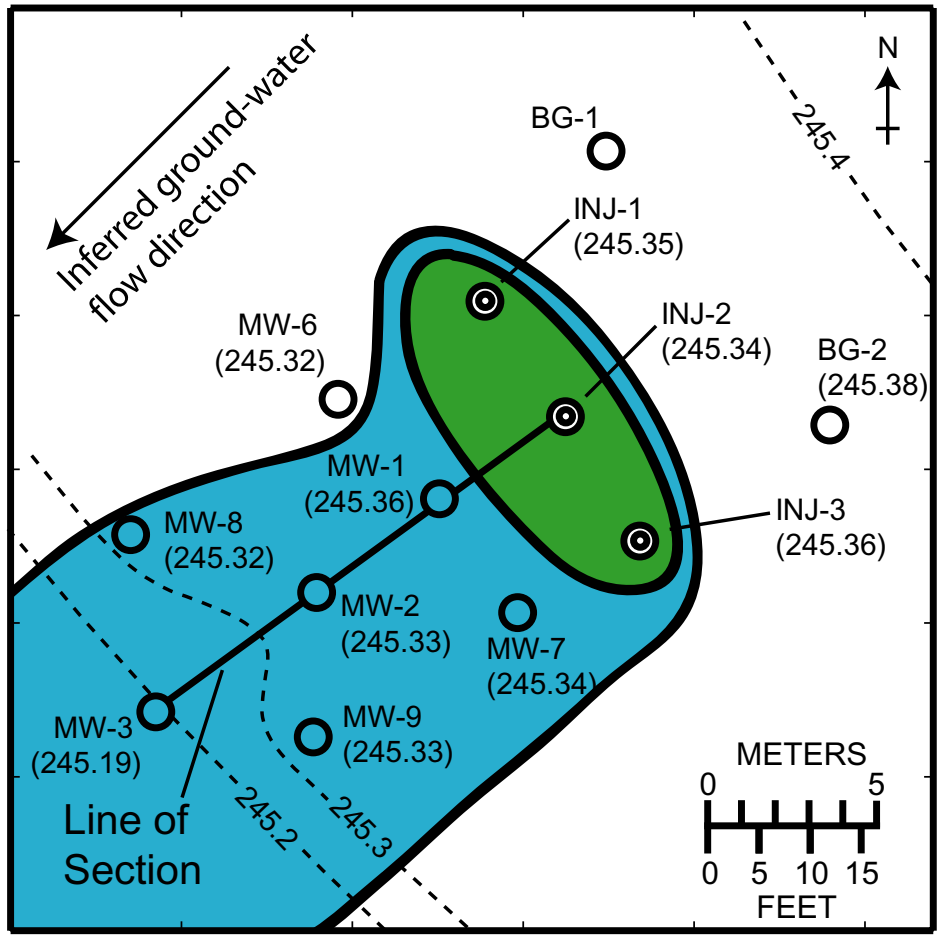

INJ-1

(245.35)

(-) Injection well, identifier, and water-table elevation in meters

MW-2

(245.36)

Monitoring well, identifier, and water-table elevation in meters

- - 245.2- - Water-table contour and elevation in meters

Region containing pure-phase vegetable oil emulsion

Region of elevated total dissolved solids

Figure 12. Interpreted conceptual model of the June 2003 areal distribution of ground water with altered chemistry (blue) and the area where pure-phase vegetable oil emulsion is found in the subsurface (green), Anoka County Riverfront Park, Fridley, Minnesota. Water levels were measured August 18, 2003. 


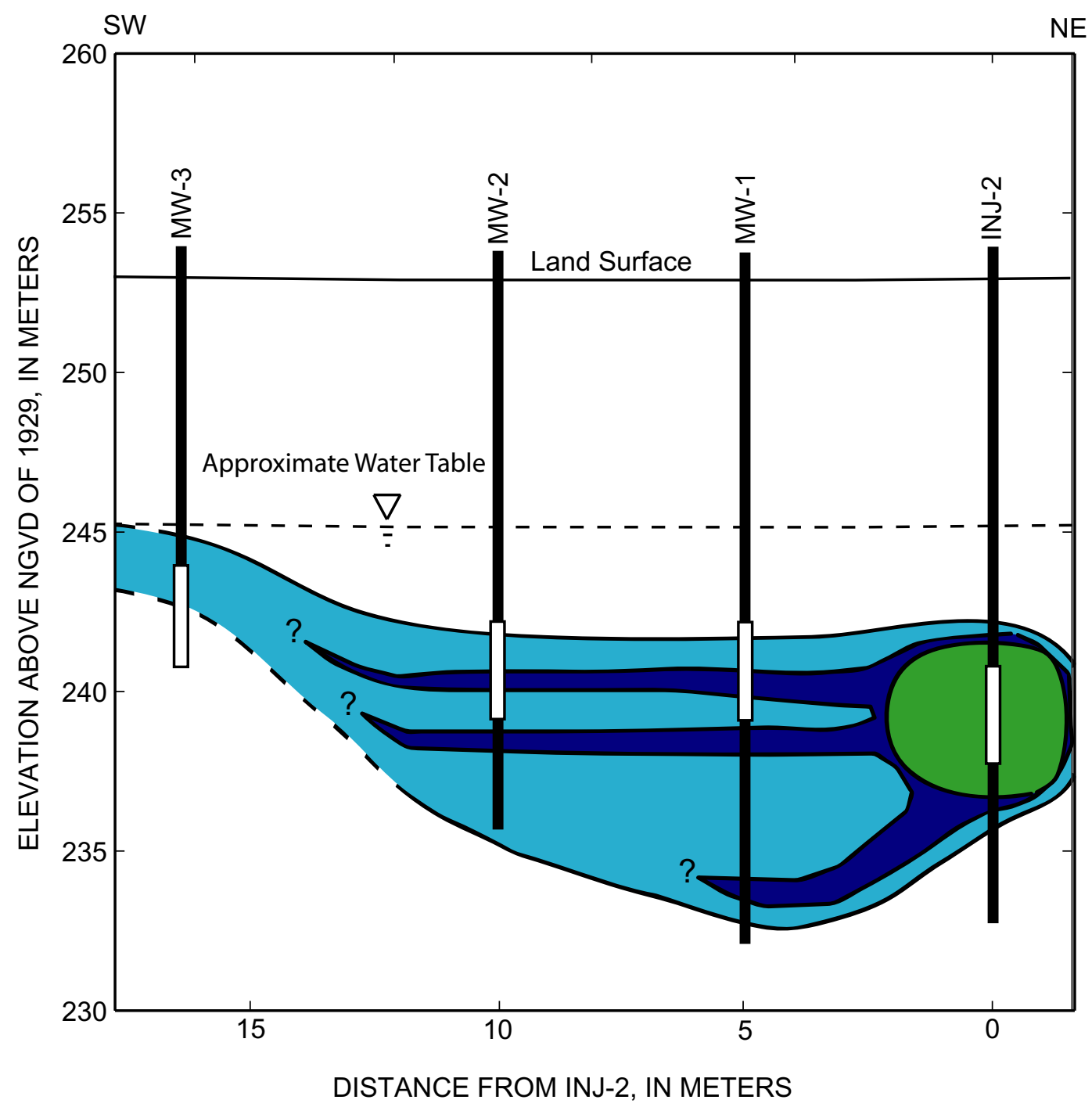

Region containing pure-phase vegetable oil emulsion

Region of highly elevated total dissolved solids

Region of moderately elevated total dissolved solids

Figure 13. Interpreted conceptual model of the June 2003 cross-sectional distribution of ground water with inferred, highly elevated total dissolved solids (TDS) (dark blue), moderately elevated TDS (light blue), and the region where pure-phase vegetable oil emulsion is found in the subsurface (green), Anoka County Riverfront Park, Fridley, Minnesota. 


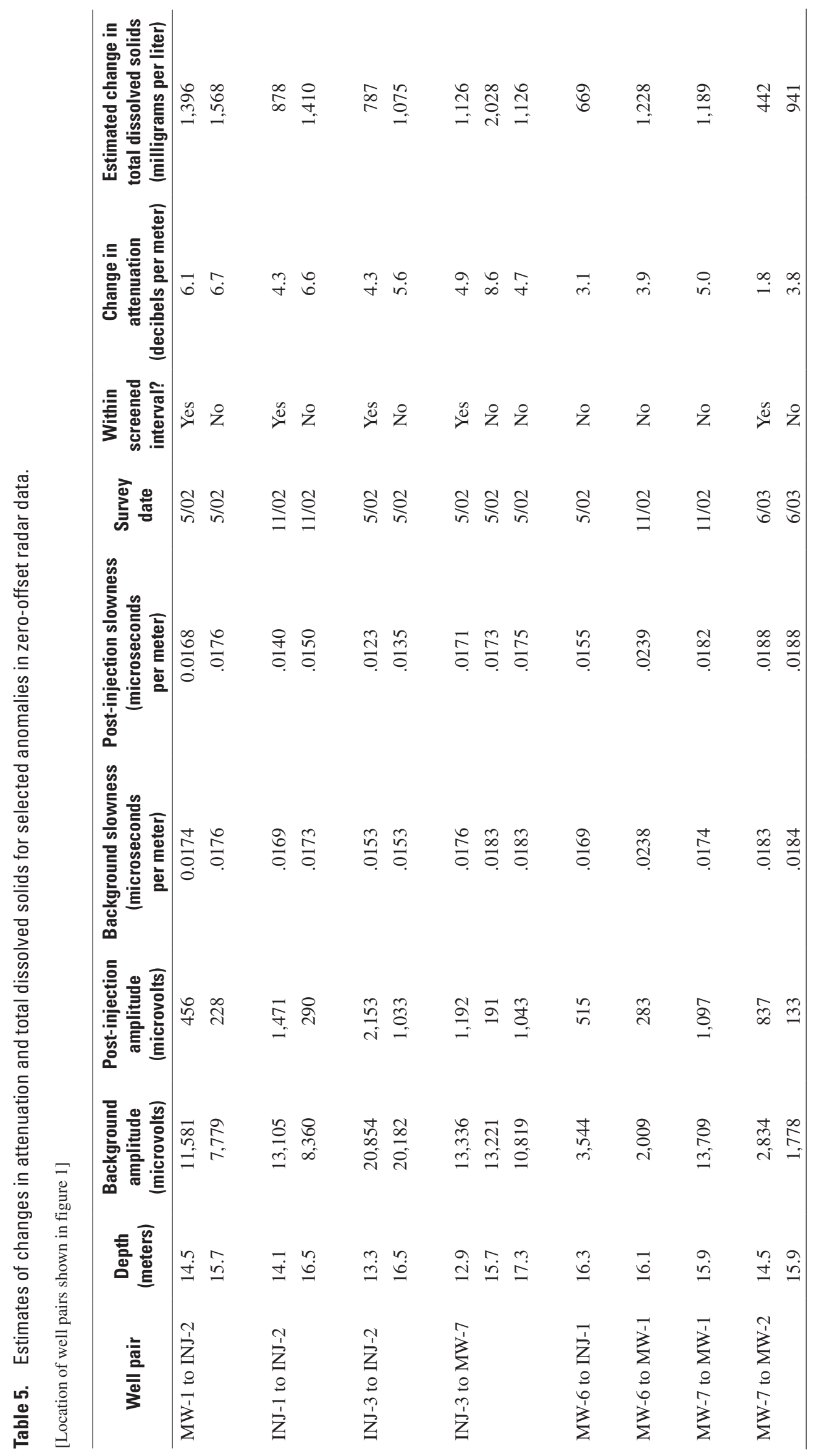




\section{Summary and Conclusions}

Cross-borehole radar monitoring of biostimulation injections of emulsified vegetable oil provided insights into the spatial and temporal distribution of the vegetable oil emulsion and the extent of ground water with altered chemistry at Anoka County Riverfront Park (ACP) in Fridley, Minnesota. Specifically, radar traveltime data proved useful for identifying the distribution of vegetable oil emulsion that remained close to the three injection wells. Radar amplitude data were useful for identifying changes in ground-water chemistry. Over time, radar attenuation increased downgradient from the injection wells, consistent with an increase in electrical conductivity and, therefore, total dissolved solids; this change does not appear to result from the colloidal-iron or magnetite tracers alone, as the attenuation change is also observed downgradient from an injection vegetable oil emulsion that did not contain a conductive tracer. The attenuation changes could result from biologically induced transformation of the aquifer sediments, biodegradation of the chlorinated-solvent contamination at the site, and (or) breakdown of the vegetable oil emulsion amendment.

Geophysical surveys provided subsurface information for areas where direct sampling was not conducted. Whereas direct sampling is restricted to the screened intervals of wells, the EM induction logs sample over unscreened intervals, and the radar data sample between wells. Comparison of zerooffset radar amplitude profiles and electromagnetic conductivity provides additional information about the lateral location of conductive features. In cases where electromagnetic anomalies are relatively weak, yet zero-offset radar attenuation anomalies are strong, the conductive feature may be located in the interior of the interwell plane; conversely, if an electromagnetic anomaly is relatively strong but the radar anomaly is weak, the feature may be closer to the borehole where the EM induction log was collected. The geophysical data from the ACP indicate that the conductive plume emanating from the emplaced and apparently immobile vegetable oil emulsion may not be adequately sampled by the present configuration of wells, given their construction and the location of well screens. Based on these results, geophysical monitoring can (1) sample larger volumes of the aquifer than traditional, direct measurements, (2) help optimize locations for additional sampling, and (3) verify amendment emplacement and effects.

\section{Acknowledgments}

This project was supported by the U.S. Navy Southern Division Naval Facilities Engineering Command, Southern Division under MIPRs N6246701MP01929 and N6246702MP02932, and by the U.S. Geological Survey Toxic Substances Hydrology Program.
The authors are grateful for contributions to this work by Clifton C. Casey (U.S. Naval Facilities Engineering Command, Southern Division) and Roelof J. Versteeg (Idaho National Environmental and Engineering Laboratory). We appreciate and acknowledge the USGS personnel who provided assistance with field work and data processing: Stephanie Johnson, Perry Jones, Mike Menheer, and Eric White; we also acknowledge assistance from B. Venky Venkatesh and Samuel Tate, Jr. (CH2M Hill, Inc.). Additionally, we are grateful to Kamini Singha (Stanford University), Richard Willey (U.S. Environmental Protection Agency), Pierre Lacombe (USGS), and Alison Waxman (USGS) for reviews of earlier summaries of this work.

\section{References}

Atekwana, E.A., Werkema, D.D., Jr., Duris, J.W., Rossbach, S., Atekwana, E.A., Sauck, W.A., Cassidy, D.P., Means, J., and Legall, F.D, 2004, In-situ apparent conductivity measurements and microbial population distribution at a hydrocarbon-contaminated site: Geophysics, v. 69, no. 1, p. 55-63.

Binley, A., Winship, P., Middleton, R., Pokar, M., and West, J., 2001, High resolution characterization of unsaturated zone dynamics using cross-borehole radar: Water Resources Research, v. 37, no. 11, p. 2639-2652.

Birchak, J.R., Gardner, C.G., Hipp, J.E., and Victor, J.M., 1974, High dielectric constant microwave probes for sensing soil moisture: Proceedings of the IEEE, v. 62, p. 93-98.

Bregman, N.D., Bailey, R.C., and Chapman, C.H., 1989, Crosshole seismic tomography: Geophysics, v. 54, no. 2, p. 200-215.

CH2M Hill Constructors, Inc., 2002, Pilot-scale study to enhance in-situ bioremediation of chlorinated solvents via vegetable oil injection at Anoka County Riverfront Park, Naval Industrial Reserve Ordinance Plant Fridley, Fridley, Minnesota: Atlanta, Georgia, CH2M Hill Constructors, Inc., CD ROM.

Day-Lewis, F.D., Lane, J.W., Jr., Harris, J.M., and Gorelick, S.M., 2003, Time-lapse imaging of saline tracer tests using cross-borehole radar tomography: Water Resources Research, v. 39, no. 10, 14 p., doi:10.1029/2002WR001722.

Day-Lewis, F.D., and Lane, J.W., Jr., 2004, Assessing the resolution-dependent utility of tomograms for geostatistics: Geophysical Research Letters, v. 31, 4 p., L07503, doi:10.1029/2004GL019617.

Dines, K.A., and Lytle, R.J., 1979, Computerized geophysical tomography: Proceedings of the IEEE, v. 67, p. 1065-1073. 
Eppstein, M.J., and Dougherty, D.E., 1998, Efficient threedimensional data inversion-soil characterization and moisture monitoring from cross-well ground-penetrating radar at a Vermont test site: Water Resources Research, v. 34, no. 8, p. 1889-1900.

Hearst, J.R., Nelson, P.H., and Paillet, F.L., 2000, Well logging for physical properties-A handbook for geophysicists, geologists, and engineers ( $2 \mathrm{~d}$ ed.): New York, John Wiley $\&$ Sons, $492 \mathrm{p}$.

Hubbard, S., Chen, J., Peterson, J., Majer, E., Williams, K., Swift, D., Mailliox, B., and Rubin, Y., 2001, Hydrogeological characterization of the D.O.E. bacterial transport site in Oyster Virginia using geophysical data: Water Resources Research, v. 37, no. 10, p. 2431-2456.

Keys, W.S., 1990, Borehole geophysics applied to groundwater investigations: U.S. Geological Survey Techniques of Water-Resources Investigations, book 2, chap. E-2, 149 p.

Kong, F., Westerdahl, H., and Kitterod, T.L., 1994, Radar tomography from environmental geotechnology-Field and simulation tests, in International Conference of Ground Penetrating Radar, 5th, June 12-16, 1994, Kitchener, Ontario, Proceedings: Waterloo, Canada, Waterloo Centre for Groundwater Research, p. 1249-1260.

Lane, J.W., Jr., Casey, C.C., Day-Lewis, F.D., Witten, A., and Versteeg, R.J., 2004b, Use of borehole radar methods and borehole geophysical logs to monitor a field-scale vegetable oil biostimulation pilot project at Fridley, Minnesota, in Proceedings of the Fourth International Conference on Remediation of Chlorinated and Recalcitrant Compounds, May 24-27, 2004, Monterey, California, Proceedings: Battelle Memorial Institute, CD-ROM, 9 p.

Lane, J.W., Jr., Day-Lewis, F.D., and Casey, C.C., 2006, Geophysical monitoring of a field-scale vegetable oil injections for biostimulation: Ground Water, doi: 10.1111/ j.1745-6584.2005.00134.x.

Lane, J.W., Jr., Day-Lewis, F.D., Harris, J.M., Haeni, F.P., and Gorelick, S.M., 2000, Attenuation-difference radar tomography-Results of a multiple-plane experiment at the U.S. Geological Survey Fractured Rock Research Site, Mirror Lake, New Hampshire, in Noon, D.A., Stickley, G.F., and Longstaff, D., eds., International Conference on Ground Penetrating Radar, 8th, Proceedings: Queensland, Australia, University of Queensland, p. 666-675.

Lane, J.W., Jr., Day-Lewis, F.D., Versteeg, R.J., and Casey, C.C., 2003, Object-based inversion of crosswell radar tomography data to monitor vegetable oil injection experiment, in Symposium on the Application of Geophysics to Engineering and Environmental Problems (SAGEEP), April 6-10, 2003, San Antonio, Texas, Proceedings: Denver, Colorado, Environmental and Engineering Geophysical Society, CD-ROM, 27 p.
Lane, J.W., Jr., Day-Lewis, F.D., Versteeg, R.J., and Casey, C.C., 2004c, Application of cross-borehole radar to monitor field-scale vegetable oil injection experiments for biostimulation, in Symposium on the Application of Geophysics to Engineering and Environmental Problems (SAGEEP), February 22-26, 2004, Colorado Springs, Colorado, Proceedings: Denver, Colorado, Environmental and Engineering Geophysical Society, CD-ROM, 20 p.

Lane, J.W., Jr., Day-Lewis, F.D., Versteeg, R.J., and Casey, C.C., 2004a, Object-based inversion of cross-well radar tomography to monitor injection experiments: Journal of Environmental and Engineering Geophysics, v. 9, no. 2, p. 63-77.

Lane, J.W., Jr., Haeni, F.P., and Day-Lewis, F.D., 1998, Use of time-lapse attenuation-difference radar tomography methods to monitor saline tracer transport in fractured crystalline bedrock, in International Conference on Ground Penetrating Radar, 7th, May 27-30, Lawrence, Kansas, 1998, Proceedings: Lawrence, Kansas, University of Kansas, p. 533-538.

Lane, J.W., Jr., Haeni, F.P., Placzek, Gary, and Wright, D.L., 1996, Use of borehole-radar methods to detect a saline tracer in fractured crystalline bedrock at Mirror Lake, Grafton County, New Hampshire, in International Conference on Ground-Penetrating Radar (GPR'96), 6th, September 30-October 3, 1996, Sendai, Japan, Proceedings: Sendai, Japan, Tohoku University Department of Geoscience and Technology, p. 185-190.

McMechan, G.A., Harris, J.M., and Anderson, L.M., 1987, Cross-hole tomography for strongly variable media with applications to scale model data: Bulletin of the Seismological Society of America, v. 77, no. 6, p. 1945-1960.

McNeill, J.D., 1986, Geonics EM39 borehole conductivity meter theory of operation: Missisauga, Ontario, Canada, Geonics, Ltd., Technical Note TN-20.

McNeill, J.D., Hunter, J.A., and Bosnar, M., 1996, Application of a borehole induction magnetic susceptibility logger to shallow lithological mapping: Journal of Environmental and Engineering Geophysics, v. 0, no. 2, p. 77-90.

Niva, B., Olsson, O., and Blumping, P., 1988, Radar cross-hole tomography at the Grimsel Rock Laboratory with application to migration of saline tracer through fracture zones: Nationale Genossenschaft fur die lagerung radioaktiver Abfalle, NTB 88-31.

Olsson, O., Falk, L., Forslund, O., Lundmark, L., and Sandberg, E., 1992, Borehole radar applied to the characterization of hydraulically conductive fracture zones in crystalline rock: Geophysical Prospecting, v. 40, no. 2, p. 109-142. 
Ramirez, A.L., and Lytle, R.J., 1986, Investigation of fracture flow paths using alterant geophysical tomography: International Journal of Rock Mechanics and Mining Science \& Geomechanics, v. 23, p. 165-169.

Schlumberger, 1989, Log interpretation principles/applications: Houston, Texas, Schlumberger Educational Services.

Telford, W.M., Geldart, L.P., and Sheriff, R.E., 1990, Applied geophysics ( $2 \mathrm{~d}$ ed.): Cambridge, U.K., Cambridge University Press, $770 \mathrm{p}$.

Todd, D.K., 1980, Groundwater hydrology (2d ed.): New York, N.Y., John Wiley and Sons, 535 p.

Wharton, R.P., Hazen, G.A., Rau, R.N., and Best, D.L., 1980, Electromagnetic propagation logging-Advances in technique and interpretation, presented at 55th Annual Technical Conference: Richardson, Texas, Society of Petroleum Engineers of AIME, Paper SPE 9267, 12 p.

Witten, A., and Lane, J.W., Jr., 2003, Offset vertical radar profiling: The Leading Edge, v. 22, no. 11, p. 1070-1076.

Wright, D.L., Grover, T.P., Ellefsen, K.J., Lane, J.W., Jr., and Kase, P.G., 1996, Radar tomograms at Mirror Lake, New Hampshire-3D visualization and a brine tracer experiment, in Symposium on the Application of Geophysics to Engineering and Environmental Problems (SAGEEP), April 28-May 2, Keystone, Colorado, Proceedings: Wheat Ridge, Colorado, Environmental and Engineering Geophysical Society, p. 565-575. 
Appendixes A-B 


\section{APPENDIX A. Zero-Offset Radar Profiles}

(a)

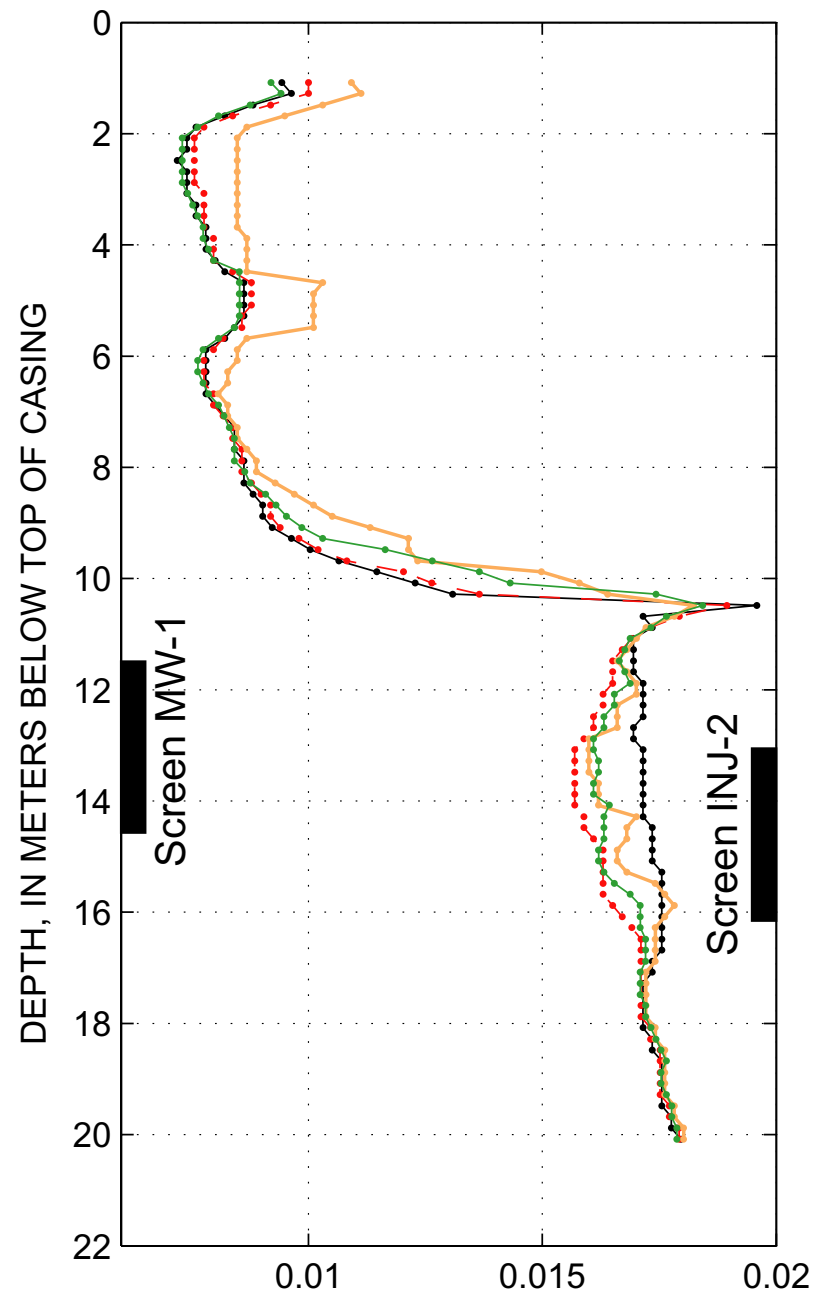

RADAR SLOWNESS, IN MICROSECONDS PER METER (b)

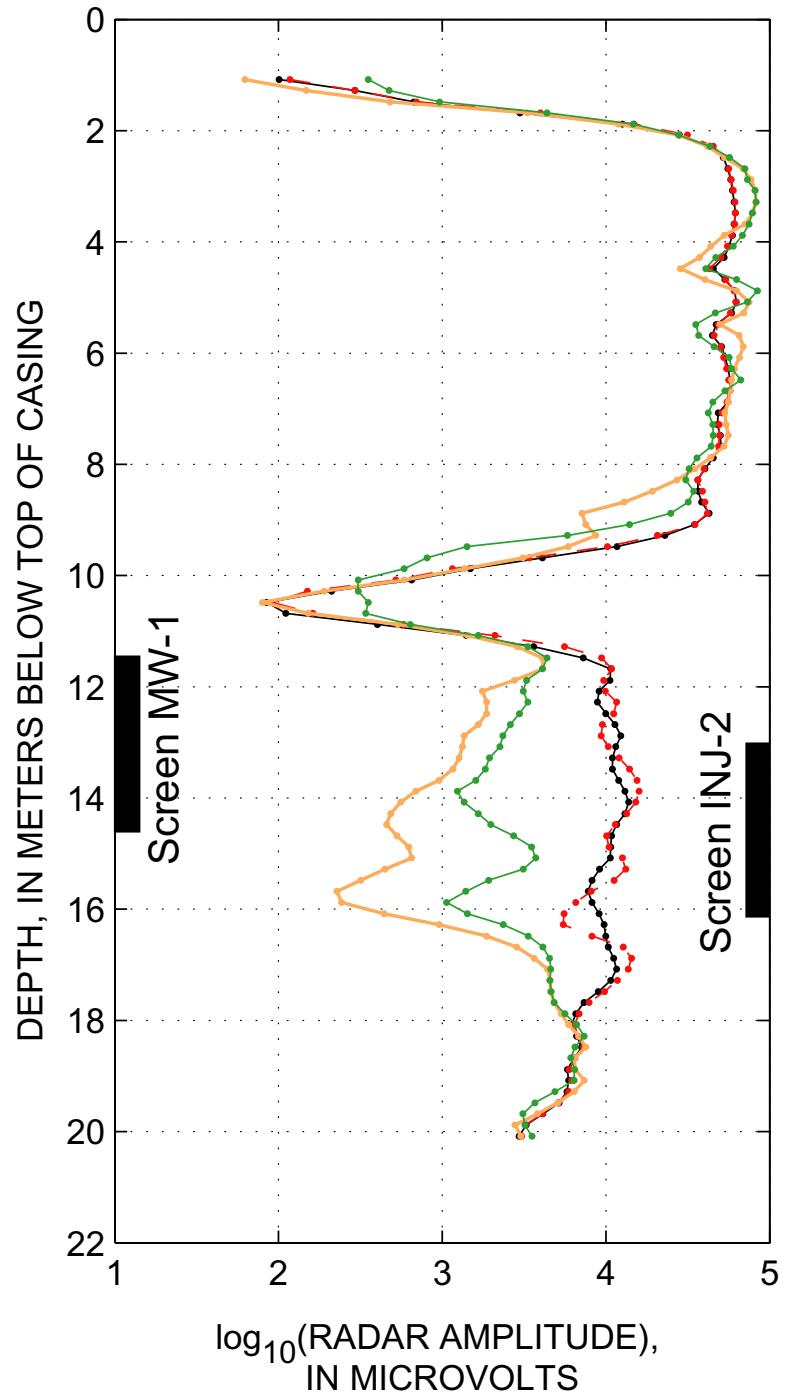

EXPLANATION

Background radar data

Radar data collected December 2001, during INJ-1 injection

Radar data collected May 2002

Radar data collected November 2002

Figure A1. (a) Zero-offset radar slowness, and (b) zero-offset radar amplitude profiles for the MW-1 to INJ-2 plane, Anoka County Riverfront Park, Fridley, Minnesota. 
(a)

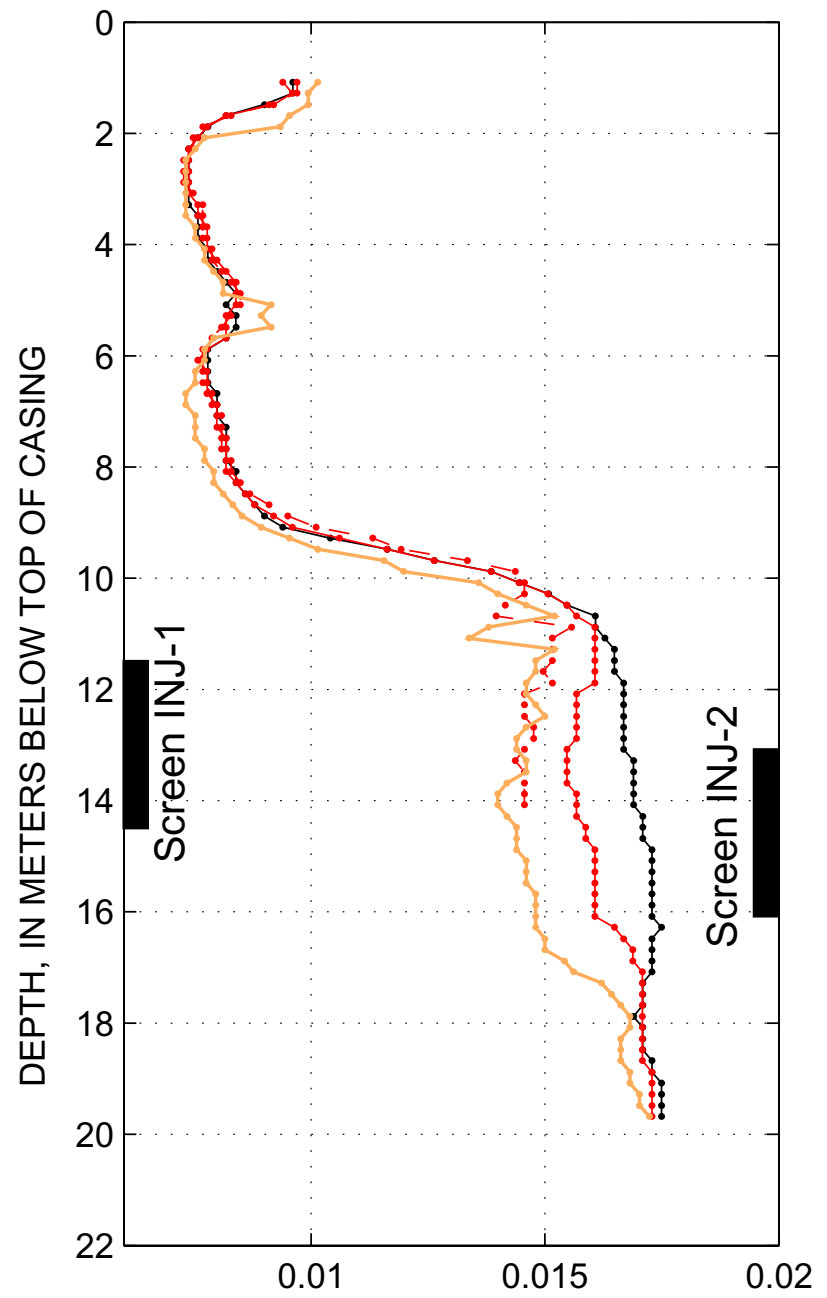

RADAR SLOWNESS, IN MICROSECONDS PER METER (b)

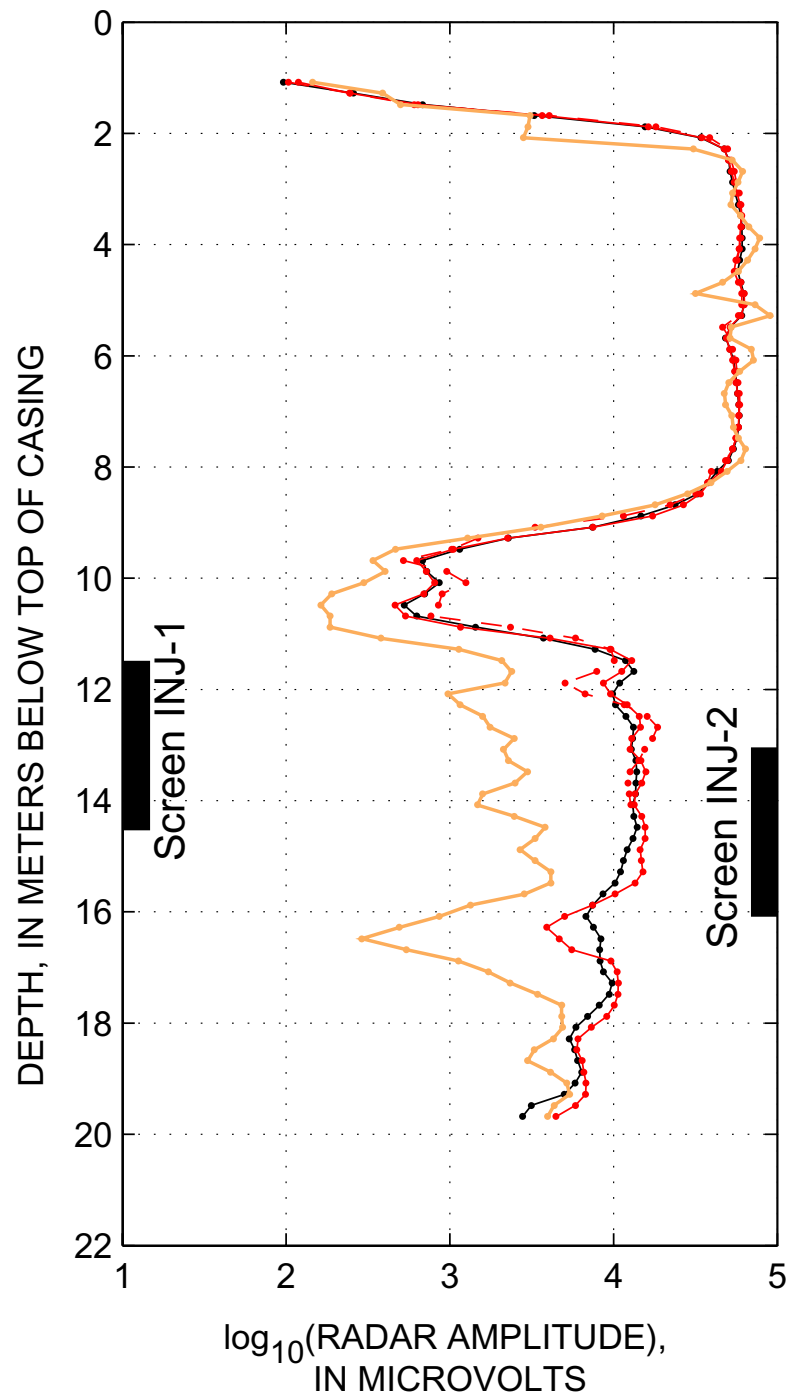

\section{EXPLANATION}

Background radar data

Radar data collected December 2001, after INJ-3 injection

Radar data collected December 2001, during INJ-1 injection

Radar data collected May 2002

Figure A2. (a) Zero-offset radar slowness, and (b) zero-offset radar amplitude profiles for the INJ-1 to INJ-2 plane. The December 2001 dataset collected during injection does not extend to the bottom of the well due to obstruction by the pump apparatus, Anoka County Riverfront Park, Fridley, Minnesota. 
(a)

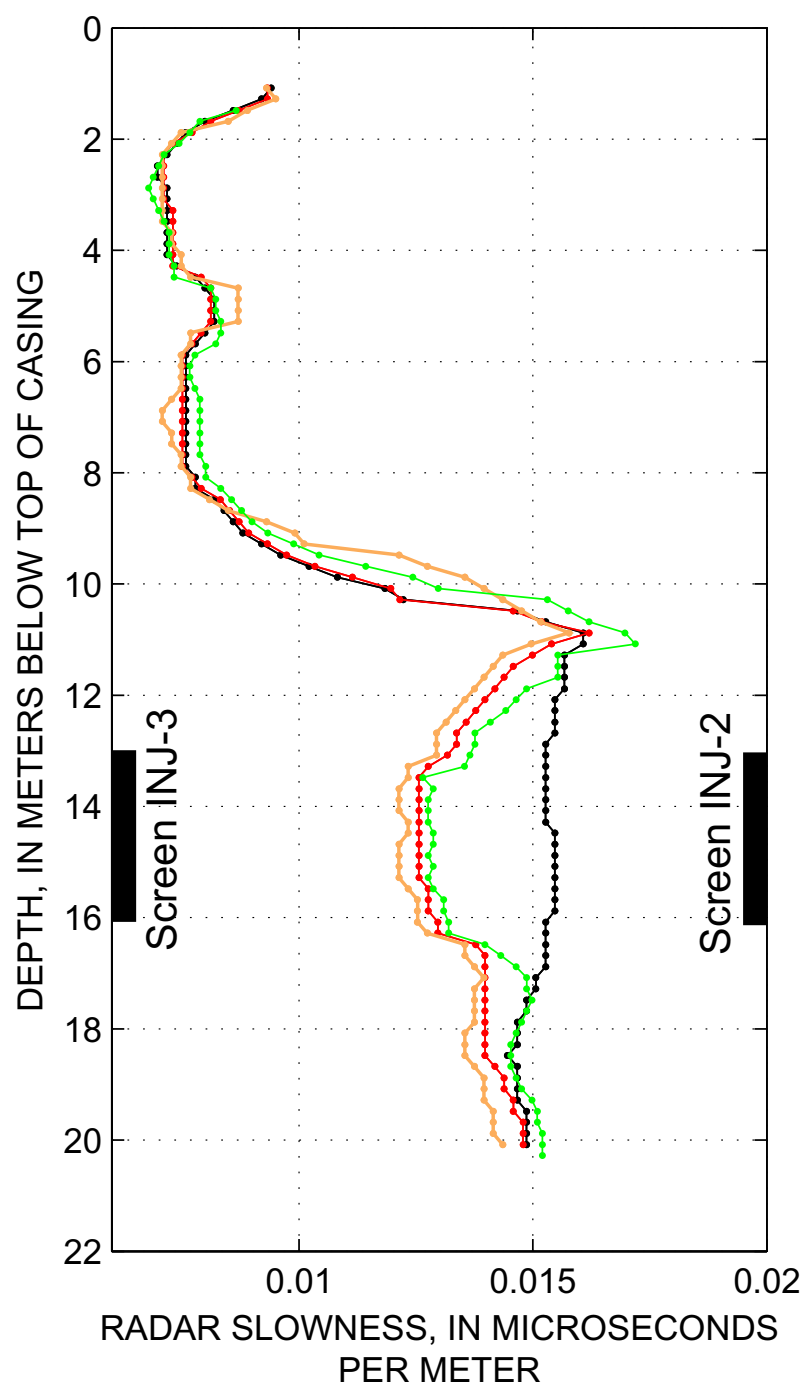

(b)

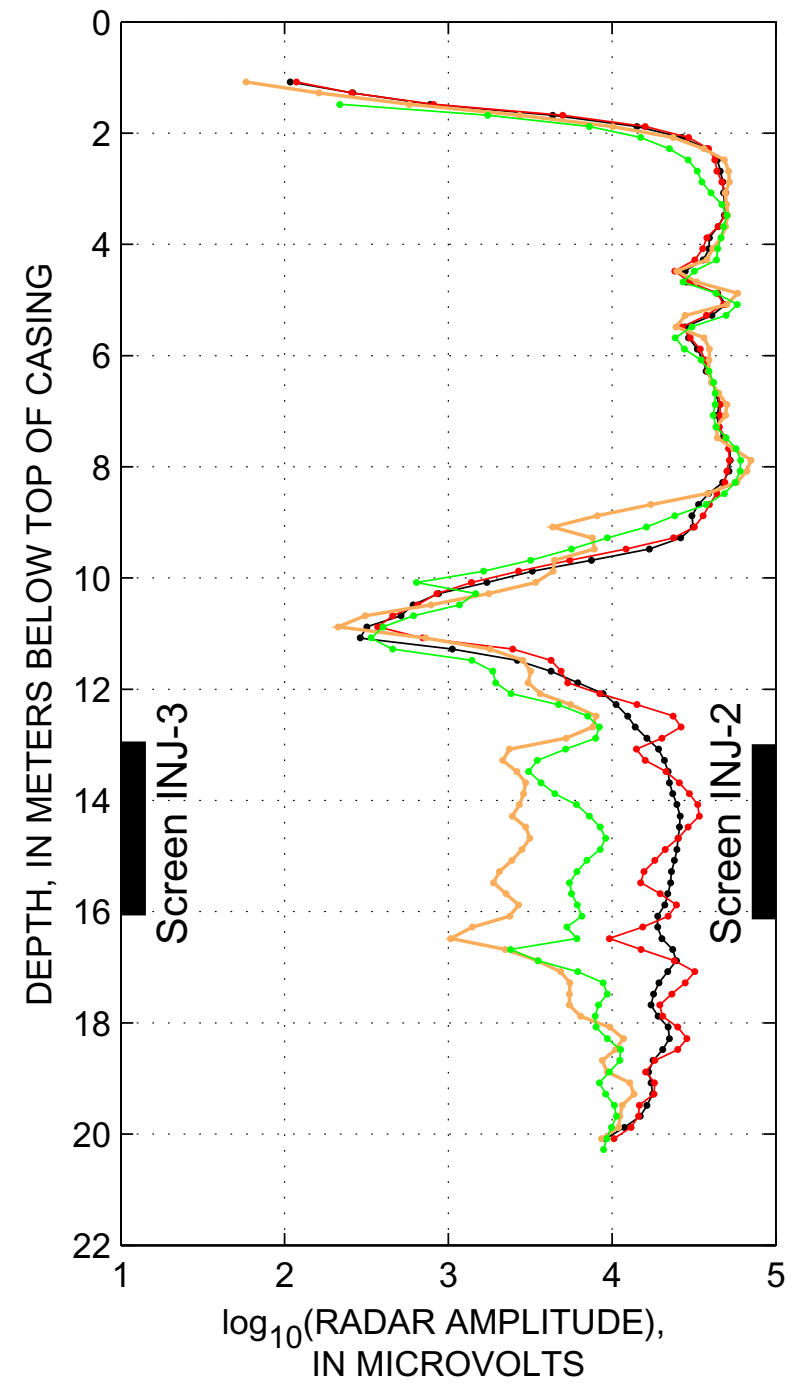

EXPLANATION

Background radar data

Radar data collected December 2001, after INJ-3 injection

Radar data collected May 2002

Radar data collected November 2002

Figure A3. (a)Zero-offset radar slowness, and (b) zero-offset radar amplitude profiles for the INJ-3 to INJ-2 plane, Anoka County Riverfront Park, Fridley, Minnesota. 
(a)

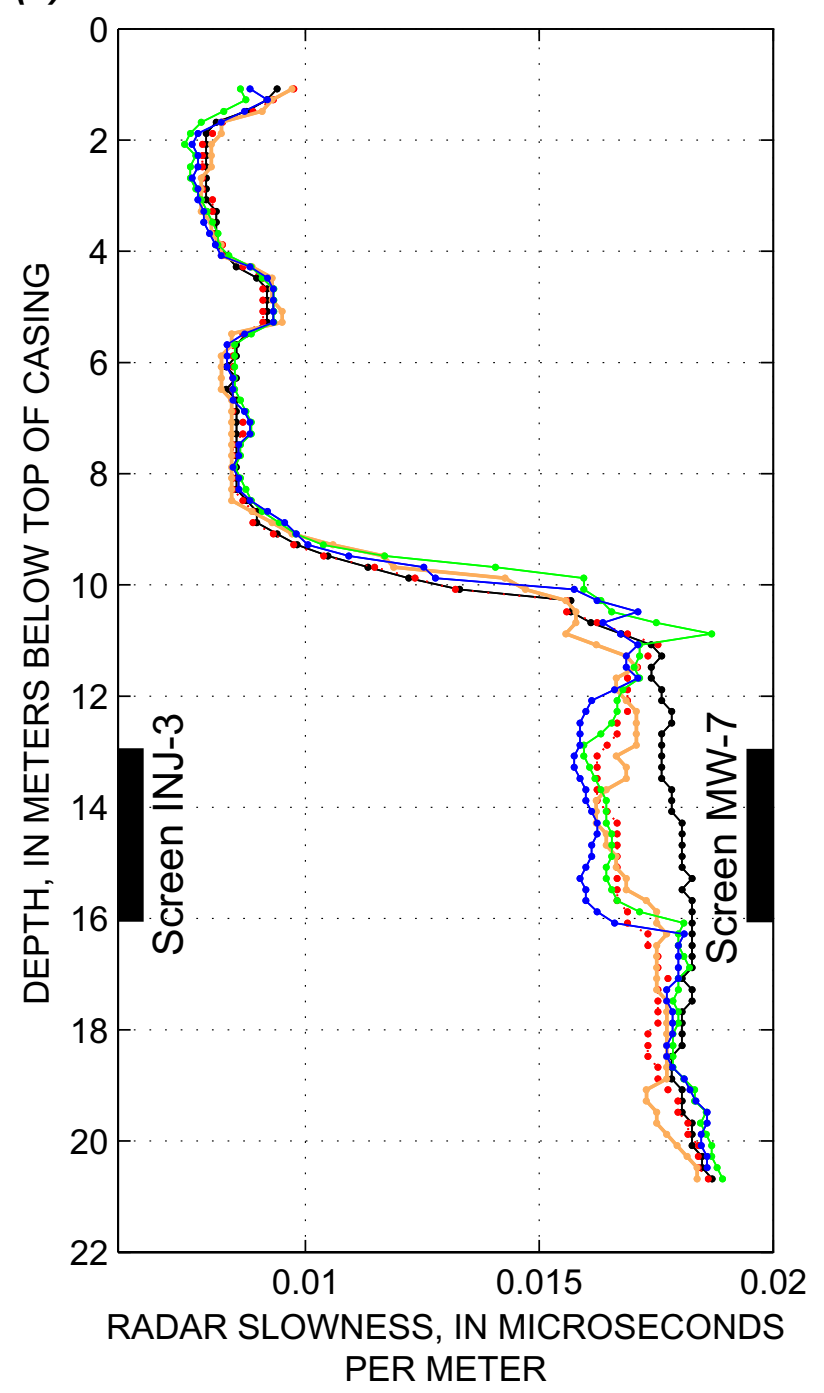

(b)

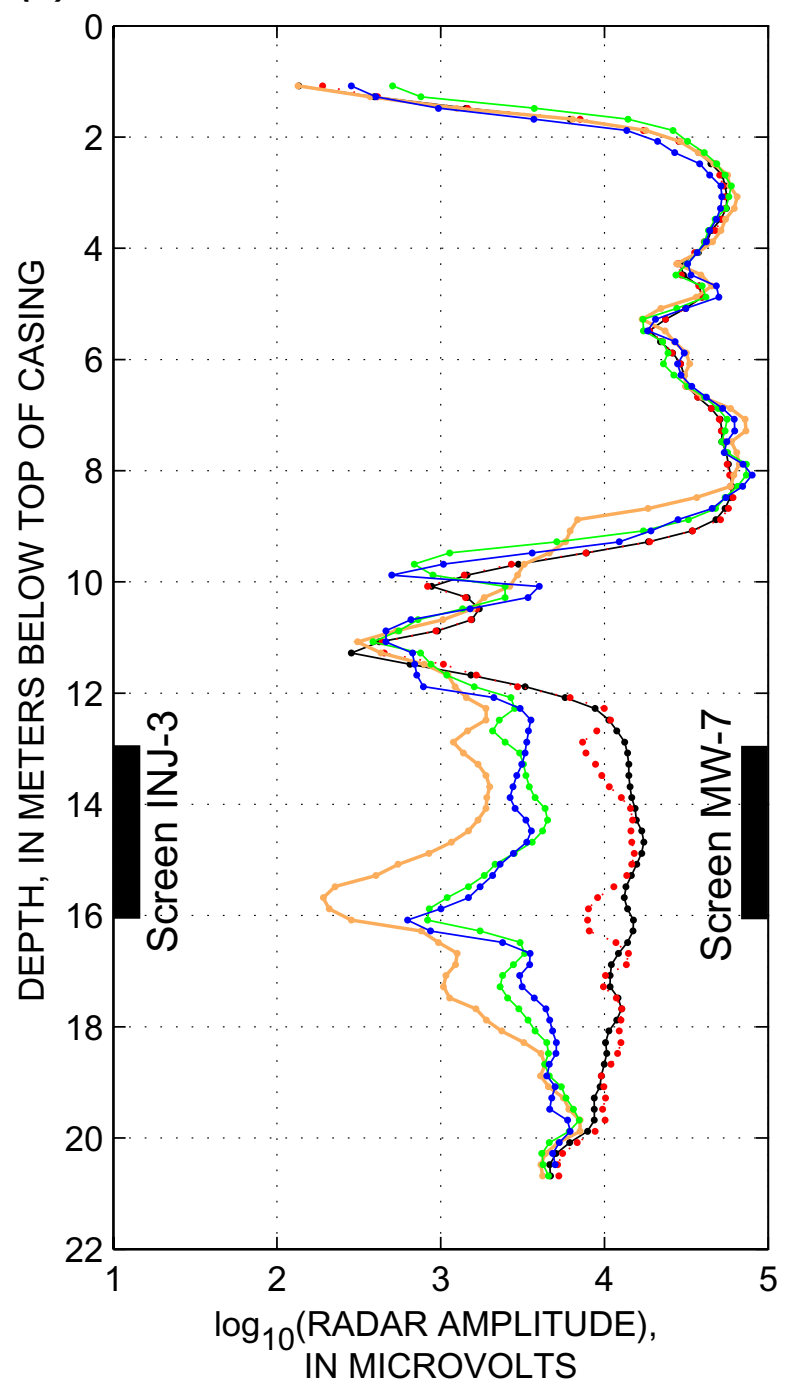

EXPLANATION

Background radar data

Radar data collected December 2001, during INJ-1 injection

Radar data collected May 2002

Radar data collected November 2002

Radar data collected June 2003

Figure A4. (a) Zero-offset radar slowness, and (b) zero-offset radar amplitude profiles for the INJ-3 to MW-7 plane, Anoka County Riverfront Park, Fridley, Minnesota. 
(a)

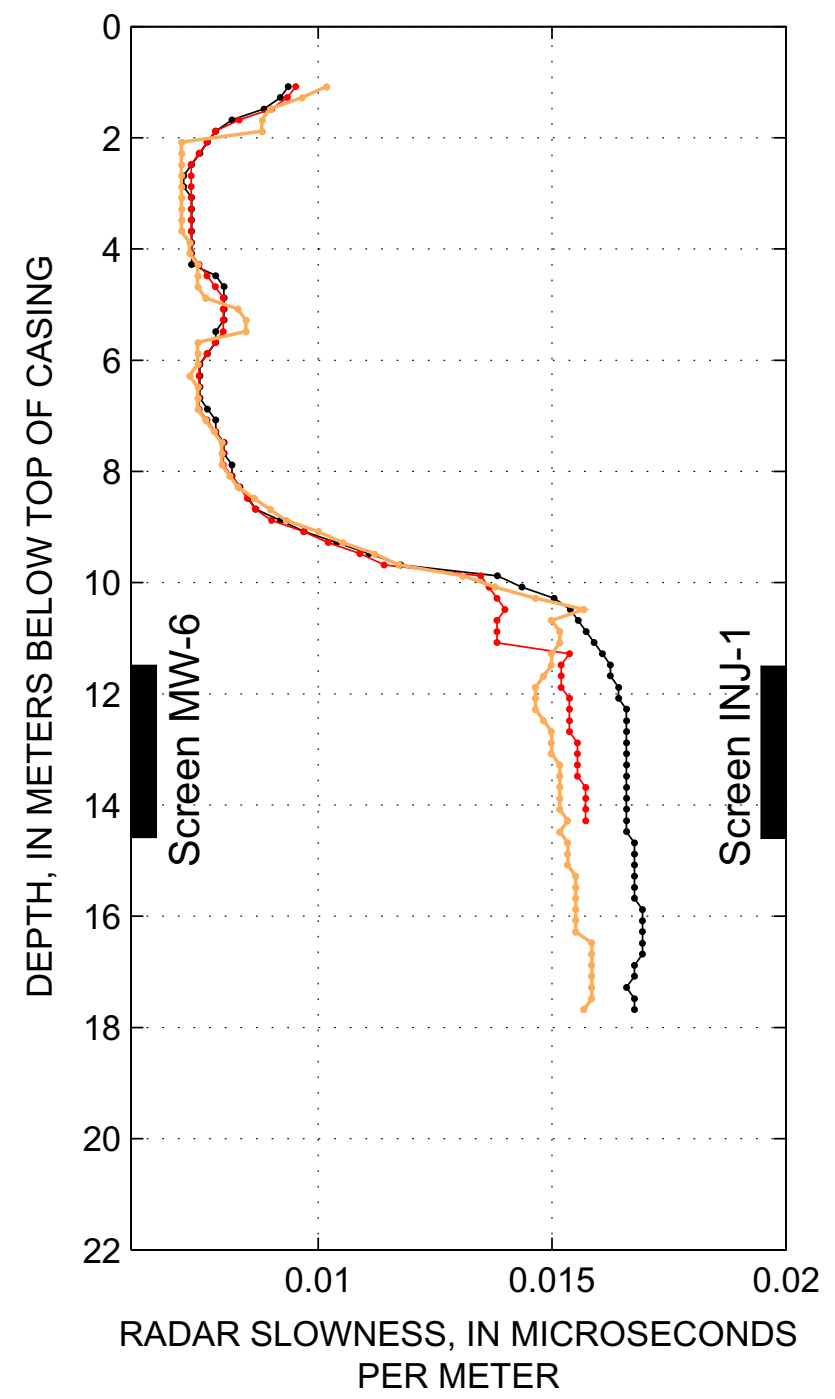

(b)

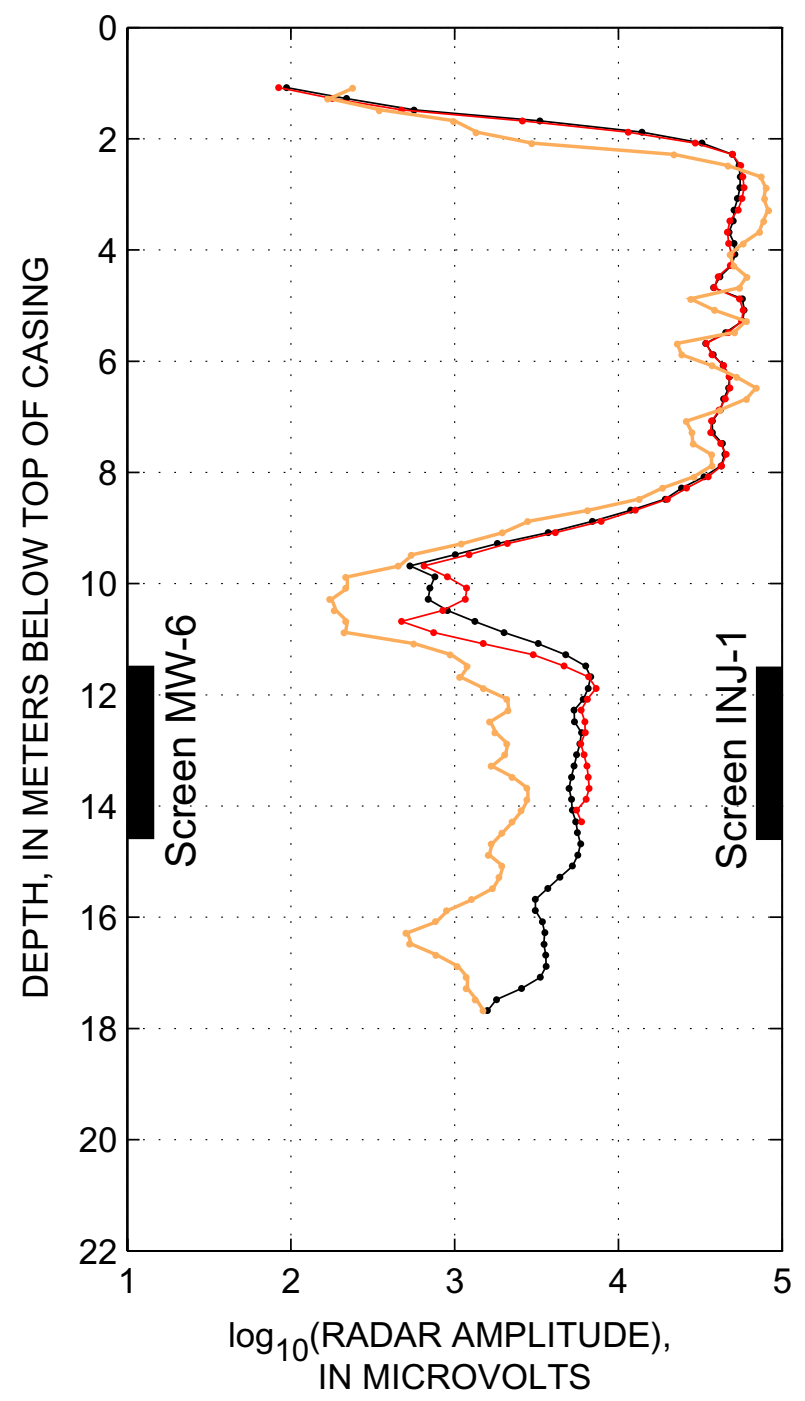

\section{EXPLANATION}

Background radar data

Radar data collected December 2001, after INJ-3 injection

Radar data collected May 2002

Figure A5. (a)Zero-offset radar slowness, and (b) zero-offset radar amplitude profiles for the MW-6 to INJ-1 plane, Anoka County Riverfront Park, Fridley, Minnesota. 
(a)

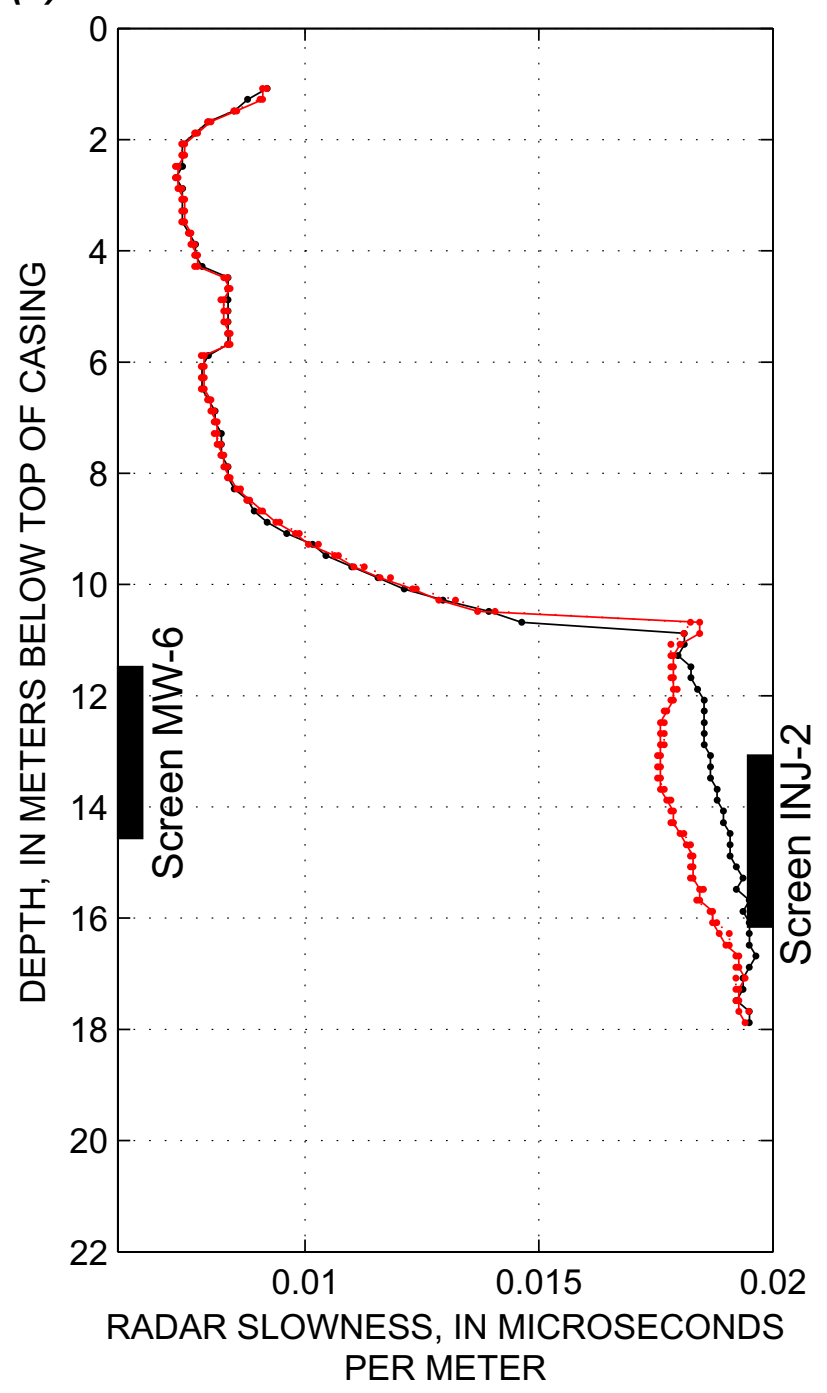

(b)

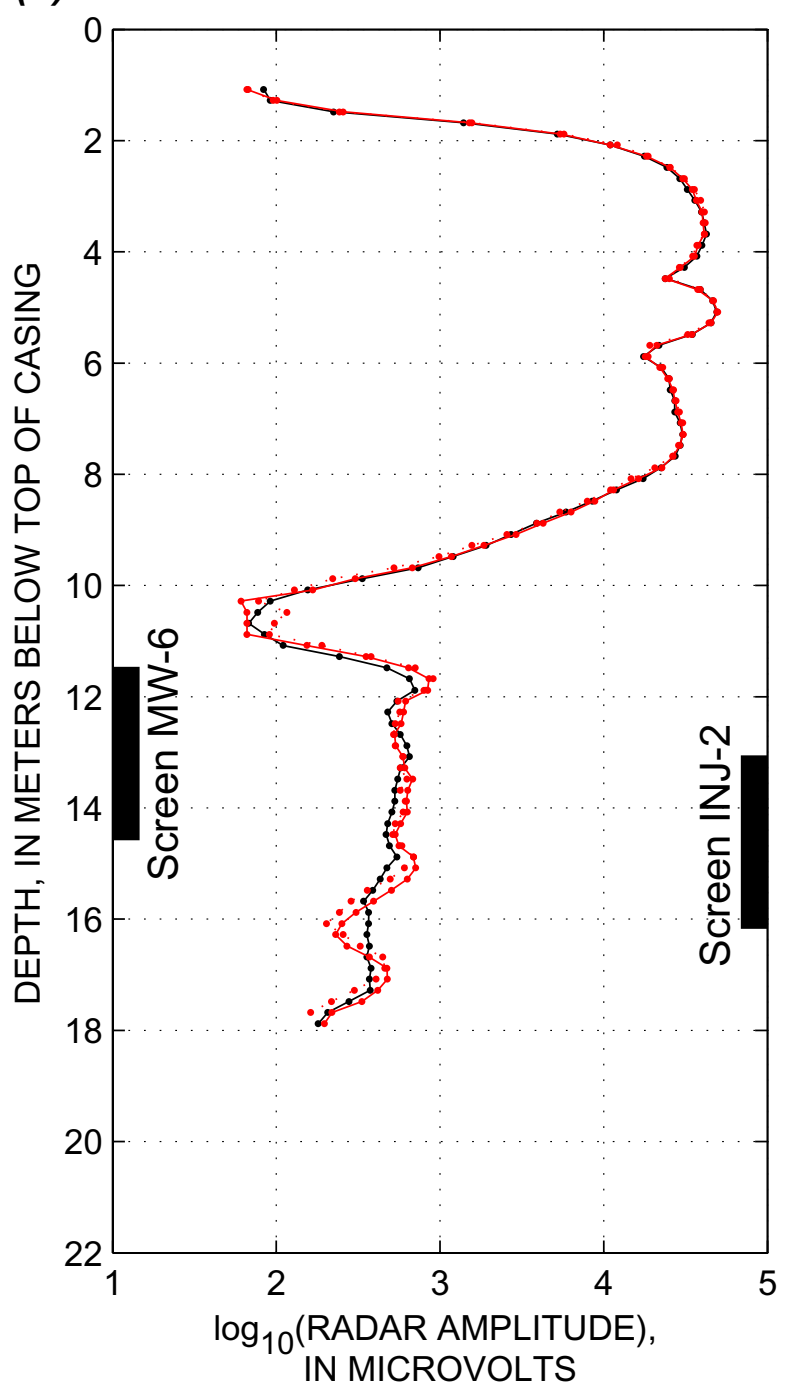

EXPLANATION

Background radar data

Radar data collected December 2001, after INJ-3 injection

Radar data collected December 2001, during INJ-1 injection

Figure A6. (a) Zero-offset radar slowness, and (b) zero-offset radar amplitude profiles for the MW-6 to INJ-2 plane, Anoka County Riverfront Park, Fridley, Minnesota. 
(a)

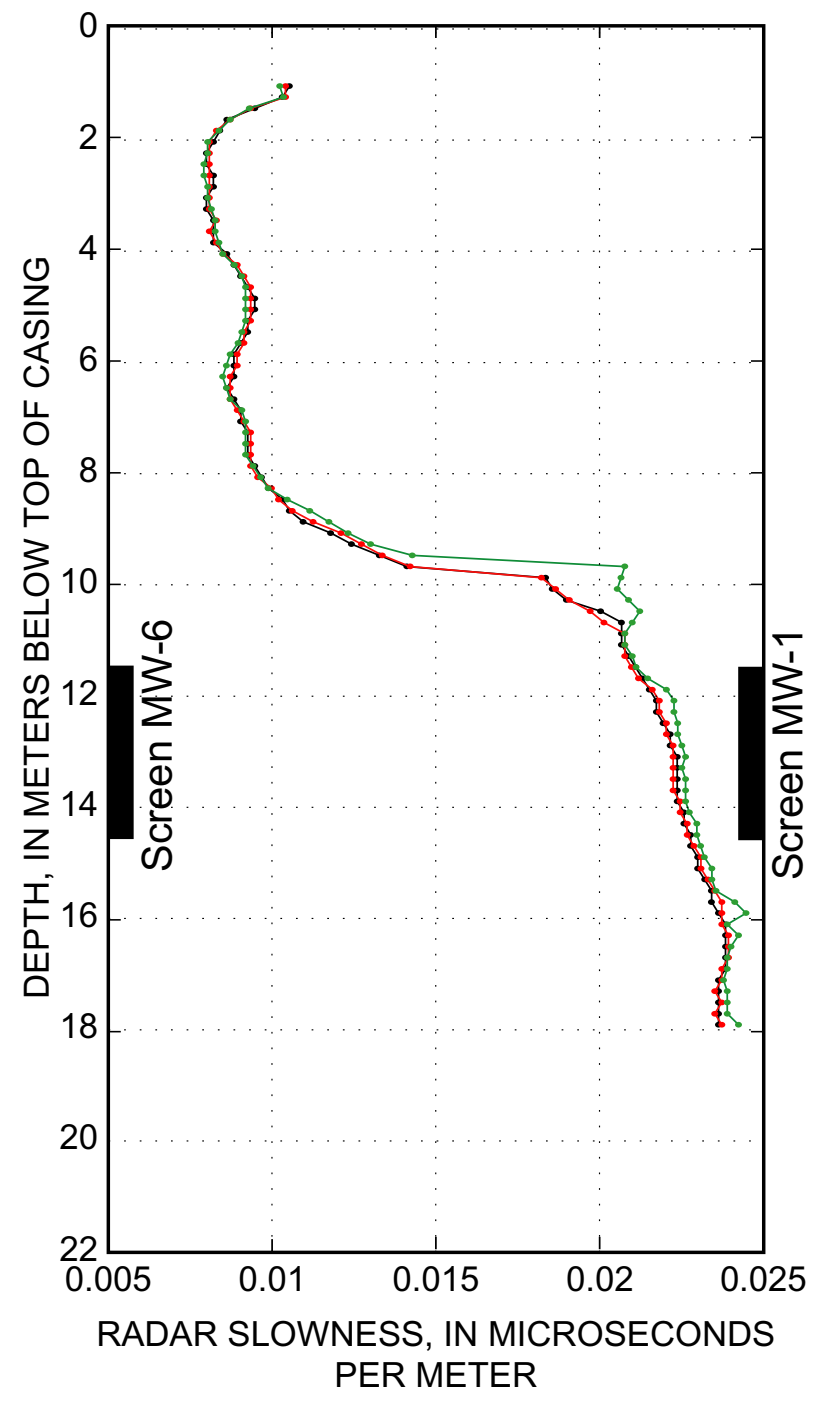

(b)

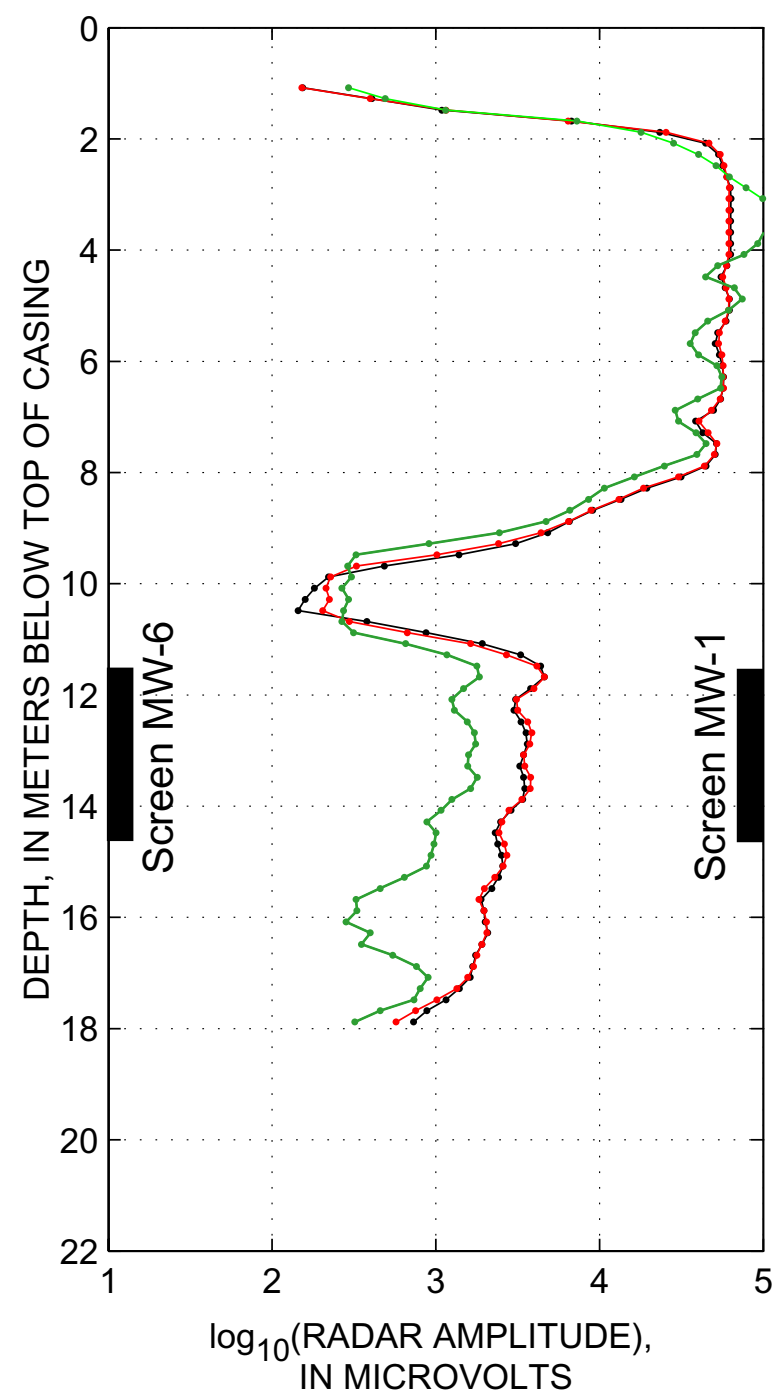

\footnotetext{
EXPLANATION

Background radar data

Radar data collected December 2001, after INJ-3 injection

Radar data collected November 2002
}

Figure A7. (a) Zero-offset radar slowness, and (b) zero-offset radar amplitude profiles for the MW-6 to MW-1 plane, Anoka County Riverfront Park, Fridley, Minnesota. 
(a)

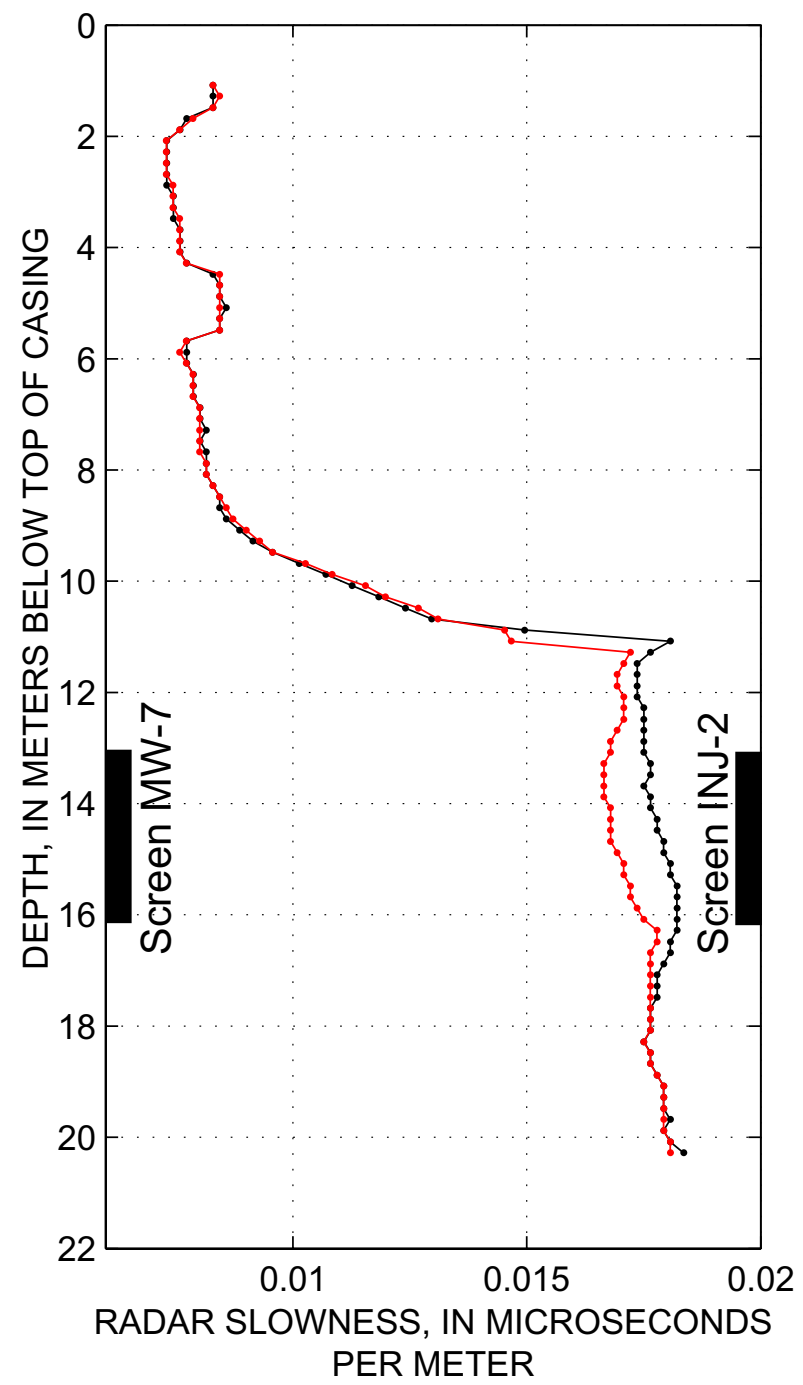

(b)

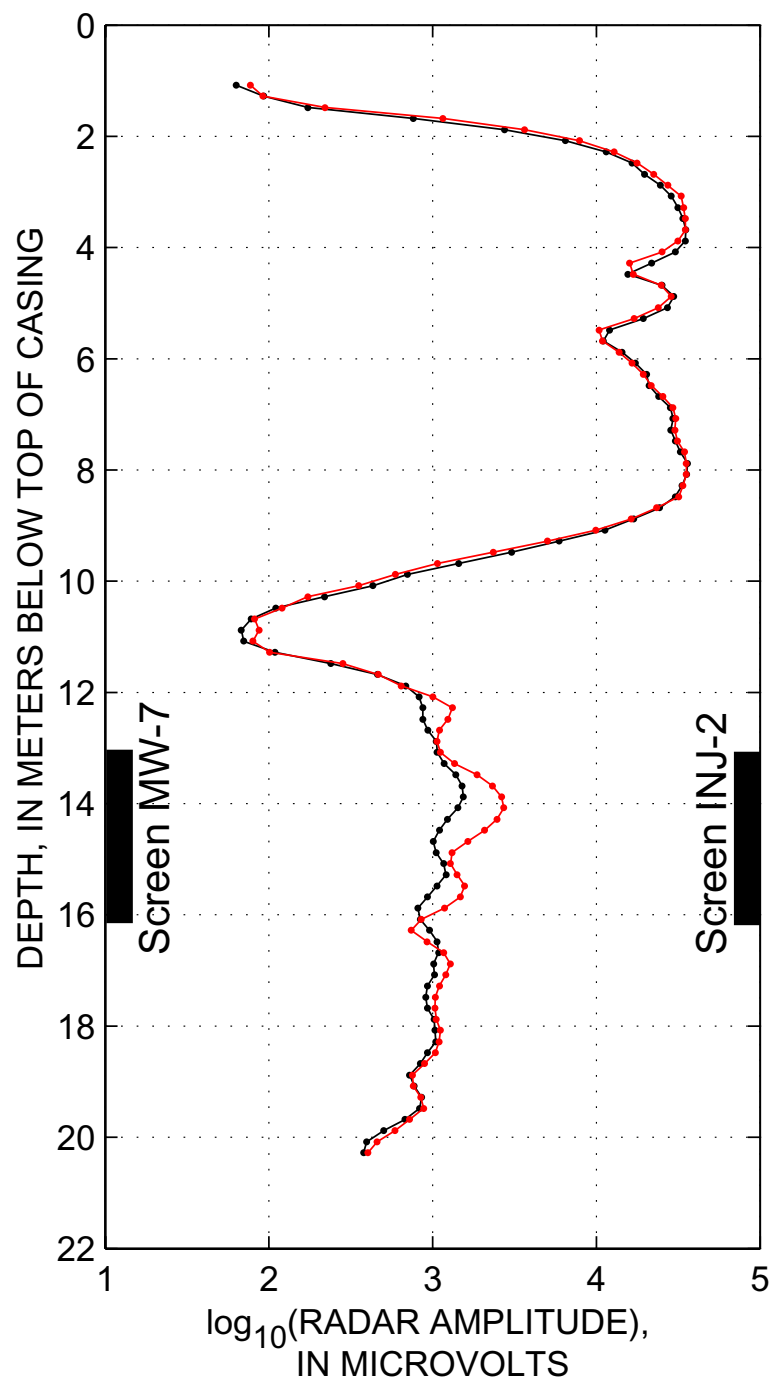

EXPLANATION

Background radar data

Radar data collected December 2001, after INJ-3 injection

Figure A8. (a)Zero-offset radar slowness, and (b) zero-offset radar amplitude profiles for the MW-7 to INJ-2 plane, Anoka County Riverfront Park, Fridley, Minnesota. 
(a)

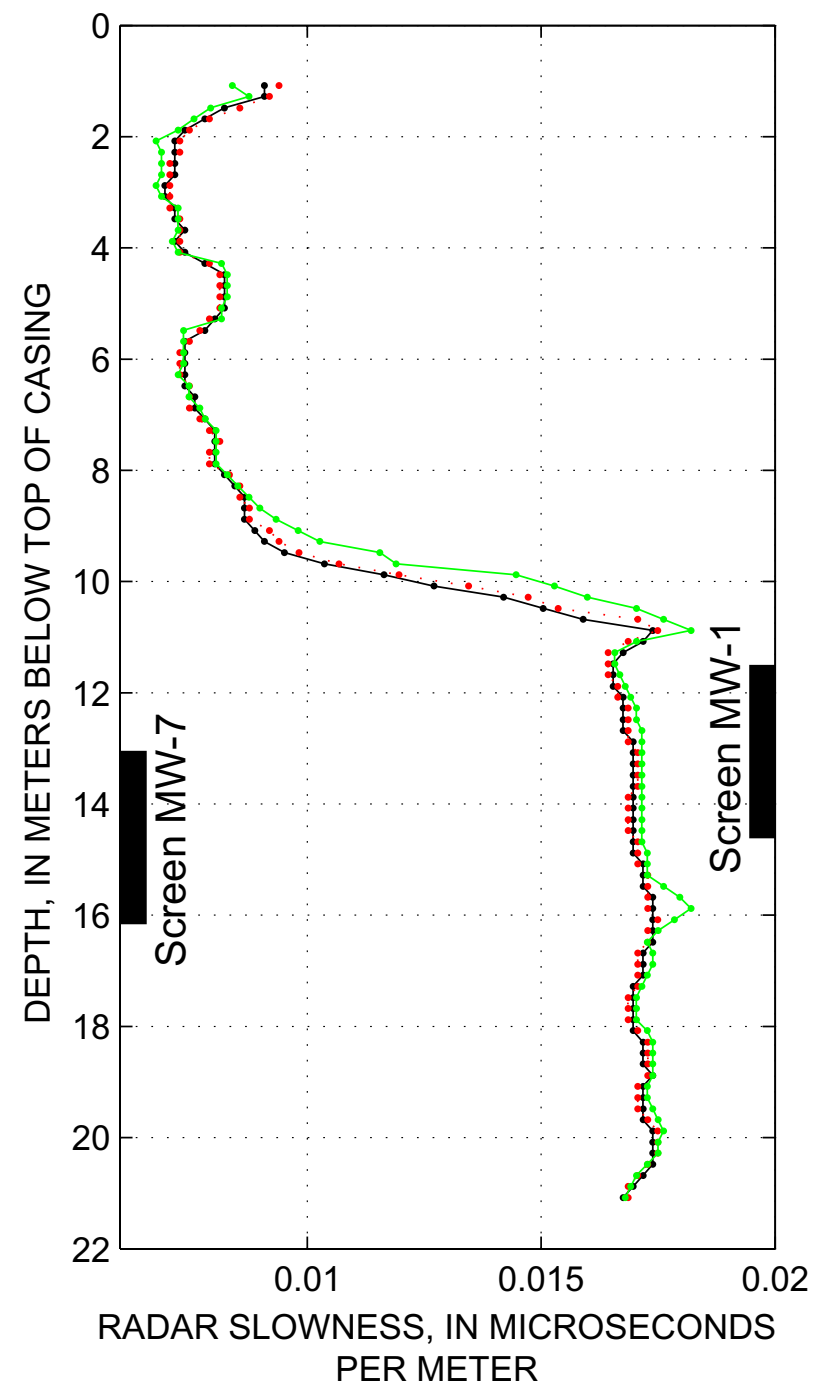

(b)

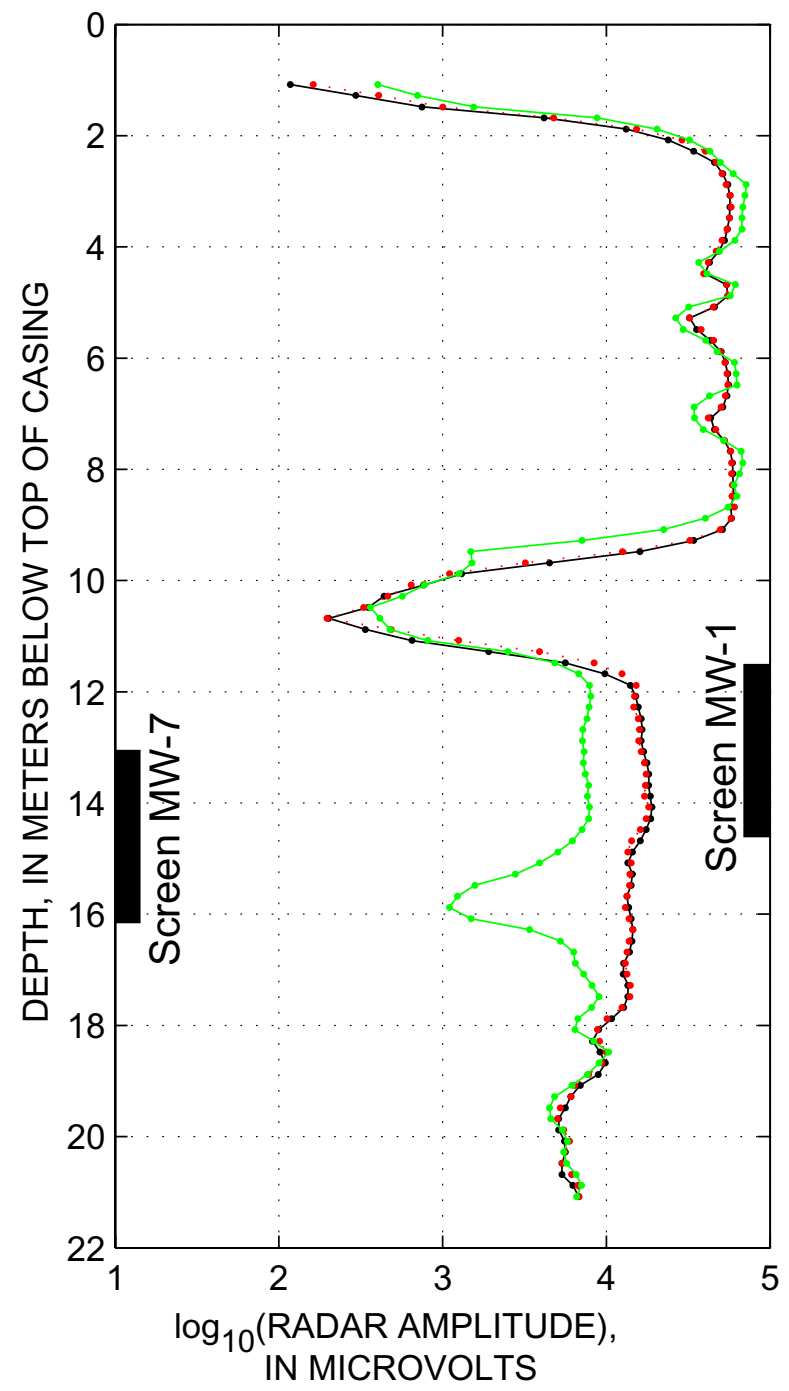

\section{EXPLANATION}

Background radar data

$\rightarrow \ldots . . . . . . .0$ Radar data collected December 2001, during INJ-1 injection

Radar data collected November 2002

Figure A9. (a) Zero-offset radar slowness, and (b) zero-offset radar amplitude profiles for the MW-7 to MW-1 plane, Anoka County Riverfront Park, Fridley, Minnesota. 
(a)

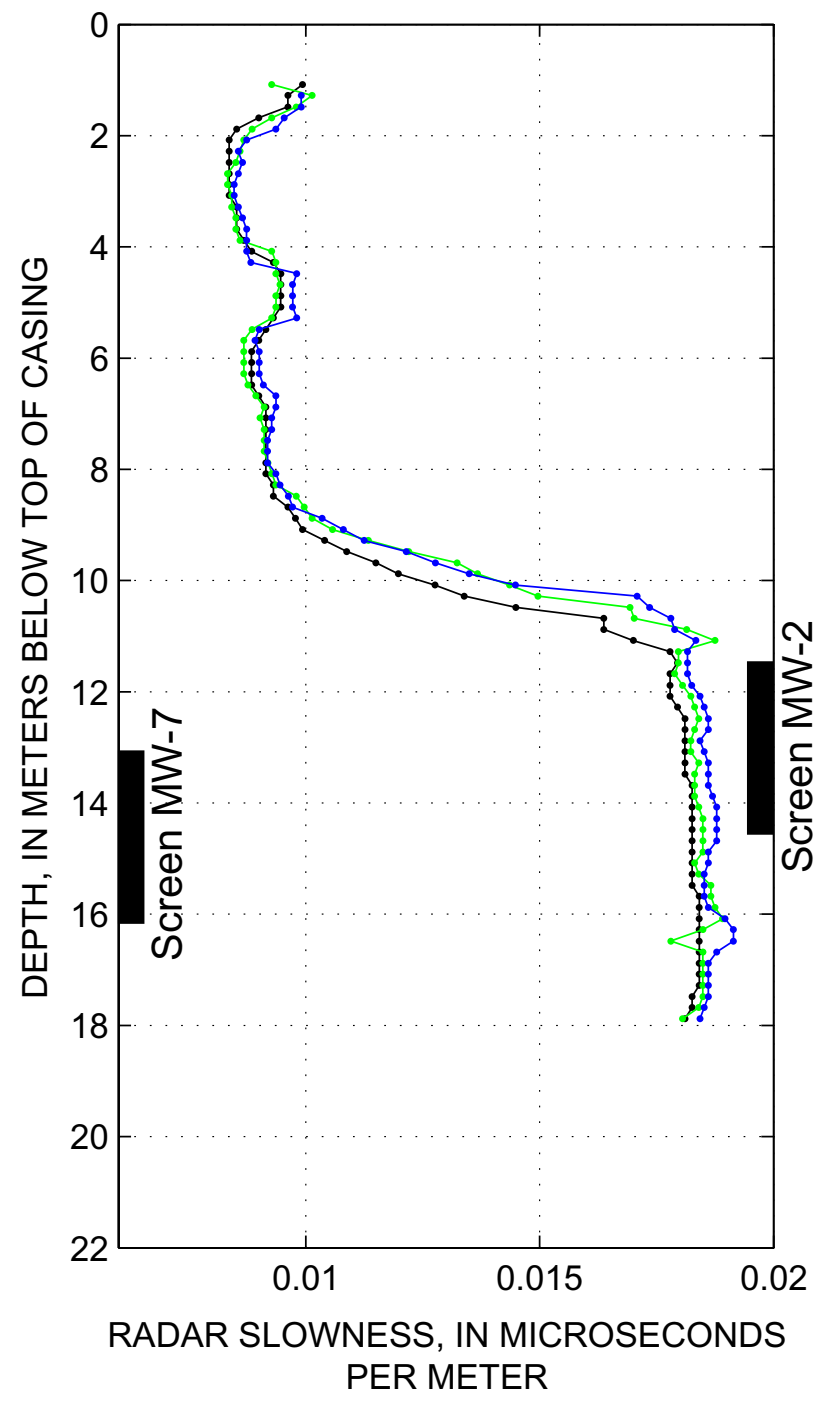

(b)

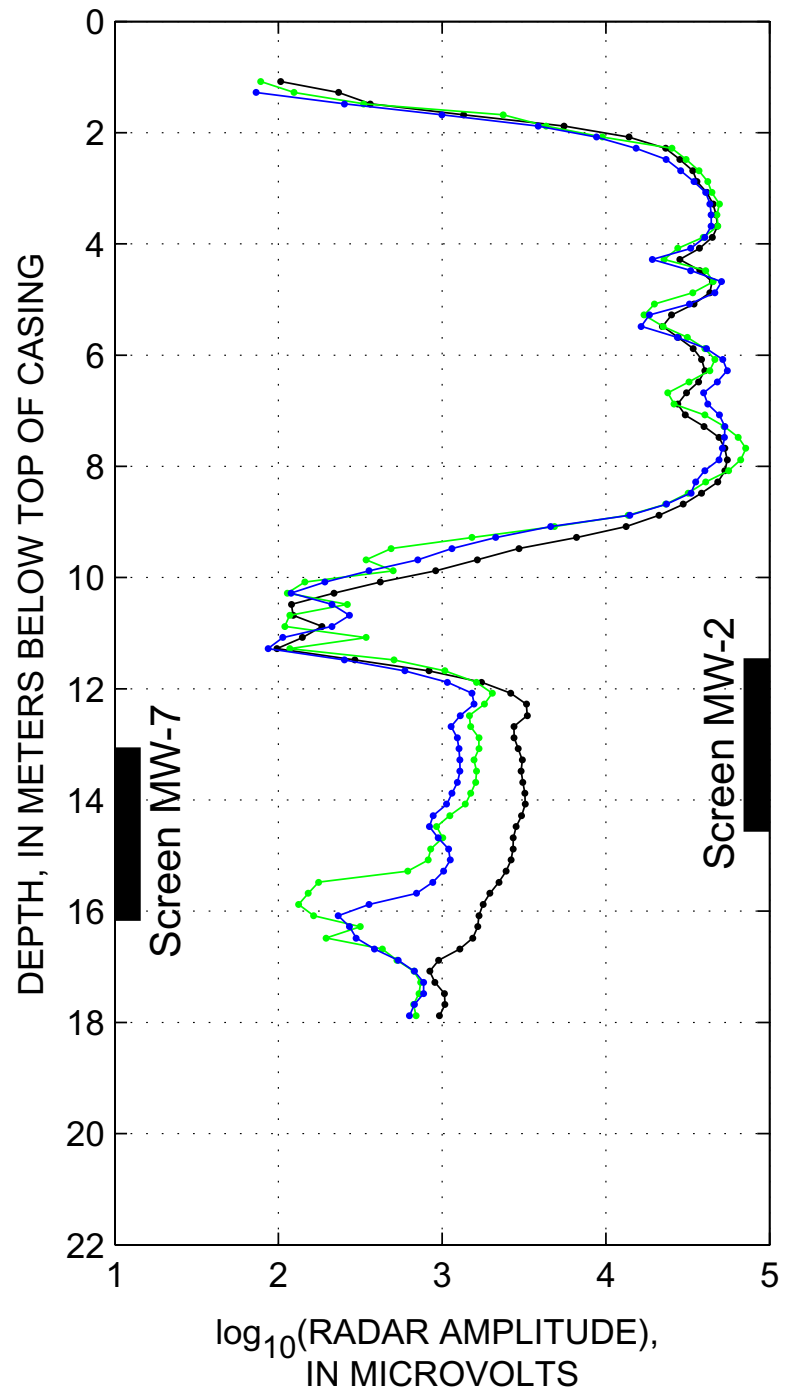

\section{EXPLANATION}

Background radar data

Radar data collected November 2002

Radar data collected December 2003

Figure A10. (a)Zero-offset radar slowness, and (b) zero-offset radar amplitude profiles for the MW-7 to MW-2 plane, Anoka County Riverfront Park, Fridley, Minnesota. 
(a)

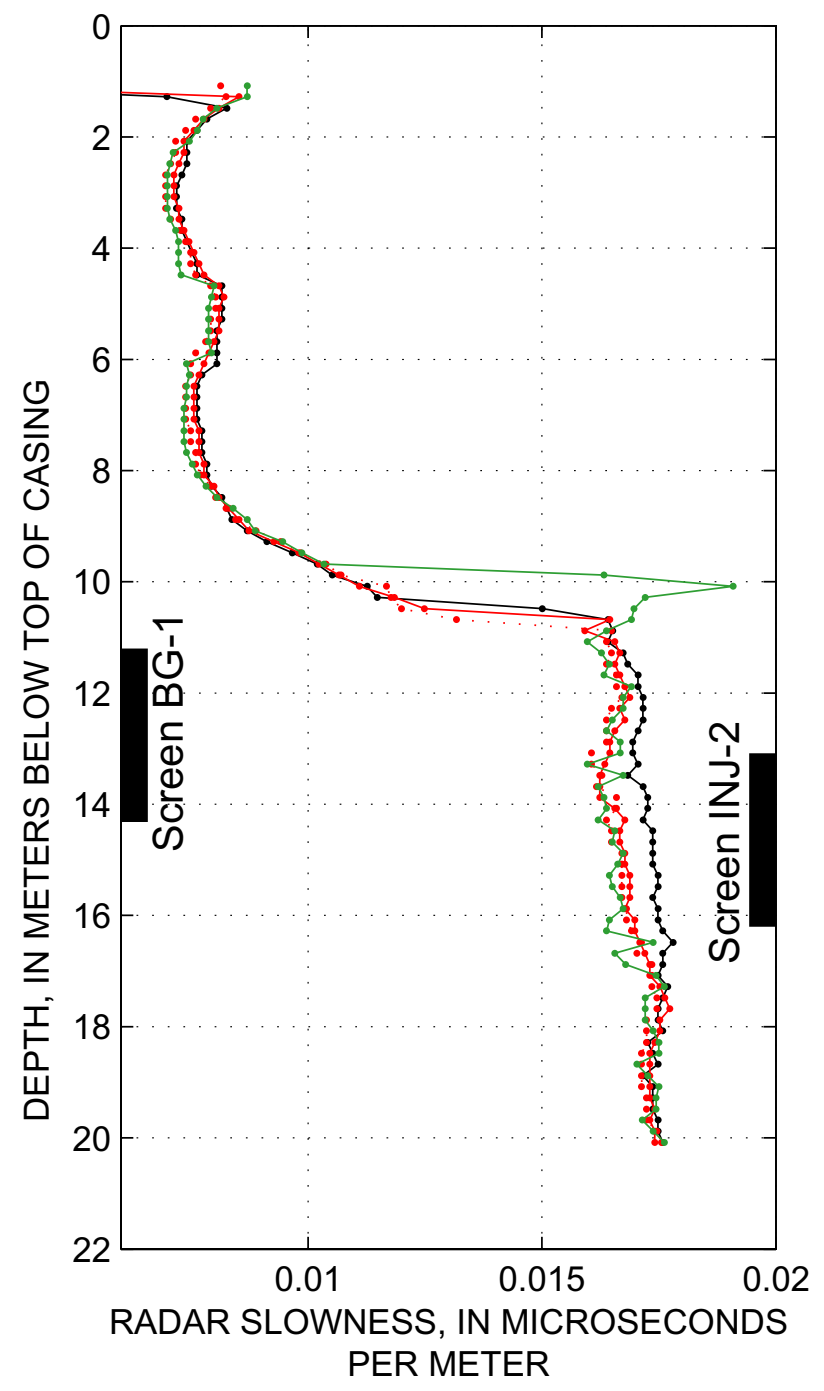

(b)

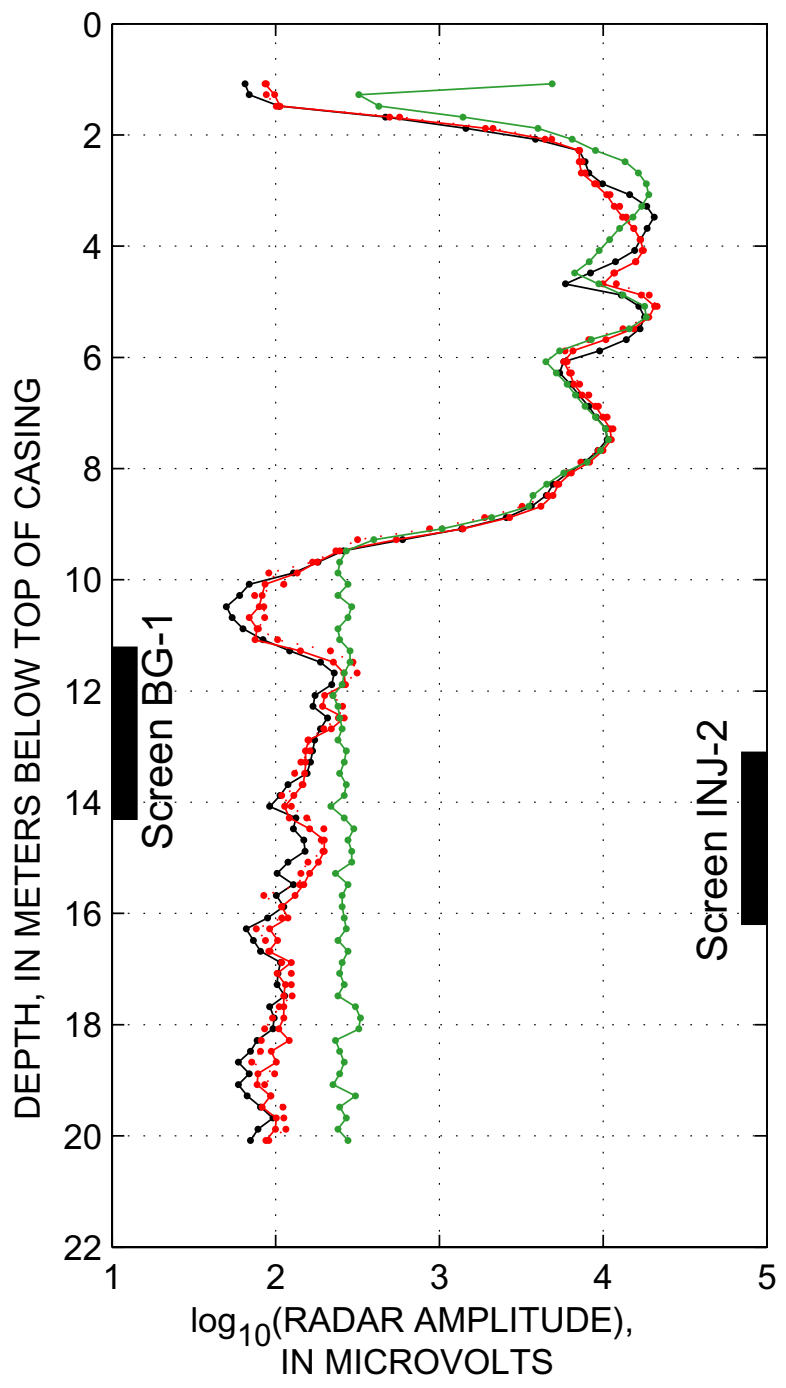

\section{EXPLANATION}

Background radar data

Radar data collected December 2001, after INJ-3 injection

Radar data collected December 2001, during INJ-1 injection

Radar data collected November 2002

Figure A11. (a)Zero-offset radar slowness, and (b) zero-offset radar amplitude profiles for the BG-1 to INJ-2 plane, Anoka County Riverfront Park, Fridley, Minnesota. 
(a)

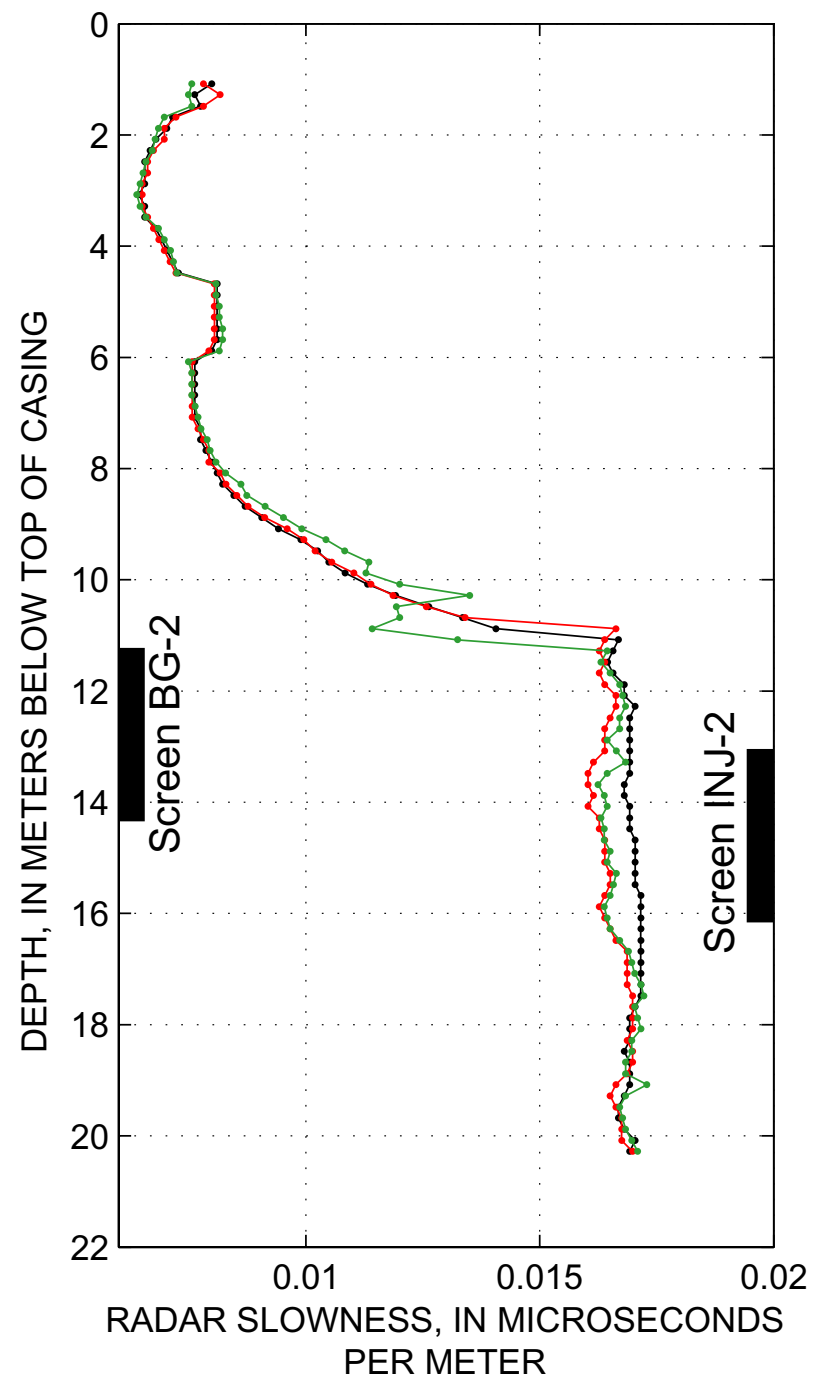

(b)

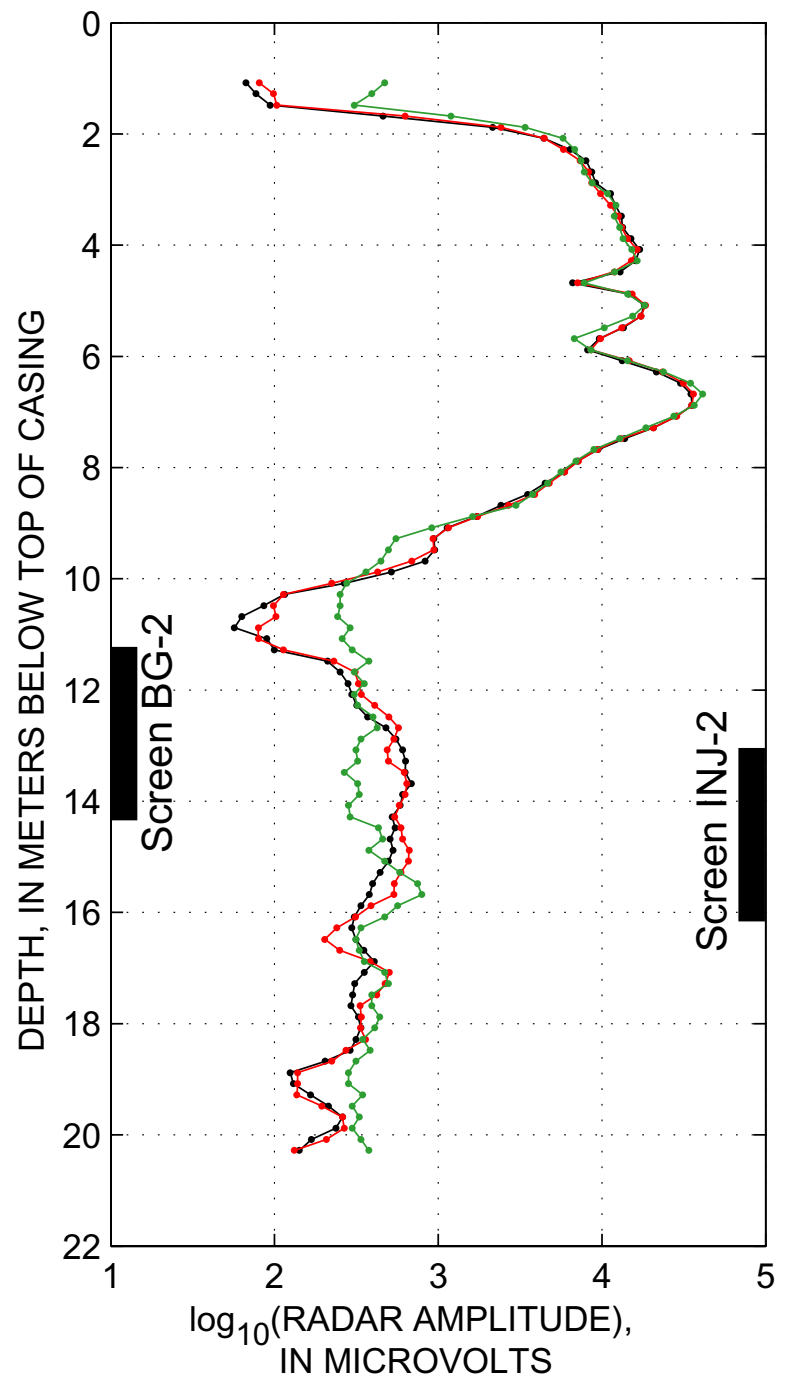

\section{EXPLANATION}

$\rightarrow$ Background radar data

Radar data collected December 2001, after INJ-3 injection

Radar data collected November 2002

Figure A12. (a)Zero-offset radar slowness, and (b) zero-offset radar amplitude profiles for the BG-2 to INJ-2 plane, Anoka County Riverfront Park, Fridley, Minnesota. 
(a)

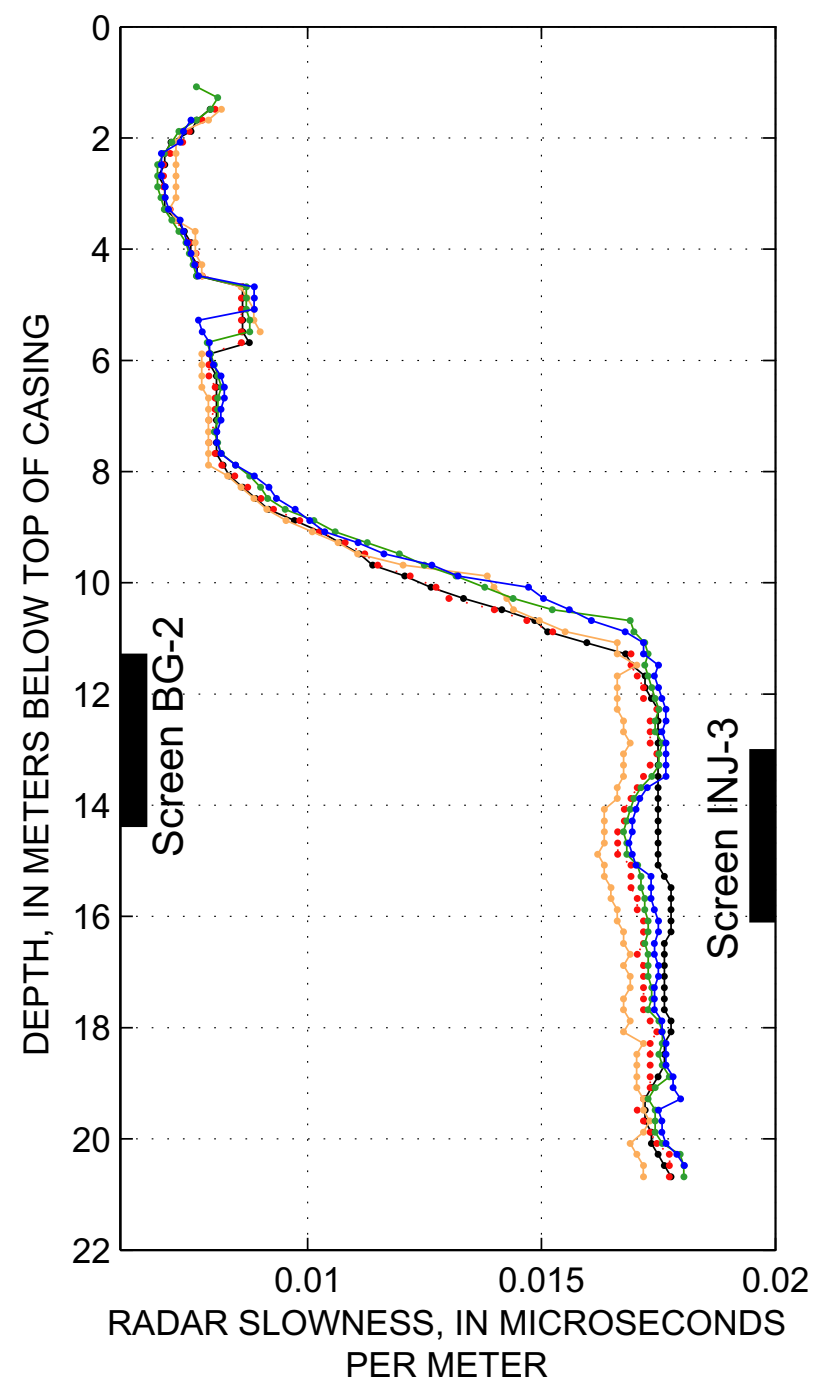

(b)

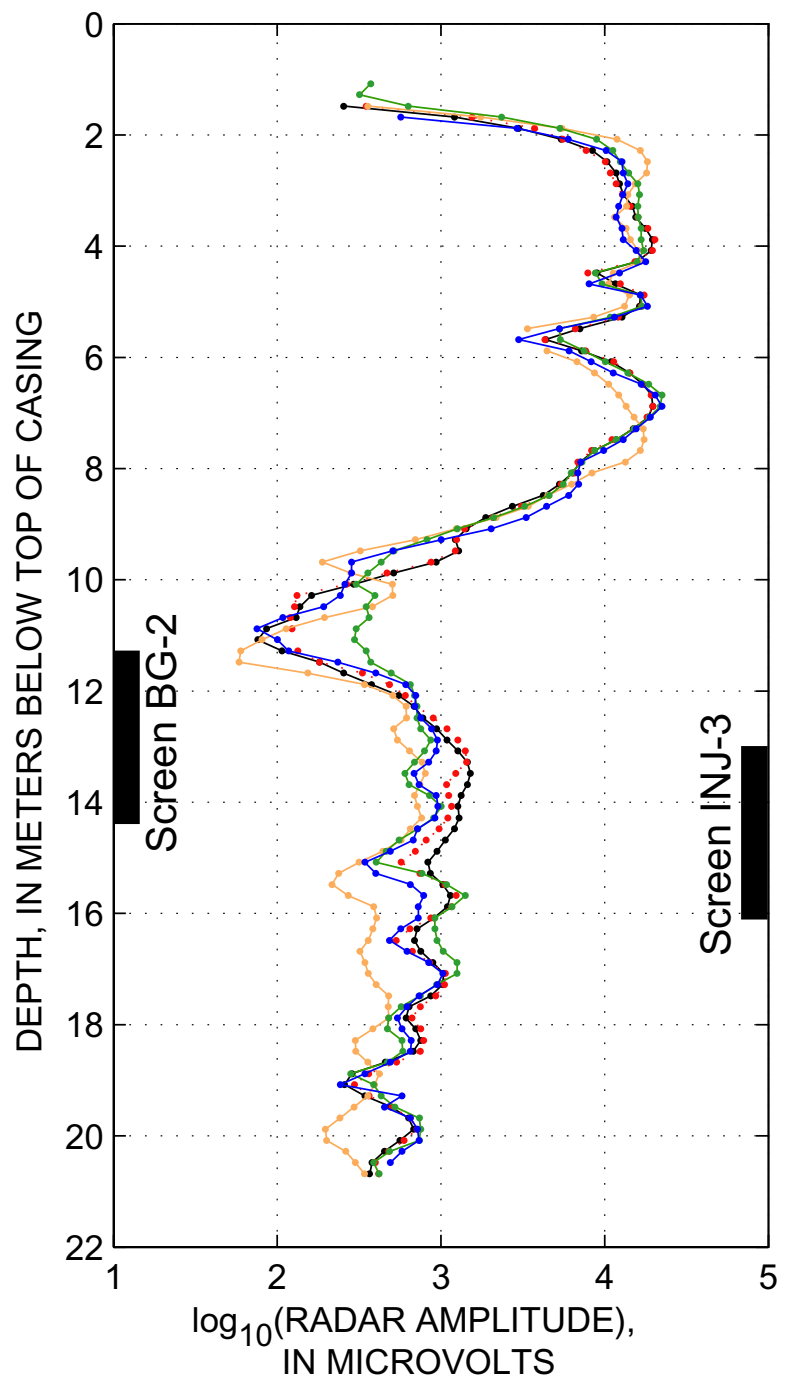

\section{EXPLANATION}

Background radar data

Radar data collected December 2001, during INJ-1 injection

Radar data collected May 2002

Radar data collected November 2002

Radar data collected June 2003

Figure A13. (a)Zero-offset radar slowness, and (b) zero-offset radar amplitude profiles for the BG-2 to INJ-3 plane, Anoka County Riverfront Park, Fridley, Minnesota. 


\section{APPENDIX B. Conventional Borehole Logs}

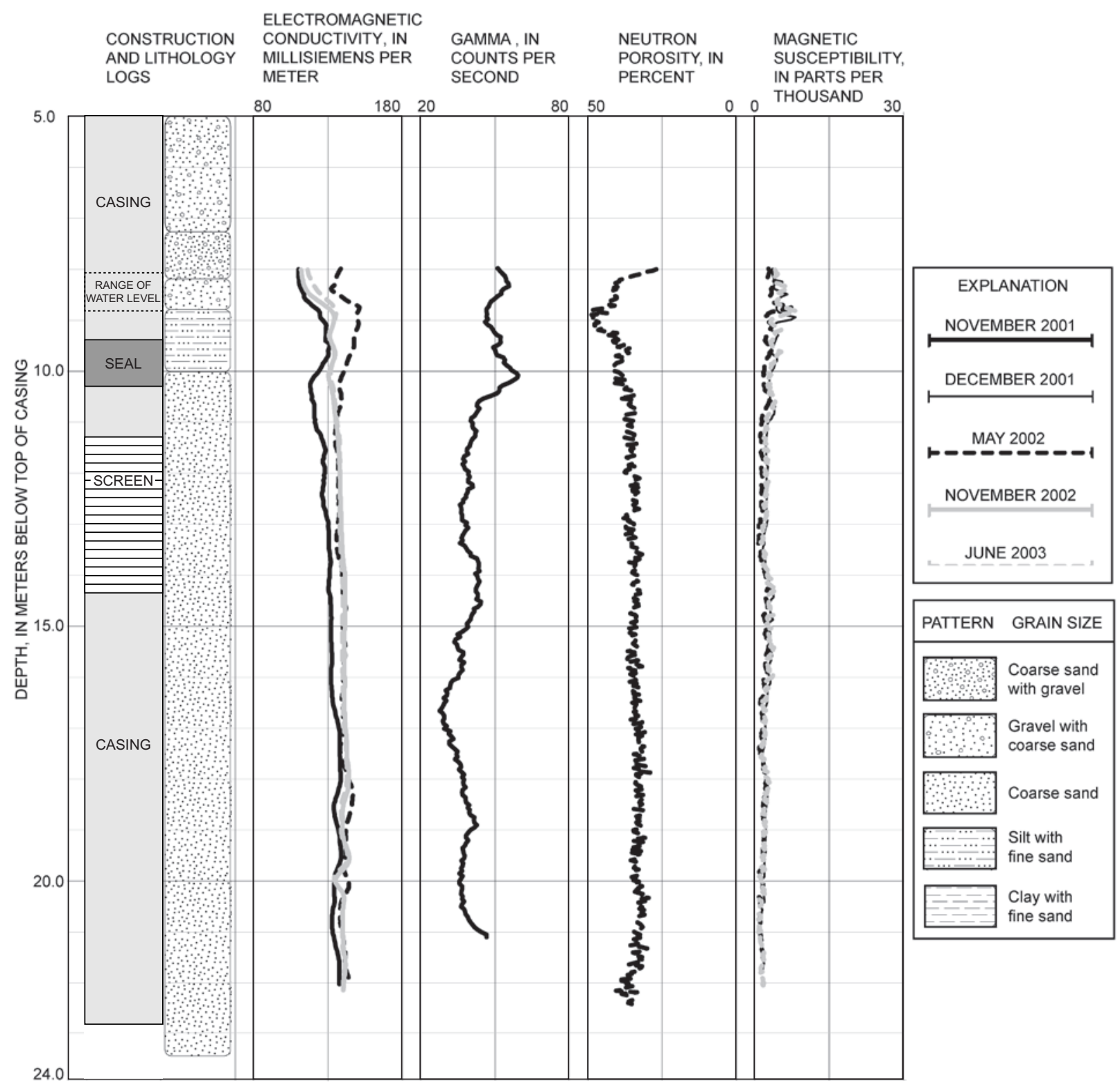

Figure B1. Borehole geophysical logs for BG-1, Anoka County Riverfront Park, Fridley, Minnesota. 


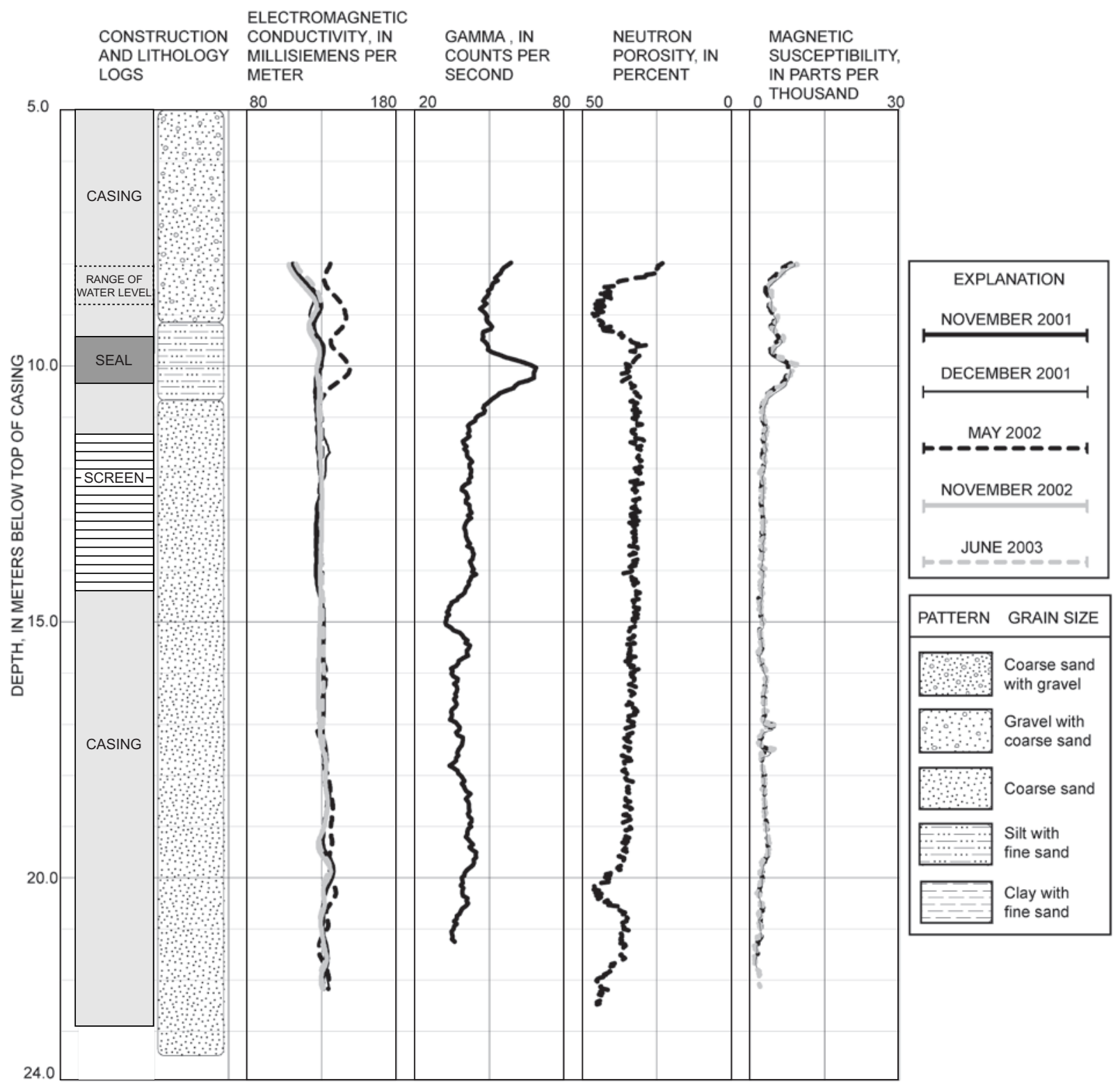

Figure B2. Borehole geophysical logs for BG-2, Anoka County Riverfront Park, Fridley, Minnesota. 


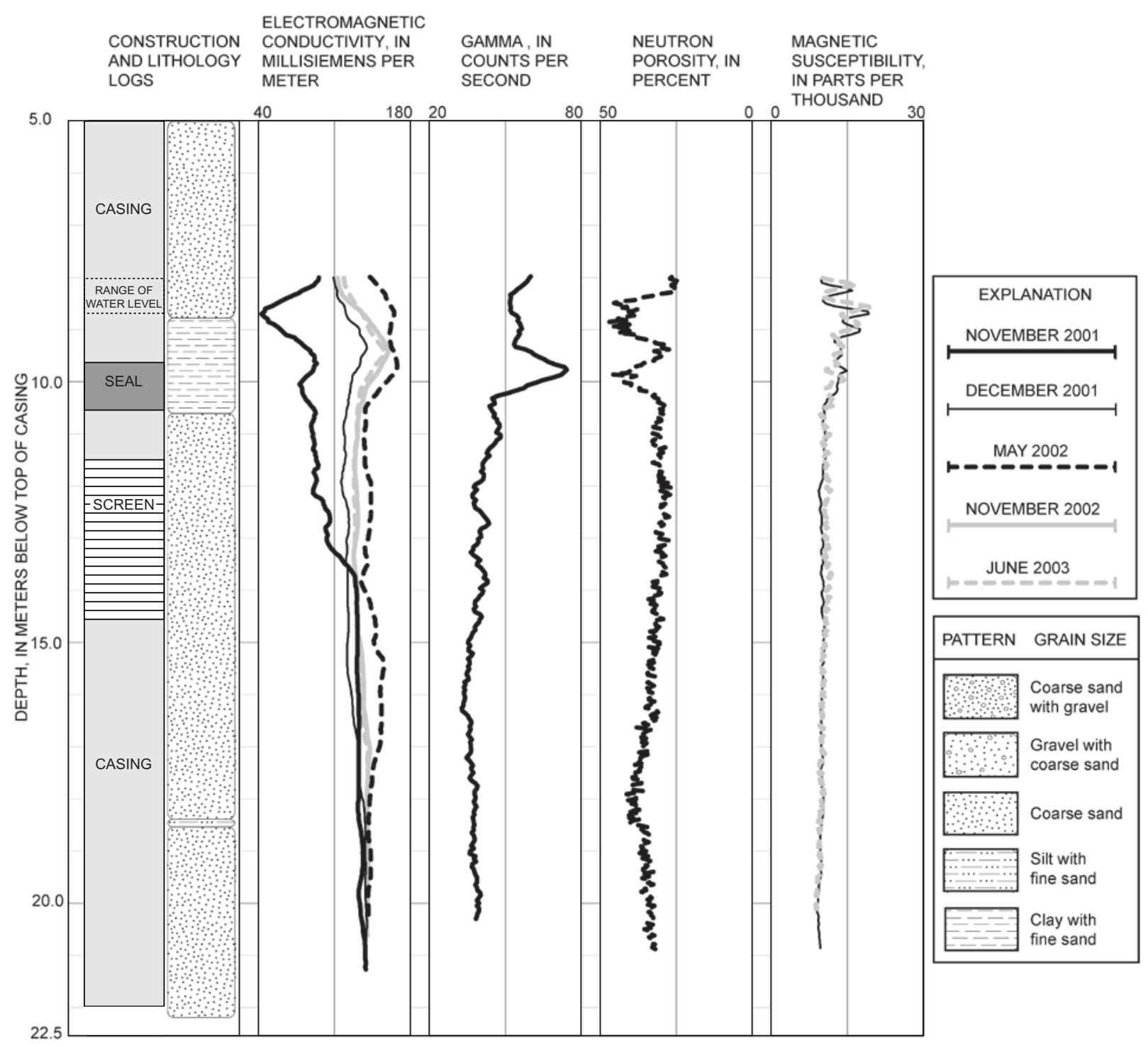

Figure B3. Borehole geophysical logs for INJ-1, Anoka County Riverfront Park, Fridley, Minnesota. 


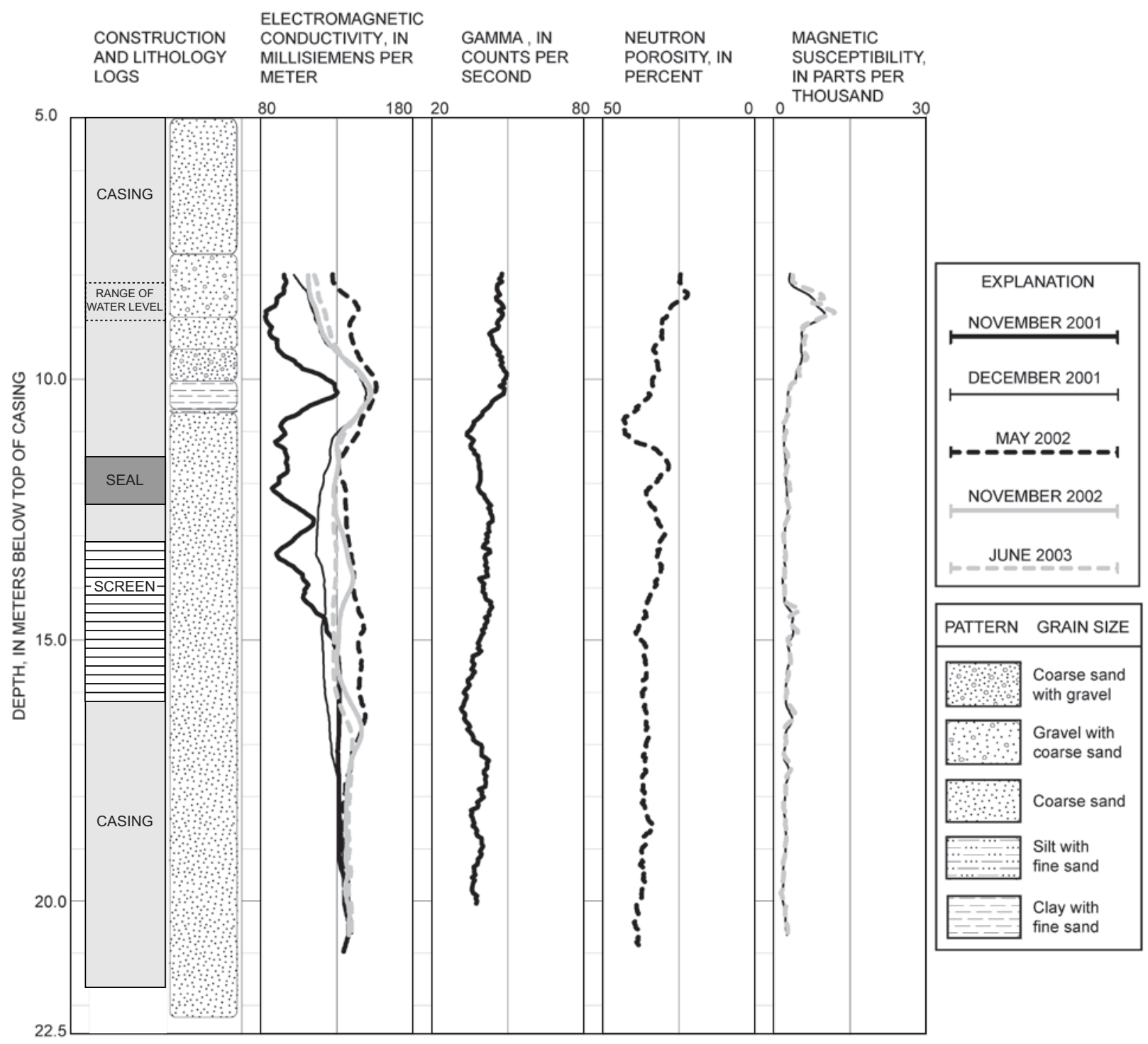

Figure B4. Borehole geophysical logs for INJ-2, Anoka County Riverfront Park, Fridley, Minnesota. 


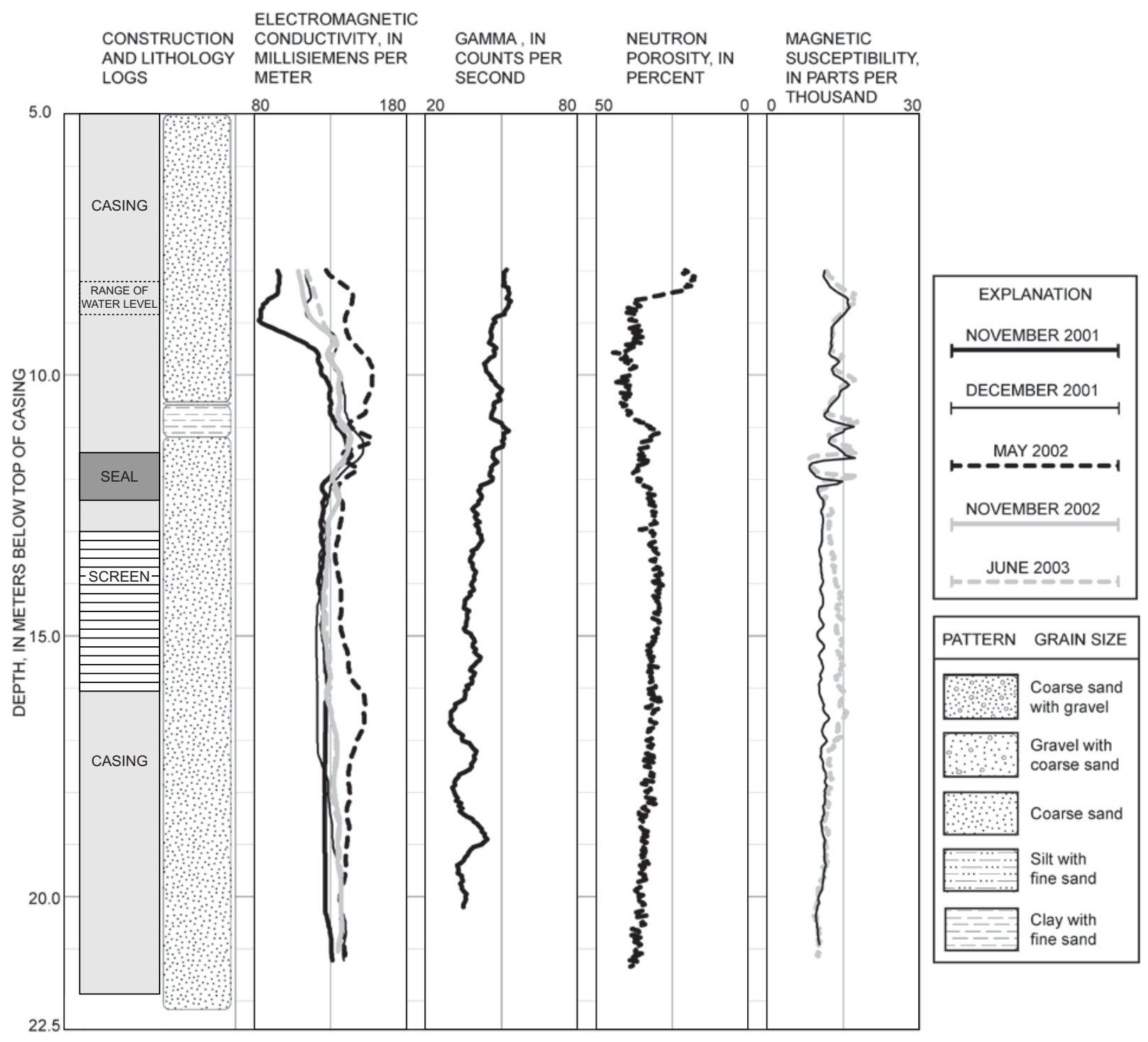

Figure B5. Borehole geophysical logs for INJ-3, Anoka County Riverfront Park, Fridley, Minnesota. 


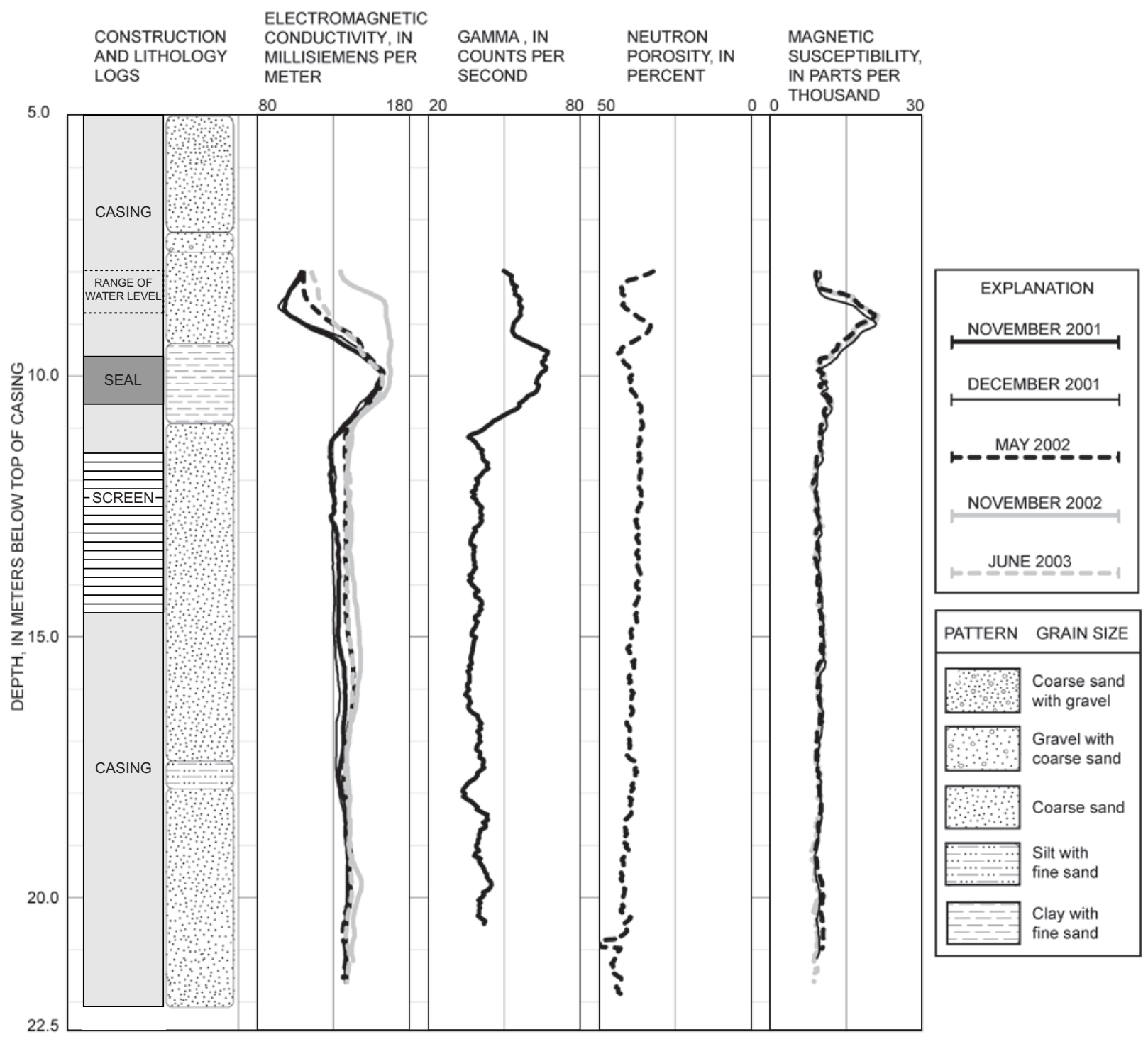

Figure B6. Borehole geophysical logs for MW-1, Anoka County Riverfront Park, Fridley, Minnesota. 


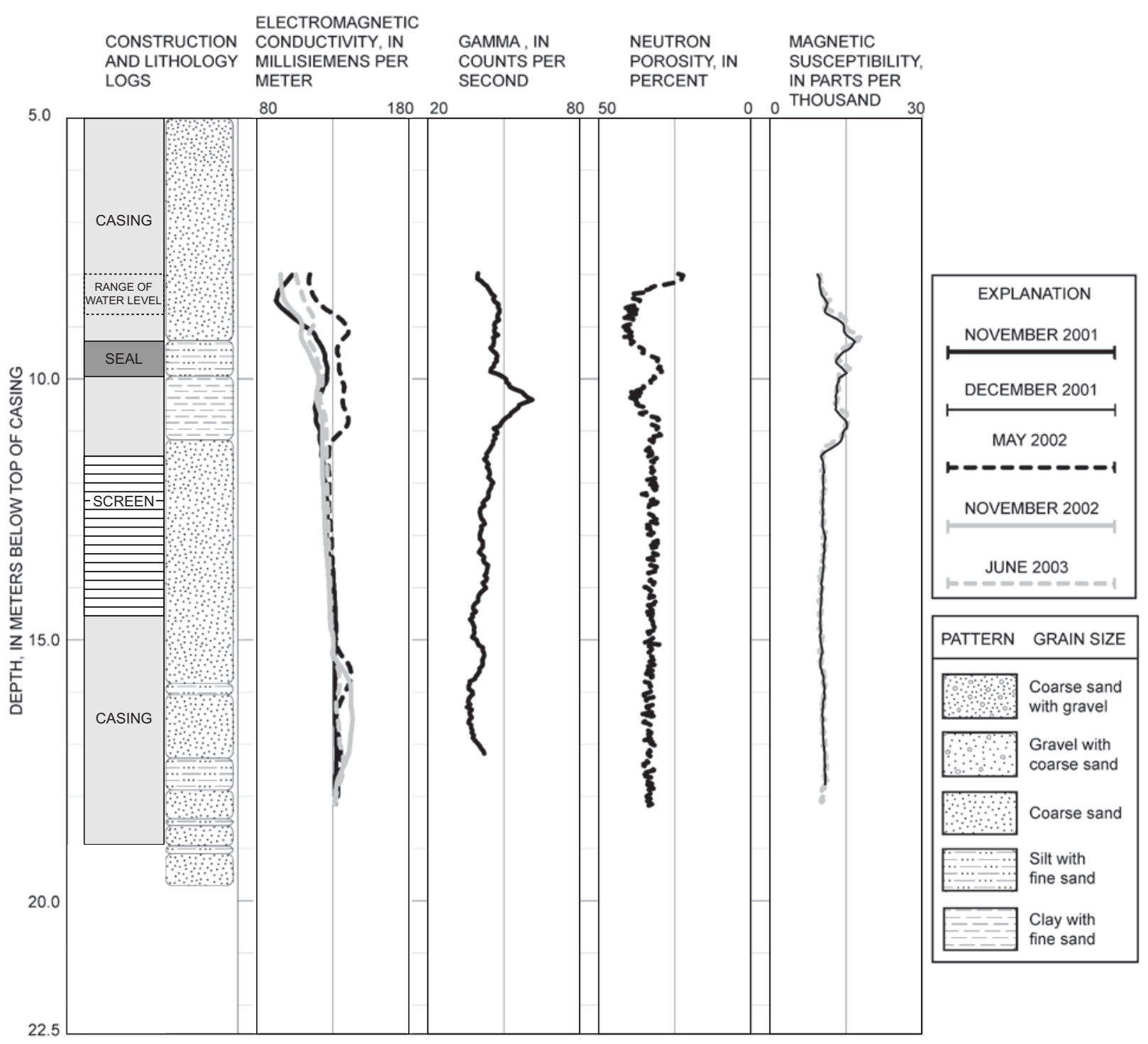

Figure B7. Borehole geophysical logs for MW-2, Anoka County Riverfront Park, Fridley, Minnesota. 


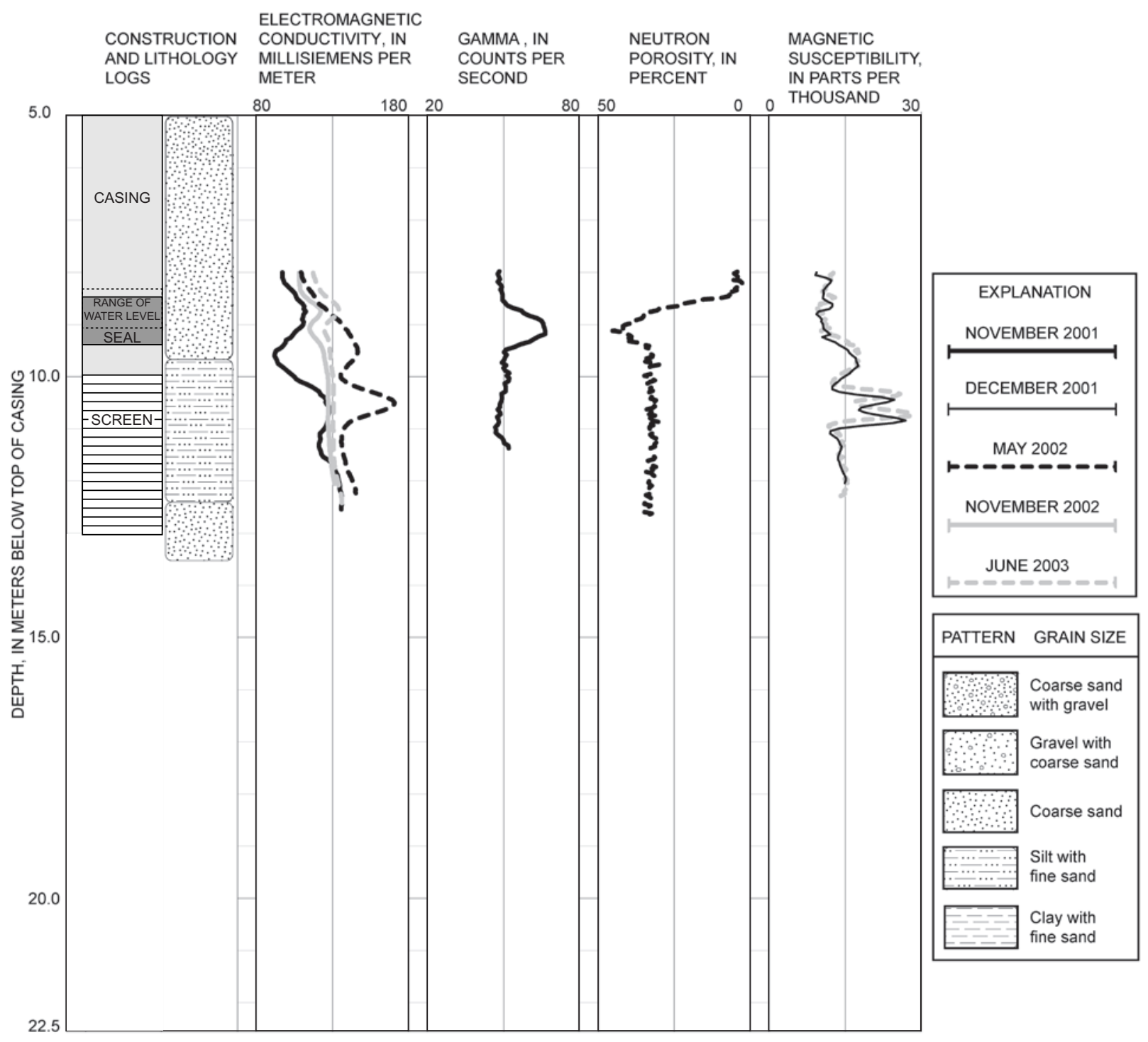

Figure B8. Borehole geophysical logs for MW-3, Anoka County Riverfront Park, Fridley, Minnesota. 


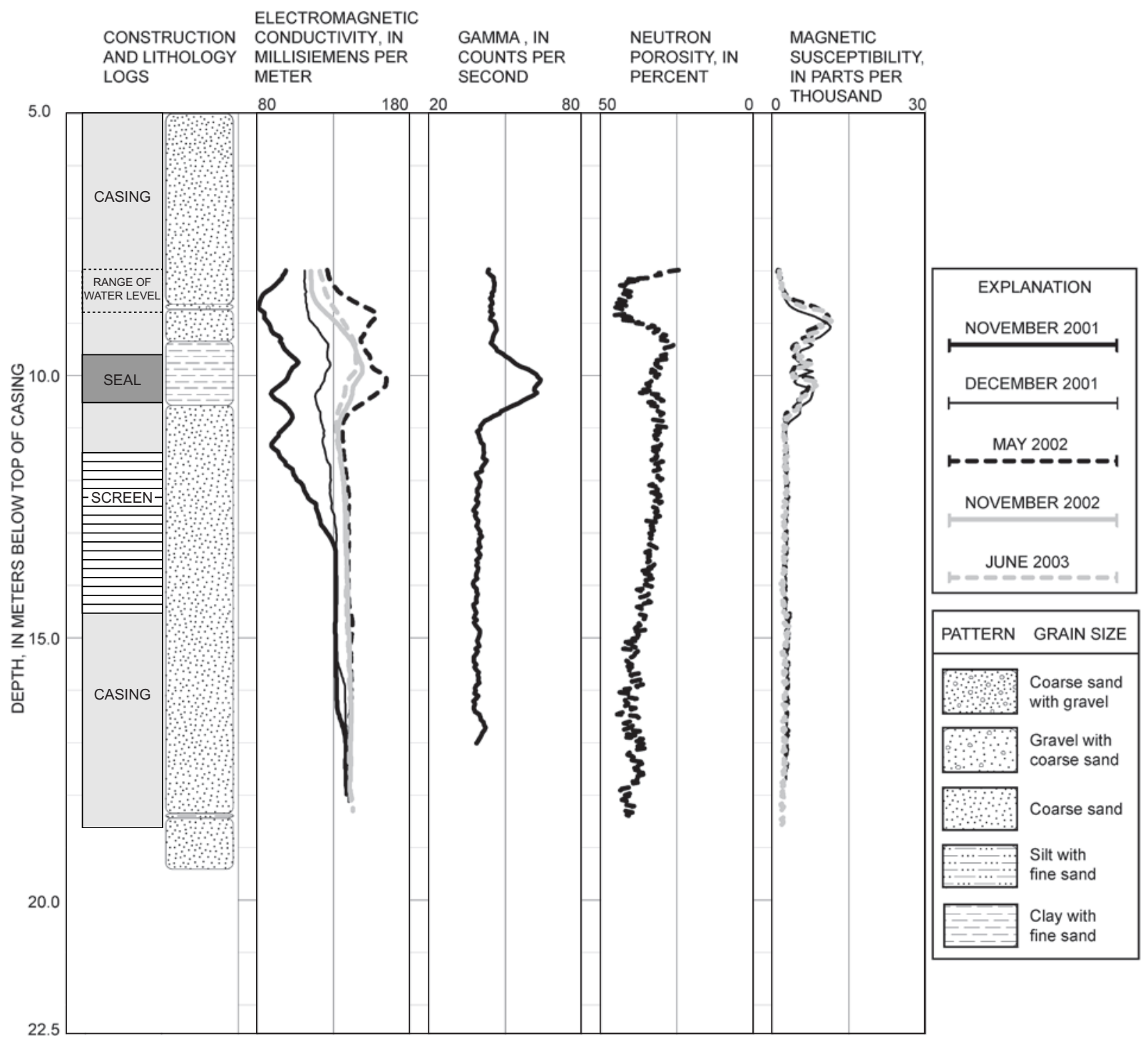

Figure B9. Borehole geophysical logs for MW-6, Anoka County Riverfront Park, Fridley, Minnesota. 


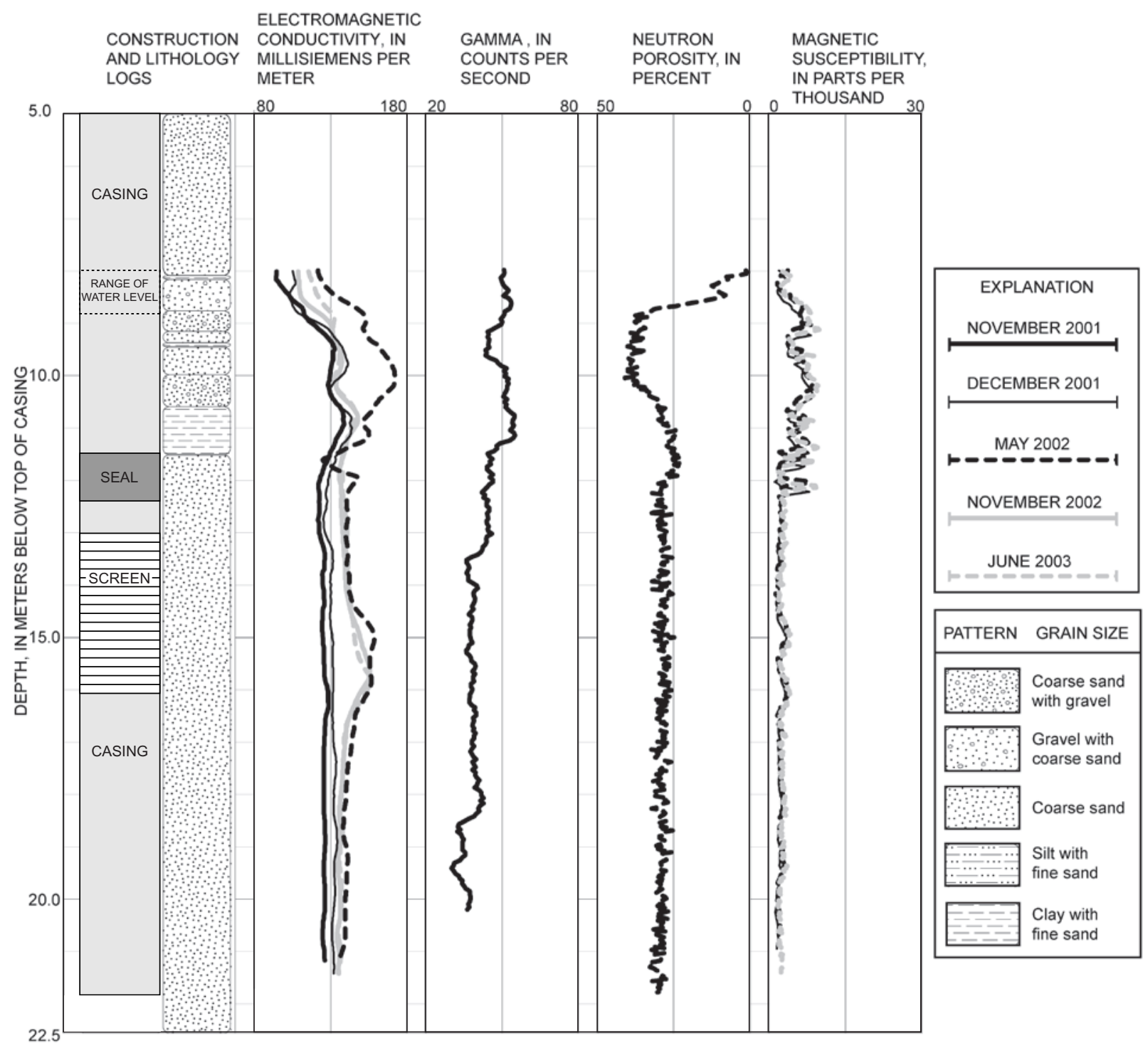

Figure B10. Borehole geophysical logs for MW-7, Anoka County Riverfront Park, Fridley, Minnesota. 


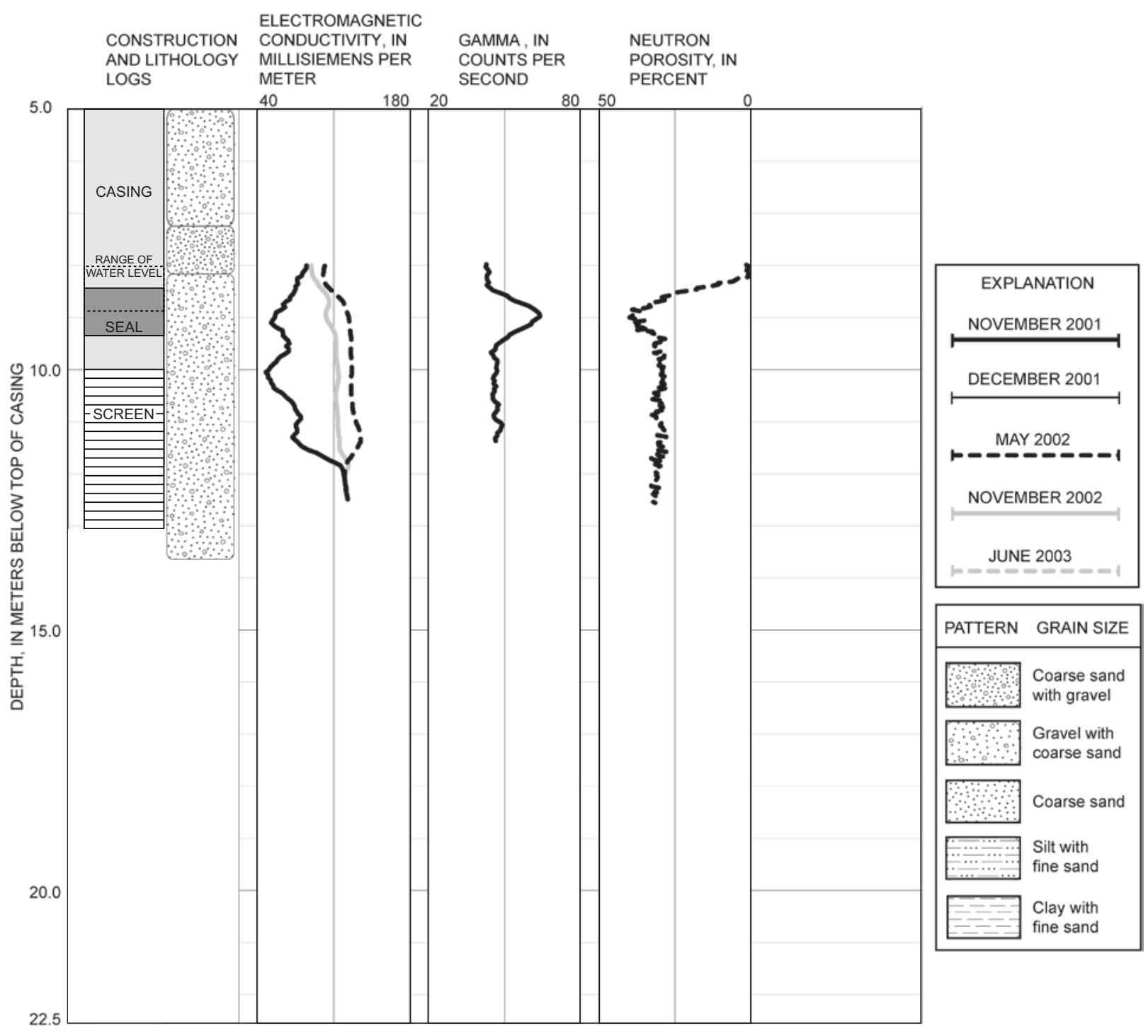

Figure B11. Borehole geophysical logs for MW-8, Anoka County Riverfront Park, Fridley, Minnesota. 


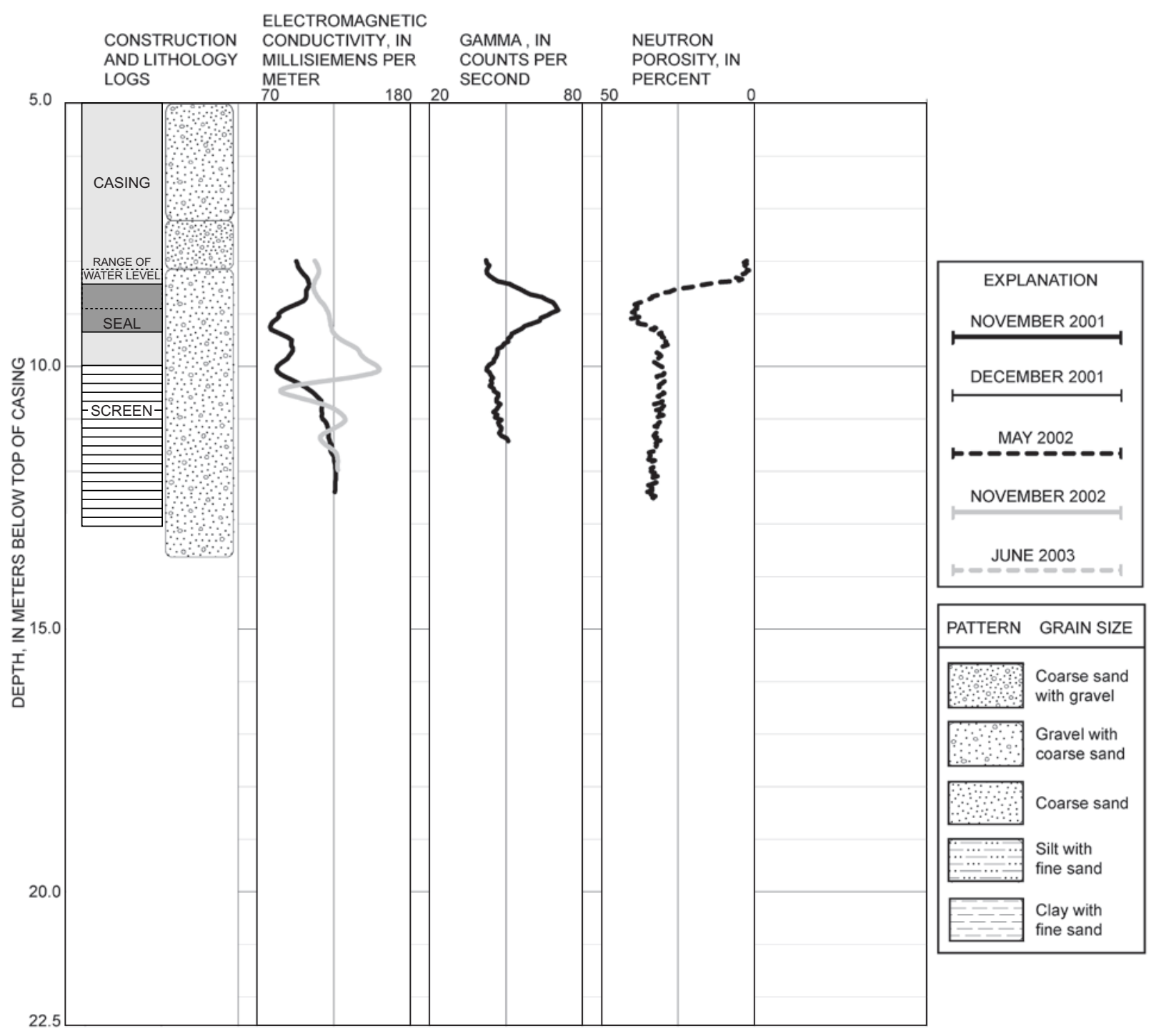

Figure B12. Borehole geophysical logs for MW-9, Anoka County Riverfront Park, Fridley, Minnesota. 
Prepared by the Pembroke Publishing Service Center

For more information concerning the research in this report, contact:

U.S. Geological Survey

Office of Ground Water

Branch of Geophysics

11 Sherman Place, Unit 5015

Storrs, CT 06269 
